Portland State University

PDXScholar

Fall 11-18-2013

\title{
"Do Not Disturb": A Micro-Macro Examination of Intrusions at Work
}

Bing Chun Lin

Portland State University

Follow this and additional works at: https://pdxscholar.library.pdx.edu/open_access_etds

Part of the Cognition and Perception Commons, and the Industrial and Organizational Psychology Commons

Let us know how access to this document benefits you.

\section{Recommended Citation}

Lin, Bing Chun, "'Do Not Disturb": A Micro-Macro Examination of Intrusions at Work" (2013). Dissertations and Theses. Paper 1500.

https://doi.org/10.15760/etd.1499

This Dissertation is brought to you for free and open access. It has been accepted for inclusion in Dissertations and Theses by an authorized administrator of PDXScholar. Please contact us if we can make this document more accessible: pdxscholar@pdx.edu. 
"Do Not Disturb": A Micro-Macro Examination of Intrusions at Work

by

Bing Chun Lin

A dissertation submitted in partial fulfillment of the requirements for the degree of

\author{
Doctor of Philosophy \\ in \\ Applied Psychology
}

Dissertation Committee:

Charlotte Fritz, Chair

Leslie Hammer

Cynthia Mohr

Donald Truxillo

Pamela Tierney

Portland State University

2013 
DO NOT DISTURB i

\begin{abstract}
Intrusions, or interruptions by others, are a common phenomenon in the modern workplace (Grove, 1983; Jett \& George, 2003), particularly in the computing and information-technology (CIT) industry, as cross-specialty, and cross-team collaborations become more common (Beck et al., 2001). The present study examines the relationship between day-to-day intrusions (measured Monday, Tuesday, and Wednesday) and strain reactions and perceived job performance over the week (measured on Thursday) among 150 CIT employees. Using a number of resource-based theories (i.e., Conservation of Resources, Ego Depletion Model, Cognitive Fatigue Model), I hypothesize that participants experiencing more frequent intrusions on a day-to-day basis will experience greater levels of overall strain reactions (i.e., fatigue, self-regulation failure, and cognitive failure), and lower levels of overall perceived job performance for the week. To test these hypotheses, I applied a micro-macro multi-wave design, such that intrusions were measured at the end of three consecutive workdays (Level-1 Predictors) and strain reactions and performance measured on the fourth day (Level-2 Outcomes). Using Structural Equation Modeling and the technique put forth by Croon and van Veldhoven (2007), I specified four models to test my hypotheses, wherein level-1 variables (i.e., dayto-day intrusions) predicted level-2 outcomes (i.e., week-level fatigue, self-regulation failure, cognitive failure, and perceived performance).
\end{abstract}

I found that day-to-day intrusions were significantly positively associated with fatigue, self-regulation failure, and perceived performance. However, day-to-day intrusions were not significantly associated with cognitive failure. These results suggest 
that intrusions may consume time and self-regulatory resources but may not consume cognitive resources, and that although intrusions cause impairment from a physical and self-regulatory perspective, they may not inhibit cognitive functioning. Future research should further investigate the relationship between intrusions and cognitive functioning. The present study is one of the first to explicitly study intrusions and recognize it as a stressor that influences both strain and performance variables. This is critical as intrusions become a more prominent fixture in the American workplace. This study also contributes to our understanding of the use of micro-macro approaches to statistical analyses, and provides additional insight into how occupational health psychologists can test long-held assumptions; namely day-to-day stressors contribute to long-term strain. 


\section{Table of Contents}

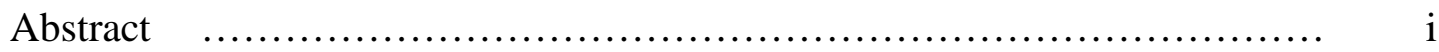

List of Tables $\quad$........................................................ iv

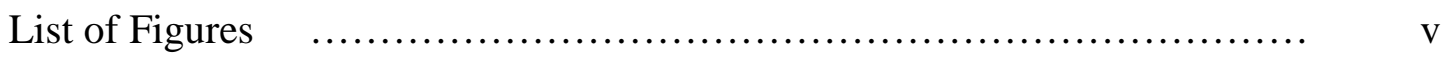

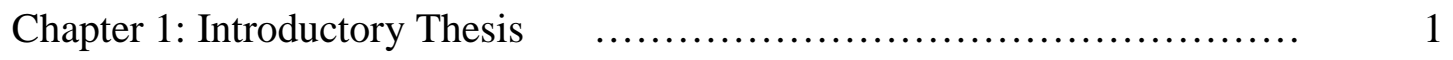

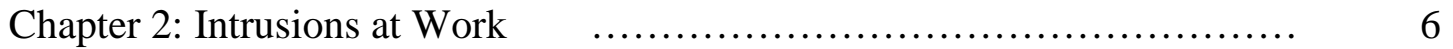

Chapter 3: Resource Framework $\quad$.................................... 13

Chapter 4: Stressor-Strain Hypotheses $\quad$............................... 20

Chapter 5: Stressor-Perceived Performance Hypothesis $\quad \ldots \ldots \ldots \ldots \ldots \ldots \ldots . . \ldots \ldots$

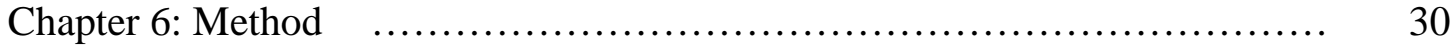

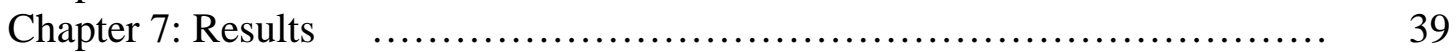



Tables $\quad$ (..................................................... 73

Figures $\quad$.

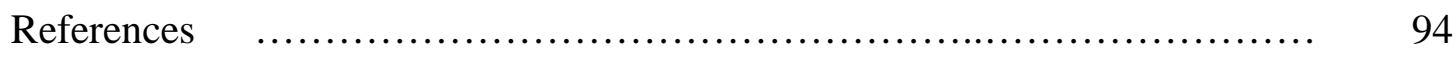

Appendices

Appendix A. Time 0 Survey ....................................... 113

Appendix B. Time 1 Survey .......................................... 117

Appendix $C$. Time 2 Survey ........................................ 120

Appendix D. Time 3 Survey ....................................... 123

Appendix E. Time 4 Survey ......................................... 126

Appendix F. Company-wide Recruitment Email ........................ 131

Appendix $G$. Recruitment Email to Participate in Time 0 ................ 134

Appendix $H$. Reminder Recruitment Email for Time $0 \ldots \ldots \ldots \ldots \ldots \ldots \ldots . . . \ldots \ldots$

Appendix I. Recruitment Email to Participate in Time 1 ................... 136

Appendix J. Reminder Recruitment Email for Time 1 .................... 137

Appendix K. Recruitment Email to Participate in Time 2 .................. 138

Appendix L. Reminder Recruitment Email for Time 2 ................... 139

Appendix M. Recruitment Email to Participate in Time 3 ................. $\quad 140$

Appendix $N$. Reminder Recruitment Email for Time 3 ................... 141

Appendix O. Recruitment Email to Participate in Time 4 .................. 142

Appendix $P$. Reminder Recruitment Email for Time 0 .................... 143

Appendix $Q$. Pilot Survey............................................ 144

Appendix R. Human Subjects Research Review Committee Approval Letter 151 


\section{List of Tables}

Table 1. Sample sizes and response rates for each company................... 73

Table 2. Variables Measured at Each Time Point ................................ 74

Table 3. Perceived Performance Items............................................ 75

Table 4. Means, Standard Deviations, and Inter-correlations .................. 76

Table 5. Variable means and standard deviations for each company ............ $\quad 77$

Table 6. Descriptive statistics of characteristics of intrusions for each time

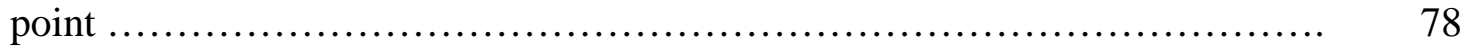

Table 7. Means, Standard Deviations, and Intercorrelations between WeekLevel Intrusions, Intrusions Measured at Each Time Point, and Intrusions

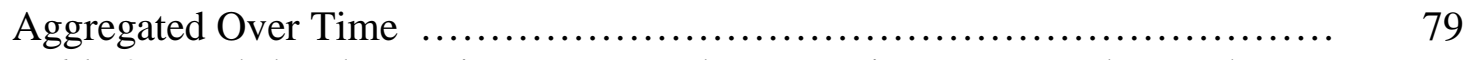

Table 8. Week-level Intrusions Regressed on Intrusions Measured at Each Time Point .......................................................... 80

Table 9. Outcome Variables Regressed on Intrusions at the Week-Level and

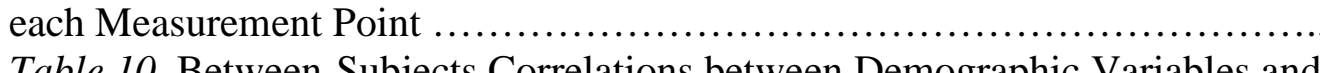
Table 10. Between-Subjects Correlations between Demographic Variables and Study Variables ..........................................................

Table 11. Results of Day-Level Fatigue, Self-Regulation Failure, Perceived Performance, Quantitative Workload, and Surface Acting Regressed on DayLevel Intrusions

Table 12. Means and Standard Deviations for Cognitive Failure Items ........... 84 


\section{List of Figures}

Figure 1. Nested measurement models comparing a 4-, 2-, and 1-factor model

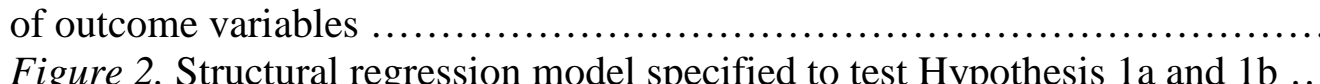
Figure 3. Structural regression model specified to test Hypothesis $1 \mathrm{c}$ and 2 ..... Figure 4. Nested measurement models comparing a 3- and 1-factor model of cognitive failure

Figure 5. Structural regression model specified to test Hypothesis 1c with cognitive failure being broken into three sub dimensions

Figure 6. Structural regression model specified to test Hypothesis 1a and 1b while controlling for collaboration hours and managerial status ................. Figure 7. Structural regression model specified to test Hypothesis 1c and 2 while controlling for collaboration hours and managerial status Figure 8. Means and standard deviations for all items on the workplace cognitive failure measure 


\section{Chapter 1: Introductory Thesis}

Interruptions at work are a common phenomenon in today's workplaces (Grove, 1983; Mintzberg, 1990). Interruptions are generally defined as temporary halts in taskrelated behavior due to the onset of a demand or secondary task (Eyrolle \& Cellier, 2000). As companies seek to streamline organizational processes, quick and constant information sharing amongst employees becomes essential for the longevity of organizations. This information sharing has been intensified due to technological advances, such as the popularization of instant messaging, email, and cellular phones (Berger \& Merritt, 1998). For example, in a technical report by Basex, it was found that interruptions at work consume an average of 2.1 hours per day (Spira, \& Feintuch, 2005). On average, emergency room physicians experience 10 interruptions per hour (Chrisholm, Collison, Nelson, \& Cordell, 2000). However, as commonly found in organizational literature, processes that are aimed at facilitating organizational functioning may not always benefit the employees or the organization itself. For example, in the same technical report by Spira and Feintuch (2005), the authors found that instantaneous information sharing though interruptions cost the U.S. economy $\$ 588$ billion dollars per year. According to Dismukes, Young, and Sumwalt (1998), nearly half of all aviation accidents are a result of lapses of concentration due to interruptions. Kirmeyer (1988) found interruptions at work to be associated with elevated perceptions of task overload. However, other literature has found that interruptions throughout the workday can be beneficial for employee well-being (e.g., Fritz, Lin \& Trougakos, 2009) and performance (e.g., Trougakos, Beal, Green \& Weiss, 2008). This is particularly true 
at the appraisal level, when secondary tasks involve behaviors that present learning opportunities or strengthen coworker relationships (Fritz, Lam \& Spreitzer, 2011). Clearly, the relationship between interruptions at work and employee effectiveness is mixed, and warrants additional research attention.

To help explain the varying effects of interruptions at work, Jett and George (2003) divide interruptions at work into four separate constructs: Distractions, breaks, intrusions, and discrepancies. While three of the four constructs have received prior research attention (albeit not explicitly), intrusions at work, or interruptions caused by others, have received little. Intrusions are a unique form of interruption as they inherently involve a dyadic social interaction whereby one individual explicitly interrupts the second employee. Considering the myriad of manifestations social interactions at work can encompass (e.g., workplace incivility, family supportive supervisory behavior), the social interaction inherent in intrusions incorporates a layer of uncertainty compared to that of other interruptions. Furthermore, given the rapid introduction of new technologies that provide new vehicles through which employees can intrude upon each other (Wallis \& Steptoe, 2006), it becomes increasingly important to study intrusions. Specifically, understanding the workplace and the various employee outcomes that are influenced by intrusions is instrumental in further developing an understanding of the modern workplace.

The present study samples computing and information-technology (CIT) employees because the CIT industry has experienced drastic changes in the recent past as organizational processes have evolved from waterfall procedures (Benington, 1956) 
toward agile procedures. Waterfall and agile procedures are general design processes describing the lifecycle of the production of software. Waterfall methods involve completing portions of software sequentially (e.g., product specification, design, construction; Royce, 1970), such that specialists have specific functions parallel with the production sequence (e.g., programming, testing, selling). Inherently, waterfall procedures involve only infrequent cross-team and cross-specialty collaboration. However, gradually, the CIT industry has been moving towards agile procedures, favoring self-organizing teams, customer collaboration, and embracing and adapting to change (Beck et al., 2001). Inherently, agile procedures involve constant, cross-specialty collaboration, making intrusions a pertinent characteristic of the workplace.

Stress, or the process whereby a stressor creates a strain (Jex \& Britt, 2008), has received growing research interest in the past 20 years. Research on work stress, in particular, has received popularity in part due to its direct and indirect costs for organizations (Quick, Quick, Nelson \& Hurrell, 1997), but also due to increased research funding (National Institute for Occupational Safety and Health [NIOSH], 2002). Quick (1999) argues that employee health can be influenced through three broad factors: Workplace factors, individual factors, and work-family factors. According to various resource-based theories (e.g., Conservation of Resources; Hobfoll, 1989), each of these factors can be conceptualized as stressors to the extent that they require resources to cope (Schaufeli \& Bakker, 2004). Strain reactions are described as the cognitive, affective, and physical reactions that occur when individuals are deprived of resources, as is the case during prolonged exposure to stressors (de Lange, Taris, Kompier, Houtman \& Bongers, 
2003). Intrusions at work are presumed to be one such workplace stressor that consumes resources valued to employees (i.e., time, self-regulatory resources, and cognitive resources). As such, in the present study, I present arguments to justify the classification of intrusions as a stressor, and discuss the various resources intrusions may consume. In addition to maintaining strain levels at a point individuals can withstand (Halbesleben, 2006), resources are also assumed to be useful for sustaining behavior consistent with task performance (Baumeister, Bratslavsky, Muraven \& Tice, 1998).

It is commonly assumed in organizational literature that stressors experienced on a day-to-day basis accumulate to influence strain reactions (Demerouti, Bakker, Nachreiner \& Schaufeli, 2001; henceforth referred to as an "accumulation effect"). However, to date, there has yet to be a single study explicitly testing this assumption. In the past 16 years, the number of multi-wave pre-experimental designs has increased, but the majority of these examinations involve testing the relationship between chronic stressors and chronic strains at differing time points (Zapf, Dormann \& Frese, 1996). While these designs allows for an indirect test of the assumption of the accumulation effect, these studies suffer from the ecological fallacy (Robinson, 1950). That is, by testing the relationships between a "chronic" stressor level and strain level (also known as a macro-macro hypothesis), we disregard the within-person fluctuation in experienced stressors on a day-to-day basis. While macro-macro studies shed insight into macro-level relationships between stressors and strains, they may, in fact, reflect an oversimplification of psychological processes (Hox, 2010). Furthermore, if occupational health psychologists are to continue using language presuming an accumulation effect, a direct 
test of this assumption is imperative. Past research has presumably neglected direct tests of the accumulation effect due to a lack of proper statistical techniques available. A direct test of the accumulation effect requires regressing a higher-level outcome variable (i.e., strain), on lower-level predictors (i.e., day-to-day stressors), or a micro-macro approach. To address this need, Croon and van Veldhoven (2007) provide a timely method for testing micro-macro hypotheses in individual-organization studies. By simply shifting the level of analysis to day-to-day stressors, and week-level strains, the present study is the first study in occupational health psychology to test the accumulation effect in the context of a new stressor.

To summarize the unique contributions of my dissertation, the present study contributes to existing psychological literature by first examining a new workplace stressor (i.e., intrusions) largely unstudied, in spite of its growing relevance. Second, the present study links this phenomenon to important worker outcomes (i.e., strain and selfperformance appraisals). Finally, the present study presents a new design and statistical method to test micro-macro hypotheses, adding to both organizational and methodological literature. To facilitate the discussion of these contributions, my dissertation first discusses the extant framework of interruptions at work, detailing the different types of interruptions, and differentiating intrusions from other types of interruptions. This is followed by a discussion of relevant time-based and resource-based theories from industrial and organizational and social psychology relevant to intrusions at work. This then serves as the basis for linking intrusions with two distinct sets of employee outcomes: Employee strain and self-performance appraisals. 


\section{Chapter 2: Intrusions at Work}

Jett and George (2003), in the first publication in organizational sciences to acknowledge interruptions as having different forms, describe interruptions as an umbrella construct for four distinct types of task cessations: Breaks, distractions, discrepancies, and intrusions. Breaks were defined by Jett and George as planned or spontaneous recesses from work that interrupt the work's flow and continuity, while distractions are psychological reactions to external stimuli or secondary activities that interrupt focused concentration on a particular primary task, and discrepancies were defined by Jett and George as inconsistencies between one's knowledge or expectations and one's immediate observations of the external world. Distinct from the aforementioned three interruption types, intrusions were described by Jett and George as unexpected encounters initiated by others that halt the flow of work. To date, distractions (e.g., Monk, Trafton \& Boehm-Davis, 2008) and breaks (e.g., Henning, Jacques, Kissel, Sullivan \& Alteras-Webb, 1997) have been studied extensively by ergonomics and cognitive psychologists. On the other hand, organizational scientists have previously studied discrepancies (e.g., Sweeny, Melnyk, Miller \& Shepperd, 2010), and to a lesser extent, breaks (e.g., Trougakos, et al., 2008). Thus, as breaks, distractions, and discrepancies have received research attention, intrusions have largely been neglected. Given the increase in the number of avenues through which employees can intrude upon each other (Wallis \& Steptoe, 2006), the increase in the use of open-floor plans (Perlow, 1999), and the increase in group work in the modern workforce, formal investigation of 
intrusions at work is necessary for Industrial-Organizational Psychologists to remain relevant for modern workers.

Similar to distractions, intrusions are interruptions caused by external stimuli; however, in the case of intrusions, the external stimuli only include other individuals (e.g., coworkers, family members). Thus one could argue that intrusions are a unique form of distraction. To avoid overlap with other similar constructs (e.g., Family-to-work conflict; Frone, Yardley \& Markel, 1997), the present study focuses solely on those intrusions initiated by colleagues (e.g., coworkers, supervisors, subordinates), while simultaneously acknowledging that intrusions from nonwork sources also represent a fruitful future research stream. Moreover, intrusions may not pertain strictly to employees physically approaching their colleagues, but can include alternative mediums such as instant messaging, email, phone calls, and text messages. Cognitive psychologists have used episodic frameworks to better understand intrusions (e.g., Trafton \& Monk, 2008).

Employees' workdays are composed of short, naturally segmented temporal periods of behavior aimed at accomplishing different goals, such as job performance (i.e., performance episodes; Beal, Weiss, Barros \& MacDermid, 2005). While behaviors during performance episodes may be diverse (e.g., writing software code, reading software manuals), all behaviors are in partial fulfillment of the higher-level goal (e.g., programming software to perform a particular task). Trougakos and Hideg (2009) further this discussion by intimating the possibility that not all behavioral episodes during the workday are devoted to job performance. Indeed, Trafton and Monk (2008) suggest that interruptions can also be viewed as an episode, such that each interruption can be 
represented as an interruption episode. Trafton and Monk describe a single interruption episode as having three associated behaviors: (a) Cognitive adjustment from the original task (henceforth referred to as the primary task) to the interrupting task (henceforth referred to as the secondary task), (b) behavior associated with addressing the secondary task, and (c) cognitive adjustment back to the primary task.

The first cluster of behaviors, the cognitive adjustment from the performance episode to the interruption episode (henceforth called the adjustment lag), is characterized by two basic behaviors. First, the employee disengages, behaviorally and cognitively, from the primary task. Second, the employee then engages, cognitively, in the secondary task. Following the adjustment lag, the employee must then engage in behaviors aimed towards the completion of the secondary task (henceforth referred to as secondary task performance). In the case of intrusions, this is the point at which the target employee begins addressing the reason the intruding employee disrupted the target employee. Secondary task performance can include behaviors as menial as engaging in small talk with the intruding employee, or behaviors requiring greater levels effort, such as problem solving. Finally, upon completing the secondary task, or reaching a point where the intruding employee is satisfied with the secondary task performance, the target employee must then cognitively readjust from the concluded secondary task back to his or her primary task (henceforth referred to as resumption lag). Similar to the adjustment lag, the resumption lag involves both cognitively disengaging from the secondary task, and cognitively engaging in the primary task. 
Although not explicitly stated, Trafton and Monk's (2008) discussion of the components of an interruption episode can be assumed to apply to intrusions because intrusions are merely one manifestation of interruptions. For example, a sample intrusion for a CIT employee would involve the employee's manager asking the employee whether their product was ready for demonstration (secondary task) while the employee is writing an unrelated software code (primary task). The CIT employee would first need to cognitively dissociate from the primary task (i.e., writing software code), and cognitively engage in their manager's query (e.g., "Are there glaring problems in the product that I need to troubleshoot right away?"). The employee would then respond to their manager (e.g., "yes/no"). To the extent this response is satisfactory to the employee's manager, the employee is then free to cognitively dissociate with the manager's query and re-engage in their primary task (e.g., writing software code for their new program). However, if the response is not satisfactory to the manager, instead of resuming their primary task, the CIT employee would likely engage in behaviors consistent with preparing for the product demonstration. Only until the employee has met the manager's standards for the product demonstration, can the employee then dissociate from the product demonstration and resume their primary task (i.e., writing software code for a new program).

In a field experiment conducted on office workers, Zijlstra, Roe, Leonora, and Krediet (1999) had participants perform various text-editing tasks, and confederates interrupted these tasks through two methods. Confederates would interrupt participants by either calling to request a phone number, or calling to request participants edit a second document. Though not explicitly stated within the study, this study manipulated 
the number of discrete intrusions experienced by participants, and found that participants worked faster to complete their primary tasks to accommodate the time displaced by the secondary tasks. However, Zijlstra and colleagues' study only spanned 8 hours spaced out over three days (i.e., an average of 2 hours and 20 minutes per day). Additionally, the researchers only exposed participants to three intrusions per day. Considering that the average full-time employee works 7.5 hours per day (United States Department of Labor, 2011) and certain occupations, such as emergency physicians, can experience between 10 and 31 interruptions every three hours (Crisholm, Collison, Nelson \& Cordeli, 2000), it is unclear whether the relationships found by Zijlstra and colleagues can be generalized to the average worker. First, given the short nature of the study, it is conceivable that demand characteristics (e.g., Hawthorne Effects) may have spurred the participants to devote more effort to primary task completion than is sustainable over a longer period of time. Second, considering Spira and Feintuch (2005) found that employees spend an average of $20 \%$ of their time at work addressing interruptions, I argue that Zijlstra and colleagues' study may not have captured the actual frequency with which employees are typically interrupted.

Lin, Kain, and Fritz (2013), in the only study to have explicitly measured intrusions, found a positive relationship between intrusions and strain (i.e., exhaustion, need for recovery, anxiety, and physical complaints). Specifically, the authors found that more frequent intrusions were associated with higher levels of strain in both work and global domains, though the relationships were stronger for work domain strain strains (i.e., exhaustion and need for recovery). Distinct from previous studies of interruptions, 
Lin and colleagues (2013) focused their measurement of intrusions on the perceptions of intrusions, representing a shift from "objective" manipulations of the construct to “subjective," passive observation. Unique from past experimental literature on interruptions, which has converged on studying interruptions as singular events, Lin and colleagues examined employees' perceptions of the intrusions experienced over a month using survey methodology. Rather than capturing the "objective" frequency of intrusions, this methodology captures employees' psychological appraisal of the frequency of intrusions, in accordance with Lazarus and Folkman's (1984) transaction model of stress that emphasizes one's appraisal of stressors.

Lin and colleagues' (2013) study provides an important landmark in our understanding of intrusions. However, key methodological limitations hindered the confidence in the conclusions researchers can draw from this study. First, the sole use of self-report measures likely enhanced the likelihood of finding spurious relationships due to common method variance. While this effect was statistically tempered using Lindell and Whitney's (2001) Correlational Marker Variable Technique, researchers argue that common method variance can never be completely ruled out without the use of more sophisticated designs (Podsakoff, MacKenzie, Lee \& Podsakoff, 2003). Additionally, cross-sectional designs preclude one's ability to draw cause-and-effect inferences. Thus, it is possible the relationship between intrusions and strain reactions may have been due to reverse-causation (i.e., strains increasing experienced intrusions). Third, participants were asked to reflect on their respective intrusions and strain levels from the previous three months to complete the measures. Due to recall deficiencies in human memory 
(e.g., serial-recency effects; Deese \& Kaufman, 1957), it is possible the measures suffered from deficiencies or contamination in construct validity. Thus, while the article established key relationships between the chronic experience of intrusions and strain, key internal validity concerns limit the study's contributions. As described in the method section, the present study not only builds on Lin and colleagues' (2013) initial examination of intrusions and strain, but through more sophisticated research design, be able to examine the effects of day-to-day intrusions on strain, and self-performance appraisals during a week. 


\section{Chapter 3: Resource Framework}

Resource-based theories provide the basis for understanding how intrusions can be linked with employee outcomes. The Conservation of Resources (COR) Theory states that individuals seek to maximize or maintain their resources, and experience strain when they perceive a threat, or actual loss of resources (Hobfoll, 1989). Resources are defined as "objects, personal characteristics, conditions, or energies that are valued by the individual or that serve as a means for attainment of these objects, personal characteristics, conditions, or energies" (Hobfoll, 1989, p. 516). Three resources of particular importance for understanding interruptions and their effects on strain are time, Self-Regulatory Resources, and Cognitive Resources.

Time as a Resource. Time is considered a valued resource for employees, as they are essential for obtaining additional resources. For example, employees invest time in performance episodes to obtain other valued resources such as money (through wages), or self-worth (through successful completion of their tasks). In fact, individuals allocate time during a workday to complete each of their requisite work tasks in order to ensure completion of all tasks, and at a sustainable pace. However, intrusions occur during performance episodes, and displace time that employees previously allocated to completing their tasks. Because employees are unlikely to account for intrusions a priori (given that by definition, they are unexpected), intrusions alter how employees can engage in performance-related tasks in a variety of ways. First, employees can shorten each subsequent performance episode by working faster or harder to "make up for lost time." Indeed, past experimental research has shown that individuals are generally 
successful at improving performance accuracy and performance time in simple tasks following an intrusion (Speier, Valacich, \& Vessey, 1999; Speier, Vessey, \& Valacich, 2003). Unfortunately, primary task performance in organizations may not always be as simple as text editing, or solving arithmetic questions. As such, working harder or faster may not always represent a viable alternative for knowledge workers, such as CIT employees. Second, employees may relocate performance episodes to a different workday. In fact, past research has shown that when employees are interrupted only $77 \%$ of employees are able to successfully resume the task during the same workday, while the remaining $23 \%$ push the task to a following workday (Mark, Gonzalez, \& Harris, 2005). Although this may be a viable option for non-urgent work tasks, the temporal relocation of tasks is not a seamless process as individuals must then condense performance episodes on the new workday. Finally, employees may stay at work longer to attend to all remaining primary tasks. However, the Fair Labor Standards Act of 1938 states that all employees working greater than 40 hours per week must be compensated at a rate of 1.5 their normal working hours (United States Department of Labor, 2010). If intrusions cause employees to work beyond their 40 hours per week, it is likely to have drastic organizational costs. Therefore, given the recent economic downturn, having employees work longer hours is an undesirable alternative for organizations.

Irrespective of the different options, intrusions result in having more works tasks to complete in the same amount of time (Perlow, 1999). Additionally, intrusion episodes consist of three distinct behavioral clusters: Adjustment lags, secondary task performance, and resumption lags, and research has suggested resumption lags can 
consume anywhere between 5-10 times as much time as secondary task performance in the CIT industry (Spira, 2012). While it is unclear how Spira (2012) came to this estimation, it provides an important reminder that each behavioral cluster in an intrusion episode can vary in the time consumed.

Self-Regulatory Resources. The Ego Depletion Model (EDM) suggests that humans have a limited ability to perform behaviors that do not result in immediate pleasure, and that these acts of volition, or self-regulation, are contingent on the availability of the ego (Baumeister et al., 1998). This is akin to Psychoanalysis' conceptualization of the ego as the central executive that controls behavior while balancing the basic desires of the id and the superego. Through a series of experiments, Baumeister and colleagues (1998) found that when participants were asked to perform one act of volition (or behaviors that did not result in immediate pleasure), their performance on subsequent acts requiring self-restraint or self-regulation was diminished. Through an additional series of experiments, Muraven, Tice, and Baumeister (1998) found that the exercising of self-regulation was most consistent with that of a limited resource (i.e., self-regulatory resources), and can be either depleted through use, replenished by experiencing positive emotions (Tice, Baumeister, Schmueli \& Muraven, 2007), or increased through small exercises of self-control (Muraven, Baumeister \& Tice, 1999).

If we assume that intrusions intersect performance episodes aimed towards completing job-related tasks causing a cessation in performance behavior, I assume that intrusions impede the attainment of a performance goal. When employees perceive an 
obstruction in goal-attainment, they are likely to experience frustration, or the negative emotional experience when goal-attainment or behaviors aimed towards attaining these goals are unexpectedly interrupted (Berkowitz, 1989; Chen \& Spector, 1992). Indeed, past experimental research has found that neutral distractions increase negative emotions such as frustration (Adamcyk \& Bailey, 2004; Bailey \& Konstan, 2006; Bailey, Konstan \& Carlis, 2006). Given that intrusions are merely one form of distraction, I assume that these findings can apply to intrusions as well. Thus, assuming engaging in secondary tasks elicited by intrusions are likely to induce frustration, engaging in these secondary tasks taxes one's self-regulatory resource levels. Furthermore, unlike other forms of interruptions, intrusions are inherently a dyadic process involving a target employee and at least one other person. Universal workplace display rules (i.e., expectations for emotional expression; Ekman \& Friesen, 1975; Hochschild, 1983) typically discourage the display of frustrated affect towards their fellow employees, forcing employees to fake, suppress, and modify their affective expressions (Ashforth \& Humphrey, 1993; Grandey, 2000) when experiencing intrusions. This is a process known as emotional labor. Emotional labor is also thought to consume self-regulatory resources as the maintenance of emotional displays consistent with display rules, particularly when one experiences emotions inconsistent with display rules, requires the exercise of volition (Grandey, 2003). While it is entirely possible that intrusions may involve content that is uplifting in nature (e.g., unexpected praise), and these intrusions may induce certain positive emotions (e.g., pride), it is still assumed that these momentary interjections likely induce frustration as well. 
In summary, intrusions are thought to consume self-regulatory resources for two reasons. First, intrusions prevent employees from completing their immediate performance goals, which likely induces negative emotions towards the secondary task (Berkowitz, 1989). Therefore, secondary task performance taxes self-regulatory resources as employees are asked to engage in a task that is not pleasurable (Baumeister et al., 1998). Second, because intrusions are inherently a dyadic process, the maintenance of emotional displays consistent with display rules is particularly important (Hochschild, 1983). However, further assuming that intrusions elicit negative emotions, the outward display of emotions inconsistent with their genuine emotions further requires selfregulatory resources (Grandey, 2003).

Cognitive Resources. The Cognitive Fatigue Model (CFM; Cohen, 1980), based on Glass and Singer's (1972) adaptive-cost hypothesis, suggests that uncontrollable and unpredictable stressors require substantially greater cognitive adaptation compared to controllable and predictable stressors. Cohen (1978) argues that unpredictable and uncontrollable stressors place substantially increased demands on attentional capacity because individuals must evaluate the threat of the stressor, and formulate an appropriate response to the stressor. It is assumed that predictable and controllable stressors place less demand on cognitive resources because their threat levels can be anticipated and appraised over a longer period of time, and appropriate coping methods can be determined prior to the experience of the stressor. Prolonged exposure to uncontrollable, unpredictable stressors result in information overload and elevated levels of cognitive fatigue. Individuals with elevated levels of cognitive fatigue are presumed to neglect 
stimuli perceived to be irrelevant to their current priorities, possibly resulting in the neglect of important information that superficially appears unrelated to task performance. Akin to Baumeister and colleagues' (1998) conceptualization of self-regulatory resources, Cohen's CFM also implies the existence of cognitive resources which can be depleted, with cognitive fatigue serving as a manifestation of depleted cognitive resources. Furthermore, depleted levels of cognitive resources have been shown to result in diminished capacity for information processing (Cohen \& Spacapan, 1978).

Intrusions are unpredictable and uncontrollable because they are inherently unexpected, and are within the control of the intruder rather than the target. Based on the CFM, intrusions are assumed to place heavy demands on cognitive resources as they require a threat appraisal (e.g., estimation of time displaced), in addition to the formulation of appropriate coping strategies (e.g., behavioral strategies for placating the intruder). Kirmeyer (1988) extends the CFM framework by stating that incomplete primary tasks may serve as distractions while attempting to cope with a secondary task. These incomplete primary tasks further place demands on a cognitive resources, as individuals must simultaneously appraise threat and formulate coping strategies for the secondary task, all while "tuning out" their incomplete primary task. Therefore, based on Trafton and Monk's (2008) conceptualization of intrusions as consisting of three behavioral clusters, I assume that the adjustment lag of intrusions (i.e., the cognitive disengagement from primary task and cognitive engagement into secondary task) to be the greatest source of cognitive resource consumption. 
Resource Summary. To synthesize the aforementioned resource-based frameworks, I assume that intrusions represent unpredictable and uncontrollable stressors (Jett \& George, 2003) that hinder the completion of immediate performance goals (Berkowitz, 1989). This results in an immediate reduction of cognitive resources as employees must evaluate the threat of the intrusion (e.g., "How much time will this take?"), formulate coping methods (e.g., how to best placate the intruder) while simultaneously ignoring the "cognitive allure" of their incomplete primary task (Cohen, 1980). Furthermore, because intrusions represent an impediment to attaining immediate performance goals, intrusions also result in frustration (Berkowitz, 1989), and subsequent behaviors aimed at addressing the intruding task place demands on self-regulatory resources (Baumeister et al., 1998). Additionally, because intrusions are a dyadic process, the target employee must maintain emotional displays consistent with display rules (e.g., flat or pleasant affect), which is assumed to be inconsistent with their genuine emotions (e.g., frustration; Grandey, 2003). While the secondary task performance may consume time, Spira (2012) argues that the subsequent resumption lag following secondary task performance consumes the greatest amount of time as individuals must then disengage from their secondary task and re-engage in their primary tasks. As such, each intrusion episode is assumed to consume three types of resources: Time, self-regulatory resources, and cognitive resources. 


\section{Chapter 4: Stressor-Strain Hypotheses}

Stress has had various conceptualizations- as a psychological state (Stanton, Balzer, Smith, Parra \& Ironson, 2001), or as a state of arousal (Yerkes \& Dodson, 1908). However, by far, the most common approach to studying stress in Occupational Health Psychology has been examining the dynamic process by which environmental demands (or Job Demands) influence strain reactions (Demerouti, Bakker, Nachreiner \& Schaufeli, 2001; Karasek, 1979). Job demands are "physical, psychological, social, or organizational aspects of the job that require sustained physical and/or psychological (i.e., cognitive or emotional) effort and are therefore associated with certain physiological and/or psychological costs" (Schaufeli \& Bakker, 2004, p.296). Job demands are conceptualized as stressors when they consume or threaten valued resources (Hobfoll, 1989). Prolonged exposure to stressors are assumed to induce strain reactions (de Lange, Taris, Kompier, Houtman \& Bongers, 2003), or the degree of physiological, psychological or behavioral deviation from an individual's normal healthy functioning (Quick, 1998). Thus, as stressors are assumed to deplete or threaten valued resources, strains are thought to be manifestations of depleted or threatened resources.

Intrusions as Stressors. Intrusions at work are assumed to consume three valued resources for employees: Time, self-regulatory resources, and cognitive resources. Specifically, the adjustment lag, secondary task performance, and resumption lag all inherent within a single intrusion episode (Trafton \& Monk, 2008), are each assumed to consume varying amounts of time. Additionally, intrusions are uncontrollable and unpredictable events, and consume cognitive resources by requiring immediate threat 
appraisals and coping strategies while ignoring the unfinished primary task that has been set aside. Furthermore, intrusions are assumed to induce negative affect thus consuming self-regulatory resources as employees both engage in the secondary task, and maintain an affective display consistent with display rules. Therefore, in the present study, I conceptualize intrusions as a stressor.

While past research has examined stressors at the event level (e.g., Social Readjustment Rating Scale; Holmes \& Rahe, 1967), much of contemporary stress literature has examined the appraisal of frequency with which one experiences these events. For example, rather than focusing on the specific work tasks that induce the perception that one has too little time to complete too many tasks, Spector and Jex (1998) measure quantitative workload with items such as "how often does your job require you to work very fast?" This is in contrast to an item to an item focusing on the event level, such as "I was asked to complete 10 tasks." This shift towards an appraisal of frequency (rather than a focus on the event) is in accordance with the Transactional Model of Stress' assertion that the appraisal of an accumulation of events may be more impactful than the objective singular events themselves (Lazarus \& Folkman, 1984). Accordingly, my measurement of intrusions also reflects an appraisal of the frequency with which employees experience intrusions. An alternative to measuring intrusions at the frequency appraisal level is to incorporate participants' valence appraisal of the stressor. That is, shifting the focus of measurement towards the extent to which one experiences an event frequently, and whether the event is positive or negative in valence. This form of measurement represents an even further departure from the appraisal of the objective 
event. However, there are several conceptual concerns with this approach in the context of intrusions.

"Negative" or "positive" events, in the context of intrusions, can represent several different constructs. Positive or negative intrusions can refer to a) the extent to which the intrusions experienced create elevated positive/negative affect or b) a judgment on whether the tone or content of intrusion was positive or negative in valence. The former definition of positive and negative intrusions has the potential to confound the measurement of intrusions with any form of affect-based outcomes. That is, in the context of a stressor-strain relationship, the former definition simply focuses the measurement on the immediate strains resulting from the stressor. Thus, finding a correlation between intrusions, in this context, and strain would be akin to finding a relationship between the frequency with which one experiences frequent strain reactions and a long-term strain variable. A strong correlation would both be unsurprising, and merely a replication of previous findings that momentary affect is correlated with affect at a later point in time (e.g., Judge \& Ilies, 2004). The latter definition, focusing on the tone or content of the intrusions, also presents a conceptual conundrum. That is, positive and negative intrusions in this instance would simply reflect the frequent experience of positive or negative social interactions with colleagues. While this represents an important research domain, and has been studied extensively (e.g., de Lange, Taris, Kompier \& Houtman, 2003; Sackett \& DeVore, 2001), it represents a vast departure from the examination of intrusions. 
Strain reactions. Strains can manifest in three forms: cognitive, affective/emotional, and physical strain (Jex \& Britt, 2008). Hobfoll’s (1989) Conservation of Resources Theory suggests that events that threaten or deplete personal resources are assumed to generate strain. Strain is operationalized in the present study using three indicators: fatigue, self-regulation failure, and workplace cognitive failure. Fatigue has been defined by early Industrial Psychologists as an overuse of the mind or muscles, leading to a depletion of energy (Holmes, 1938), and is the constellation of feeling sleepy, tired, sluggish and drowsy (Watson \& Clark, 1994). Fatigue has been previously been associated with a variety of stressors, such as workload and hours worked (Spector, Dwyer \& Jex, 1988), physical characteristics of the workplace (Mocci, Serra \& Corrias, 2001), and situational constraints (Sonnentag \& Zijlstra, 2006). By definition, fatigue can be conceptualized as a state of low physical and cognitive resources. Given that intrusions are also associated with resource loss, I hypothesize that employees that experience greater levels of intrusions are likely to experience fatigue. Self-regulation failure is characterized by mental and physical exhaustion, weakened self-control, and lethargy, and is presumed to be a direct reflection of one's lack of selfregulatory resources (Ciarocco, Twenge, Muraven \& Tice, 2011). Intrusions are assumed to decrease self-regulatory resources both through the engagement in a secondary task that is undesirable (Baumeister et al., 1998), but also through the outward display of emotions consistent with display rules but inconsistent with genuine emotions (Grandey, 2003). Therefore, I hypothesize that when employees experience a greater number of intrusions they are likely to consume greater amounts of self-regulatory resources, as 
reflected in greater levels of self-regulation failure. Cognitive failure is defined as a "cognitively based error that occurs during the performance of a task that the person is normally successful in executing" (Martin, 1983, p. 97), and is assumed to reflect both a deficit in cognitive resources available, and a consequence of cognitive fatigue. Intrusions, by definition, are unexpected and uncontrollable stressors (Jett \& George, 2003). Given that cognitive resources are required to assess threat, generate coping strategies, and disengage from an incomplete primary task, I assume that intrusions consume cognitive resources (Cohen, 1980). Therefore, employees that experience more frequent intrusions are likely to experience greater levels of workplace cognitive failure.

Thus, in summary, I hypothesize that intrusions experienced on a day-to-day basis is associated with strain reactions, and these strain reactions are operationalized through three variables: Fatigue, self-regulation failure, and cognitive failure.

Hypothesis 1: Compared with other employees, participants experiencing more frequent intrusions experience higher levels of strain outcomes.

Hypothesis 1a: Participants experiencing more frequent intrusions experience higher levels of fatigue.

Hypothesis 1b: Participants experiencing more frequent intrusions experience higher levels of self-regulation failure.

Hypothesis 1c: Participants experiencing more frequent intrusions experience higher levels of cognitive failure. 


\section{Chapter 5: Stressor-Perceived Performance Hypothesis}

Motowidlo (2003) defines Job Performance as the "total expected value to the organization of the discrete behavioral episodes that an individual carries out over a period of time" (p. 39). Motowidlo argues that because Industrial-Organizational Psychologists are unlikely to have effects on the expected value of behavior of a particular employee, employee behavior should be the focus of job performance measurement, though the two terms (i.e., employee behavior and job performance) are typically used interchangeably. Performance behaviors can also be thought to be a function of self-regulatory and cognitive resources. That is, when employees experience an abundance of these resources, they are likely to perform at higher levels. Conversely, when employees experience decrements in these resources they are likely to perform at lower levels. Specifically, a decrease in cognitive resources available (as in the case of frequent intrusions) is likely to adversely influence the performance on subsequent tasks requiring cognition (Cohen \& Spacapan, 1978; Hartley, 1973; Rotton, Olszewski, Charleton \& Soler, 1978). Although this may not result in performance behavior decrements in jobs that do not require higher level cognition (e.g., line manufacturers) many occupations (e.g., CIT employees) do require higher level cognition to adequately complete in-role performance behaviors. Similarly, research by Baumeister and colleagues (e.g., Baumeister et al., 1998; Muraven, Tice \& Baumeister, 1998) has demonstrated that when self-regulatory resources are low, subsequent acts requiring volition are decremented. In the work context, assuming intrusions consume selfregulatory resources, it is possible that a decrement in self-regulatory resources could 
result in job performance decrements. For example, re-engaging in primary tasks after the completion of a secondary task may be more difficult when self-regulatory resources are low, as employees may be tempted to merely take a break, or leave work early.

Past literature has examined the relationship between frequent interruptions and task performance with mixed results. For example, in a field experiment, Zijlstra and colleagues (1999) found that the frequency of intrusions was not significantly associated with performance decrements. However, as stated earlier, Zijlstra and colleagues' manipulation of the frequency of intrusions drastically understated the prevalence of intrusions. On the other hand, Eyrolle and Cellier (2000), using a naturalistic observation of telephone operators, found that customer intrusion (in the form of phone calls) frequency resulted in an increase of the processing time of their current tasks. While the actual frequency of intrusions was not listed in the article, it can be assumed that Eyrolle and Cellier's measurement of the frequency of intrusions has greater validity compared to Zijlstra and colleagues' study. Therefore, based on past research on intrusion frequency and experimental task performance, and based on the aforementioned resource-based framework, I hypothesize that employees experiencing greater day-to-day intrusions rate their own performance as lower.

Typically, a target employee's performance is rated by "others" (e.g., supervisors, subordinates or coworkers) due to employee's potential for leniency or self-enhancement biases (Meyer, 1991). Unfortunately, performance appraisals conducted by "others" present several conceptual problems. First, it has previously been demonstrated that performance appraisals conducted by “others" (e.g., supervisors, coworkers) are biased 
by organizational politics (Longenecker, Sims \& Gioia, 1987). This can be particularly problematic in the context of intrusions as "other" reports of performance may come from the intruder themselves. This becomes problematic because the intruder possibly inflates their ratings of the target employee's performance either as reciprocation for their time (Emerson, 1976), or because they perceive, erroneously or otherwise, that the target employee's help is central to their in-role performance. Second, in the case of CIT employees, in-role performance is not easily observable by "others" because much of the work relies on mental calculations and planning. That is, by focusing on the actual behavior of employees, "others" may not be able to determine a target employee's quality and quantity of work completed until an observable product is produced. Because this may take years to complete, I believe "other" ratings of performance are likely to be a poor reflection of a target employee's actual job performance.

Because self-reported performance and "other" reports of performance each present conceptual and methodological limitations, traditional ratings of performance from any source are likely to be both contaminated and deficient. Thus, in contrast to traditional methods of assessing self-report performance, I assess employees’ performance relative to their own expectations, thereby assessing perceived performance. Perceived performance can be defined as the extent to which employees believe they attained the job performance goals they set during the week. While traditional self-report ratings of performance are likely to be inflated due to leniency and self-enhancement biases (Farh \& Dobbins, 1989), this effect is likely to be tempered when employees compare their actual performance with the expectations they carry for their own 
performance, thus less likely to bias perceived performance scores. Specifically, a measure of an employees' performance relative to their own standards is composed of a) an employee's actual job performance, and b) participants' expectations of themselves. I assume that individuals' tendency to inflate ratings of their own accomplishments is likely to inflate both ratings of their own job performance as well as their expectations of themselves. Thus, by asking participants to rate their perceived performance, I likely capture a purer estimation of an employee's actual job performance. Perceived performance ratings are also assumed to fluctuate with resource fluctuations. Specifically, not only are consumptions of consumptions of time, self-regulatory, and cognitive resources associated with perceived performance through declines in job performance, past research has also connected consumption of resources with perceived inefficacy (Lee \& Ashforth, 1996). Specifically, prolonged resource consumption has been associated with perceptions of exhaustion and indifference (i.e., depersonalization), and increases in these experiences have been associated with deflated perceptions of one's own personal accomplishments (Byrne, 1994). Maslach, Schaufeli and Leiter (2001) suggest "it is difficult to gain a sense of accomplishment when feeling or exhausted or when helping people toward whom one is indifferent" (p. 403).

In summary, intrusions consume time, self-regulatory resources, and cognitive resources. Inherently, when employees lose time, self-regulatory resources, and cognitive resources, they have fewer of these resources to dedicate to task performance, resulting in poorer performance on tasks (Cohen \& Spacapan, 1978; Baumeister et al., 1998). Additionally, losses in resources are likely to induce feelings of exhaustion and apathy 
resulting in greater perceptions of inefficacy and losses in personal accomplishment. The combination of these detriments is assumed to be reflected in decreased perceived performance.

Hypothesis 2: Compared with other employees, participants experiencing more frequent intrusions rate themselves lower on perceived performance. 


\section{Chapter 6: Method}

\section{Participants \& Procedure}

A total of 167 employees from six small companies in the computing and information-technology (CIT) industry were sampled for the purposes of the present study. All participants were expected to contribute to coding projects, but specific tasks across jobs varied, including software planning, software coding, researching competing products, managing clients, and hardware support. Due to prearranged nondisclosure agreements, the names and details of these organizations have been withheld. Sample sizes and response rates varied across the six organizations and time points, and can be found in Table 1.

The sampling of CIT employees was chosen because CIT employees are likely to be intruded upon via several media due to increased availability of technology (e.g., intranet direct messages, forum discussions, instant messaging, email, text messages, phone calls). Therefore, it is likely that CIT employees experience more varying levels of intrusions compared to other industries. Because high levels of variability in predictor variables is preferred for enhanced statistical power, the use of CIT workers was preferred compared to using a heterogeneous sample of employees of multiple industries. Furthermore, given the shift from waterfall work procedures to agile work procedures, cross-expertise and cross-team collaborations are becoming the norm, which should further increase the likelihood CIT employees experience intrusions. 
Participation in the present study consisted of completing five online surveys in total, all hosted by a third-party survey administration website, Surveymonkey. The first online survey measured trait-level variables (Time 0) and was to be completed at any point prior to the main study. The final four surveys were to be completed by participants over four consecutive days (i.e., Monday-Thursday). Day-to-day intrusions were measured on Monday (Time 1), Tuesday (Time 2), and Wednesday (Time 3), and weeklevel strain and perceived performance were measured on Thursday (Time 4). A full copy of each survey can be found in Appendix A through E. See Table 2 for a list of the specific variables measured at each time point.

Organizations were solicited to participate by contacting my former college classmates from Purdue University, who were currently associated with the CIT industry. First, a company-wide email (Appendix F) was sent to all eligible participants (i.e., adult, full-time, knowledge workers) using a listserv. This simultaneously allowed me to reach all company employees by sending a single email, and also protected the identity and contact information of those employees who chose not to participate. In this initial email, interested participants were instructed to email me. Of the total 229 possible employees, a total of 196 employees (across the 6 organizations) emailed me expressing interest. Of this participant pool, an invitation to participate in the study was sent describing the overarching goals of the study, as well as link for the Time 0 survey (Appendix G). At the conclusion of the Time 0 survey are instructions to email me to participate in the Time 1 survey. This allowed me to determine which employees had completed the survey, and those employees who required reminder emails. Participants were sent 
reminders to complete this survey on Sundays at noon, 2:00PM, 4:00PM, 6:00PM, 8:00PM, and midnight. To be considered for data collection during that week, employees had to complete the Time 0 survey by 5:00AM that Monday. This reminder email can be found in Appendix H. Of the 196 potential employees, 167 employees completed the Time 0 survey (Response rate $=85.20 \%$ ). All 167 employees who completed the survey emailed me. These 167 participants were then used as the recruitment pool for the Time 1 participant pool. On Monday, a recruitment email to complete the Time 1 survey was sent at 1:00PM local time to each participant (Appendix I). Again, at the conclusion of the Time 1 survey, employees were asked to email me. Reminder emails reminder emails (Appendix J) were sent to participants who did not complete the Time 1 survey at 3:00PM, 4:00PM, 5:00PM, and 7:00PM. Of the 167 employees solicited, 150 employees participated $($ Response rate $=89.82 \%)$. These 150 participants were used as the final recruitment pool for the remaining time points. On Tuesday, a recruitment email to complete the Time 2 survey was sent at 1:00PM local time for each participant (Appendix K). At the conclusion of the Time 2 survey, employees were asked to email me. Reminder emails reminder emails (Appendix L) were sent to participants who did not complete the Time 2 survey at 3:00PM, 4:00PM, 5:00PM, and 7:00PM. Of the 150 employees solicited, 141 employees participated (Response Rate $=94.00 \%)$. On Wednesday, a recruitment email to complete the Time 3 survey was sent at 1:00PM local time for each participant (Appendix M). At the conclusion of the Time 3 survey, employees were asked to email me. Reminder emails (Appendix N) were sent to participants who did not complete the Time 3 survey at 3:00PM, 4:00PM, 5:00PM, and 
7:00PM. Of the 150 participants solicited, 145 employees participated (Response Rate = 96.67\%). Finally, on Thursday, a recruitment to complete the Time 4 survey was sent at noon (Appendix O). At the conclusion of the Time 4 survey employees were asked to email me to indicate they had completed the study and to be entered into a drawing for a prize. Reminder emails (Appendix P) were sent to employees who had not completed the Time 4 survey at 2:00PM, 4:00PM, 6:00PM, 8:00PM, 10:00PM and midnight. Of the 150 employees solicited, all 150 employees participated $($ Response Rate $=100 \%)$.

To incentivize organizational support for participating, each organization received a technical report or presentation. To incentivize employee participation in the two most critical time points, employees were entered into a drawing to receive MDR-ZX100 Over-ear Headphones (\$17.99 per unit). Over-ear headphones were purchased and distributed to 50 out of 150 participants who emailed me to be entered into the drawing (33.33\% participants received headphones). Human Subjects Research and Review approval to follow this procedure can be found in Appendix R.

\section{Measures}

Intrusions. Lin and colleagues (2013) developed a measure of intrusion frequency. However, because the psychometric properties of the measure were not suitable for the present study (namely measure of frequency assessed with agreement rating scale rather than frequency scale, poor factor structure, item stems unsuitable for diary designs), I developed a new measure of intrusions for the purpose of the dissertation. This measure consisted of 5 items ( 4 positively-worded, and 1 negatively- 
worded), including: I was interrupted by others," "My work flow was interrupted by others," "I had to stop working to attend to others' interruptions," "I was able to work long periods without being interrupted," and "Others stopped me while I was working." Participants were asked to respond on a 5-point Likert-type scale (1=Not even once; $5=$ Constantly).

An initial pilot study was conducted including 131 workers and student workers. Forty student workers completed the pilot survey without compensation. Criteria for participation were that students were over 18, and were either currently employed (either part- or full-time), or had been employed in the past 6 months. Ninety-one participants were collected from an introductory psychology class as part of an extra-credit assignment. Students who did not meet the criteria for participation were allowed to solicit someone else who did meet the criteria to complete the survey on their behalf (provided that they had not previously completed the survey) to obtain extra credit. This survey can be found in Appendix Q.

Initial results from this pilot suggested the internal consistency of the measure using all five items was strong (coefficient alpha $=.87$ ), but was stronger when the negatively worded item (i.e., "I was able to work long periods without being interrupted) was omitted (coefficient alpha =.91). Using Confirmatory Factor Analysis to test the unidimensionality of the measure, I found that both the $5-\left(\chi^{2}=5.617, \mathrm{df}=6\right.$, RMSEA=.000) and 4-item $\left(\chi^{2}=4.968, \mathrm{df}=3, \mathrm{RMSEA}=.071\right)$ scales yielded acceptable fit. Not surprisingly, in the 5-factor model, the reverse scored item yielded the weakest factor loading (.505; SE=.103), while the second lowest factor loading estimate was for item 5 
(“Others stopped me while I was working"; 0.900; $\mathrm{SE}=.075$ ). At the recommendation of the committee during the proposal meeting, it was recommended the negative item be dropped, yielding a final measure of four items.

In the present study, I measured intrusions at Time 1 through Time 3 using four items that I developed. Participants were asked to respond based on a 5-point Likert scale (1= "Never;" 5 = "Always"). Coefficient alphas were consistently high at all three time points: .87 at Time $1, .84$ at Time $2, .85$ at Time 3 .

Fatigue. Fatigue was measured at Time 4 using 4 items from the Positive and Negative Affect Schedule: Expanded Edition (PANAS-X; Watson \& Clark, 1994). Sample items include: "sleepy" and "tired." Participants were asked to respond on a 1 to 5 Likert scale (1= "Very slightly or not at all;" 5= "Extremely"). Coefficient alpha for this variable was high at .84 .

Self-Regulation Failure. Self-regulation failure was measured at Time 4 using the 4-item short version of the State Self-Control Capacity Scale (SSCCS; Ciarocco et al., 2001). Sample items include: "If I were tempted by something right now, it would be very difficult to resist," and "I feel like my willpower is gone." Participants were asked to respond on a 1 to 5 Likert-type scale (1= "Never;" 5= "Always"). Coefficient alpha for this variable was high at .82 .

Cognitive Failure. Cognitive Failure was measured at Time 4 using an adaptation of Wallace and Chen's (2005) 15-item Workplace Cognitive Failure measure. Two items from this measure were adapted: "Cannot remember work-related phone numbers" was 
changed to "Cannot remember work-related contact information," and "Unintentionally press control switches on machines," was changed to "Unintentionally press buttons on machines," to better reflect the tasks of the sample. Participants were asked to respond on a 1 to 5 Liker-type scale (1="Never," 5="Always"). Coefficient alpha for this variable was high at .98 .

Past literature has divided cognitive failure into three subdimensions: Memory, attention, and behavior (Wallace \& Chen, 2005). Coefficient alpha for each of these dimensions were also high for memory, attention and behavior at .94, .92, .96, respectively. Additionally, Confirmatory Factor Analyses suggested the data better fit the three factor model compared to the one-factor model $\left(\Delta \chi^{2}=45.71, \Delta \mathrm{df}=3, \mathrm{p}<.001\right)$. However, because I did not hypothesize differential effects across subdimensions, for the sake of parsimony, a unidimensional model of Cognitive Failure was retained. Nonetheless, analyses including these subdimensions as criterion variables were included in the Additional Analyses section.

Perceived Performance. Perceived performance were measured at Time 4 using 6 items from an adapted version of the 7-item measure developed by Williams and Anderson (1991). One item from the original 7-item measure was omitted (i.e., "I engaged in activities that will directly affect my performance evaluation") because the adapted stem (i.e., "I engaged in activities that will directly affect my performance evaluation to my expectations") yielded an item that was unclear. Participants were asked to rate the frequency of their performance behaviors relative to their own expectations (e.g. "I adequately completed assigned duties relative to my own expectations"). 
Employees were asked to respond on a 5-point scale with anchors 1= "Not at all," 5= "All the time." A list of the original items and adapted items can be found in Table 3. Coefficient alpha for this variable was high at .78.

Additional Variables. Additional variables that were thought to be associated with intrusions were measured at each time point. For a comprehensive list of variables measured at each time point, consult Table 2. Variables that were deemed relevant for the analyses in the present dissertation included demographic variables measured at Time 0 (i.e., age, gender, managerial status, and collaboration hours), fatigue, self-regulation failure, perceived performance, quantitative workload and surface acting measured on Time 1, 2, and 3, and quantitative workload and surface acting measured at Time 4.

Age, sex, managerial status and collaboration hours were each measured using a single item (i.e., what is your age? What is your sex? Is managing other employees part of your job? How many hours do you spend collaborating with your hours per week?). Past literature suggests age, sex, managerial status, and collaboration hours may be associated with strain and perceived performance (Brewer \& Shapard, 2004; Lin et al., 2013; Ones \& Viswesvaran, 1998), thus were measured as potential control variables.

Quantitative workload refers to the extent to which employees feel they have too many work tasks to complete with too little time (Spector \& Jex, 1998). Surface acting refers to the frequency with which employees must suppress their genuine emotions and display emotions that are not genuine (Brotheridge \& Lee, 2003). Surface acting is one mechanism through which intrusions were assumed to consume self-regulatory resources, 
and quantitative workload is assumed to be an operationalization of reduced time to complete work tasks. Therefore, both were measured as potential outcome variables (i.e., Time 1 through 4) or control variables (i.e., Time 4). Quantitative workload was measured using the five-item Quantitative Workload Inventory (e.g., " How often does your job require you to work very fast?"). Surface acting was measured using three items developed by Brotheridge and Lee (2003; e.g., "How often do you resist expressing your real emotions?"). Participants were asked to respond to quantitative workload items and surface acting items using a 5-point Likert-type scale (1= "Never," 5= "Always").

In addition to the Time 4 measurement point, fatigue, self-regulation failure, and perceived performance were also measured at the Time 1, Time2, and Time 3 measurement points to determine whether intrusions had micro-micro relationships with these outcome variables on each day. Cognitive failure was not measured on each day because of the length of the measure. Fatigue, self-regulation failure, and perceived performance were measured at each time point using the same measures described on page 37 through 38 . 


\section{Chapter 7: Results}

\section{Preliminary Analyses}

SPSS 20.0 was used for all preliminary analyses. Prior to any analyses, the data was examined for univariate and multivariate outliers using Cook's D. Casewise diagnostics and residual statistics were also examined in order to see that the assumptions of normality, linearity, and homoscedasticity of residuals were met, permitting general linear models analysis (Tabachnick \& Fidell, 2012) and structural equation analysis (Kline, 2010). A composite score was calculated for all study variables by calculating participant means across all items in each measure (i.e., Time 1 Intrusions, Time 2 Intrusions, Time 3 Intrusions, Fatigue, Self-Regulation Failure, Cognitive Failure, Perceived Performance). To determine whether outcome variables were empirically distinct, I conducted a series of nested Confirmatory Factor Analyses. First, a single factor model was specified wherein all items loaded onto a single latent variable. This model yielded poor fit $\left(\chi^{2}=1348.14, d f=378, \chi^{2} / d f=3.57, \mathrm{RMSEA}=.13, \mathrm{NFI}=.68\right.$, $\mathrm{CFI}=.74)$. A second, equivalent two-factor model was specified wherein all fatigue, selfregulation failure, and cognitive failure items loaded onto a single strain factor, and perceived performance items loaded onto a second factor. This model also yielded poor fit $\left(\chi^{2}=1354.75, d f=378, \chi^{2} / d f=3.58, \mathrm{RMSEA}=.13, \mathrm{NFI}=.68, \mathrm{CFI}=.74\right)$. Finally, a four factor model was specified wherein each item loaded onto their corresponding latent factor (e.g., fatigue items loading on a fatigue latent factor). This model yielded

acceptable fit $\left(\chi^{2}=1047.11, d f=375, \chi^{2} / d f=2.79, \mathrm{RMSEA}=.11, \mathrm{NFI}=.75, \mathrm{CFI}=.82\right)$, and this model fit significantly better than the two-factor model $\left(\Delta \chi^{2}=307.65, \Delta d f=3\right.$, 
$\mathrm{p}<.001)$. These results corroborate the efficacy of examining the four measures as separate outcome variables. See Figure 1 for an illustration of these models.

Means, standard deviations, between- and within-subjects correlations for all study variables and demographics can be found in Table 4. Given the micro-macro analysis used in the present study is inherently a between-subjects analysis, discussion of variable inter-correlations centers on between-subject correlations only. Intrusions measured at each time point were significantly correlated with Time 2 and 3 yielding the smallest correlation $(r=.37, p<.01)$ and Time 1 and 2 yielding the largest correlation $(r$ $=.72, p<.01)$. All outcome variables were also significantly correlated at the $\alpha=.01$ level, ranging from $r=.80$ between fatigue and self-regulation failure, and $r=-.40$ between fatigue and self-regulation failure. Finally, out of a possible 12 correlations between intrusions at each time point and outcome variables, only 5 correlations were significant at the $\alpha=.05$ level. These included Time 1 intrusions and self-regulation failure $(r=.23, p<.01)$, Time 2 intrusions and self-regulation failure $(r=.20, p<.05)$ and performance $(r=-.21, p<.05)$, and Time 3 intrusions and fatigue $(r=.29, p<.01)$ and self-regulation failure $(r=.40, p<.01)$. Demographics variables, such as age, sex, managerial status and collaboration hours were also included in our data collection, and all were found to be significantly associated with study variables. Specifically, age was found to be significantly associated with all outcome variables, including fatigue $(r=-$ $.30, p<.01)$, self-regulation failure $(r=-.29, p<.01)$, cognitive failure $(r=-.51, p<.01)$, and perceived performance $(r=.42, p<.01)$, suggesting older employees rated their strain levels lower and performance higher than younger employees. This is consistent 
with past meta-analytic literature that has shown older employees have higher levels of work-related health outcomes (e.g., Brewer and Shapard, 2004). Sex was also significantly associated with Time 2 intrusions $(r=-.17, p<.05)$, cognitive failure $(r=$ $.21, p<.05)$ and perceived performance $(r=-.20, p<.05)$, such that women reported experiencing fewer intrusions, more cognitive failure, and lowered levels of perceived performance. The fact that women reported fewer intrusions is surprising, given that past literature has demonstrated that women are more likely to be intruded (Lin et al., 2013). Finally, the perceived performance score differences and cognitive failure scores are not surprising considering men are more likely to fake on tests and more heavily influenced by social desirability (Ones \& Viswesvaran, 1998). Finally, past literature has demonstrated that managerial status and collaboration hours can be critical variables in the examination of intrusions and strain (Lin et al., 2013). Thus, not surprisingly, managerial status was associated Time 2 intrusions $(r=-.22, p<.01)$, Time 3 intrusions $(r$ $=-.21, p<.05)$, self-regulation failure $(r=.19, p<.05)$, cognitive failure $(r=.41, p<$ $.01)$, and perceived performance $(r=-.21, p<.05)$. Collaboration hours were also found to be associated with fatigue $(r=.21, p<.05)$, cognitive failure $(r=.44, p<.01)$, perceived performance $(r=-.48, p<.01)$.

Means and standard deviations across study variables also varied across organizations, and can be found in Table 5. A one-way between subjects ANOVA was conducted to compare mean levels of study variables across groups. Overall, there were mean differences across organizations in Time 1 intrusions $[\mathrm{F}(5,144)=2.88, \mathrm{p}<.05)]$, Time 3 intrusions $[\mathrm{F}(5,139)=2.32, \mathrm{p}<.05)]$, fatigue $[\mathrm{F}(5,144)=2.49, \mathrm{p}<.05)]$, 
cognitive failure $[\mathrm{F}(5,144)=16.05, \mathrm{p}<.01)]$, and performance $[\mathrm{F}(5,144)=7.38, \mathrm{p}<$ .05)]. Post Hoc comparisons using Bonferroni adjustments yielded mean differences between Company A $(\mathrm{M}=3.21, \mathrm{SD}=.78)$ and $\mathrm{F}(\mathrm{M}=2.44, \mathrm{SD}=.38)$ in Time 1 intrusions. Company A $(\mathrm{M}=1.58, \mathrm{SD}=.83)$ was significantly lower than Companies $\mathrm{C}$ $(\mathrm{M}=2.58, \mathrm{SD}=.99), \mathrm{D}(\mathrm{M}=2.72, \mathrm{SD}=.96), \mathrm{E}(\mathrm{M}=3.50, \mathrm{SD}=.06)$, and $\mathrm{F}(\mathrm{M}=3.29$, $\mathrm{SD}=.60)$ in Cognitive Failure. Company $\mathrm{B}(\mathrm{M}=1.97, \mathrm{SD}=.78)$ was significantly lower than Company $\mathrm{D}(\mathrm{M}=2.72, \mathrm{SD}=.96), \mathrm{E}(\mathrm{M}=3.50, \mathrm{SD}=.06)$, and $\mathrm{F}(\mathrm{M}=3.29, \mathrm{SD}=$ $.60)$ in Cognitive Failure. Company $\mathrm{C}(\mathrm{M}=2.58, \mathrm{SD}=.99)$ was also significantly lower than Company $\mathrm{D}(\mathrm{M}=2.72, \mathrm{SD}=.96), \mathrm{E}(\mathrm{M}=3.50, \mathrm{SD}=.06)$, and $\mathrm{F}(\mathrm{M}=3.29, \mathrm{SD}=$ $.60)$ in Cognitive Failure. Finally, Company B $(\mathrm{M}=4.04, \mathrm{SD}=.56)$ was significantly higher in performance than Company $\mathrm{D}(\mathrm{M}=3.47, \mathrm{SD}=.54), \mathrm{E}(\mathrm{M}=3.39, \mathrm{SD}=.14)$, and $\mathrm{F}(\mathrm{M}=3.39, \mathrm{SD}=.29)$. Post Hoc comparisons yielded no mean differences across companies in Time 3 intrusions and fatigue after adjusting for family wise error rate using Bonferroni adjustments.

In addition to the frequency of intrusions experienced, participants were also asked whether the majority of intrusions experienced on each day were short/medium/long, simple/moderate/complex, expected/unexpected, and welcome/neutral/unwanted. Additionally, participants were also asked what percentage of intrusions were in person/email/instant messaging/phone/text messaging and if the intrusions were positive/neutral/negative in nature. Across Time 1 to Time 3, employees, on averages, experienced $3.99(\mathrm{SD}=4.43)$ intrusions per day, with each consuming 9.81 $(\mathrm{SD}=14.53)$ minutes. Employees reported that the majority of the experienced intrusions 
were short (55.19\%), simple (51.18\%), expected (53.07\%), and neutral (60.99\%).

Furthermore, most intrusions occurred in person (46.69\%) versus email (15.92\%), instant messaging (10.90\%), phone (19.24\%), or text messaging $(7.25 \%)$, and most reported the intrusions as positive (58.17\%) versus neutral (28.99\%), or negative (12.84\%).

Additional descriptive statistics of intrusion characteristics can be found in Table 6 .

\section{Main Analyses}

AMOS version 21.0 was used for all main analyses in accordance with Croon and van Veldhoven's (2007) recommendations. Rather than implementing pair-wise, or listwise deletion techniques for missing data, I included all incomplete cases and used Full Information Maximum Likelihood (FIML) Estimation. This technique has been demonstrated to produce fewer biased parameter estimates and is less likely to inflate Type I Error rates in comparison to the other two more popular approaches (Enders \& Bandalos, 2001). Per FIML requirements, data from incomplete cases were assumed to be missing at random.

Data were hierarchically structured with day-level (level-1) data nested within week-level (level-2) data. Past research with hierarchically structured data has focused on macro-micro approaches with higher-level variables predicting lower-level outcome variables. However, substantially less research has examined micro-macro relationships where lower-level variables predict higher-level variables. Croon and van Veldhoven (2007) found that traditional methods of regressing level-2 outcomes on aggregated level1 predictors yielded biased parameter estimates (although the biases decreased with 
extremely large sample sizes), and put forth a new method for modeling level-1 variables predicting level-2 outcomes. However, to date, no studies in Industrial-Organizational Psychology have implemented this method, particularly as it pertains to multi-wave data.

To minimize biases in parameter estimation, Croon and van Veldhoven (2007) recommended using group member scores as indicators of a latent group-level variable arguing that traditional methods of specifying group-level variables (e.g., averaging across group members) is only appropriate when group means of predictor variables can be assumed to be accurate estimations of the parameters that characterize the general level of the individual scores. Applying this approach to multi-wave designs, I specified day-level predictor scores as indicators of week-level latent predictor variables, and regressed week-level outcome variables on the week-level predictor latent variables.

To test Hypothesis 1 (i.e., participants experiencing more frequent intrusions experience higher levels of strain), separate structural regression models were specified wherein latent week-level strain was regressed on latent week-level intrusions with daylevel intrusions serving as the observed indicator variables.

Specifically, to test Hypothesis 1a (i.e., participants experiencing more frequent intrusions experience higher levels of fatigue), intrusions at Time 1, Time 2, and Time 3 were specified as observed indicator variables for a latent week-level intrusions variable. This measurement model was then specified to predict a second measurement model with week-level fatigue items serving as indicators for a week-level fatigue latent variable.

This model had good fit $\left(\chi^{2}=21.90, d f=13, \chi^{2} / d f=1.68, \mathrm{RMSEA}=.07, \mathrm{NFI}=.95, \mathrm{CFI}\right.$ 
$=.98)$. Additionally, the latent week-level intrusions variable was a significant predictor of week-level fatigue $(r=.20 ; \beta=.17, S E=.083, p<.05)$, thus supporting Hypothesis 1a. In other words, week-level intrusion frequency measured on a day-to-day basis was positively associated with week-level fatigue. The pictorial illustration of this can be found in Figure 1.

To test Hypothesis $1 \mathrm{~b}$ (i.e., participants experiencing more frequent intrusions experience higher levels of self-regulation failure), intrusions at Time 1, Time 2, and Time 3 were specified as observed indicator variables for a latent week-level intrusions variable. This measurement model was then specified to predict a second measurement model with week-level self-regulation failure items serving as indicators for a week-level self-regulation failure latent variable. This model had marginally acceptable fit $\left(\chi^{2}=\right.$ 41.72, $d f=13, \chi^{2} / d f=3.21, \mathrm{RMSEA}=.11, \mathrm{NFI}=.90, \mathrm{CFI}=.93$ ), but the latent weeklevel intrusions variable was a significant predictor of week-level self-regulation failure $(r=.40 ; \beta=.45, S E=.114, p<.01)$, thus supporting Hypothesis $1 \mathrm{~b}$. In other words, week-level intrusion frequency measured on a day-to-day basis was positively associated with week-level self-regulation failure. The pictorial illustration of this can be found in Figure 2.

To test Hypothesis 1c (i.e., participants experiencing more frequent intrusions experience higher levels of cognitive failure), intrusions at Time 1, Time 2, and Time 3 were specified as observed indicator variables for a latent week-level intrusions variable. This measurement model was then specified to predict a second measurement model with week-level cognitive failure items serving as indicators for a week-level cognitive failure 
latent variable. This model had acceptable fit $\left(\chi^{2}=304.91, d f=134, \chi^{2} / d f=2.28\right.$, RMSEA $=.09, \mathrm{NFI}=.89, \mathrm{CFI}=.93$ ), but the latent week-level intrusions variable was not a significant predictor of week-level cognitive failure $(r=-.02 ; \beta=-.06, S E=.285, p$ $=.842)$. These results failed to support Hypothesis 1c. In other words, week-level intrusion frequency measured on a day-to-day basis was not significantly associated with week-level cognitive failure. The pictorial illustration of this can be found in Figure 3.

To test Hypothesis 2 (i.e., participants experiencing more frequent intrusions rate themselves lower on perceived performance.), intrusions at Time 1, Time 2, and Time 3 were specified as observed indicator variables for a latent week-level intrusions variable. This measurement model was then specified to predict a second measurement model with week-level performance items serving as indicators for a week-level performance latent variable. This model had marginally acceptable fit $\left(\chi^{2}=75.35, d f=26, \chi^{2} / d f=2.90\right.$, RMSEA $=.11, \mathrm{NFI}=.82, \mathrm{CFI}=.87$ ), but the latent week-level intrusions variable was a significant predictor of week-level perceived performance $(r=-.27 ; \beta=-.20, S E=.079, p$ $<.05)$, thus supporting Hypothesis 2. In other words, week-level intrusion frequency measured on a day-to-day basis was negatively associated with week-level perceived performance. The pictorial illustration of this can be found in Figure 3.

\section{Additional Analyses}

Akin to the week-level measurements of outcome variables, a measure of weeklevel intrusions was also administered on Time 4 such that employees were asked to complete the day-to-day measure of intrusion frequency, but reflect on the intrusion they 
experienced over the week. Week-level intrusions were moderately correlated with intrusions measured at each time point (i.e., $r_{\text {Timel }}=.52 ; r_{\text {Time2 }}=.57 ; r_{\text {Time } 3}=.44$; see Table 7), and when regressed on intrusions measured at all three time points, it was found that the model explained $38 \%$ of variability in week-level intrusions $\left(\beta_{\text {Timel }}=.13, \mathrm{p}=.20\right.$, $\beta_{\text {Time } 2}=.37, \mathrm{p}<.01, \beta_{\text {Time3 }}=.26, p<.01, \Delta R^{2}=.38$; see Table 8 ). When intrusions measured at Times 1-3 were aggregated (i.e., averaged), week-level intrusions were only correlated with the aggregated measure of intrusions at .63. These results suggest that although week-level intrusions and the aggregate of Time 1,2, and 3 intrusions may be theoretically identical, they are empirically distinct. I contend that measuring intrusions at Time1, 2, and 3 may be the ideal method of capturing intrusions that occur over the week as week-level assessments conducted at the end of the week may be subject to recall biases, and also may not reflect the dynamic nature of intrusions in the workplaces.

Week-level intrusions were strongly related to all relevant outcomes, and using hierarchical regression, it was found that intrusions measured from Time 1, 2, and 3 explained incremental variance on only two of the four outcome variables. Specifically, week-level intrusions were entered into the first step of the regression model, and intrusions experienced on Time 1,2, and 3 were entered into the second step of the regression model. Week-level intrusions significantly predicted fatigue $(\beta=.19, p<.05$, $\left.\Delta R^{2}=.04\right)$, and intrusions measured on each day explained incremental variance over week-level intrusions $\left(\beta_{\text {Timel }}=-.10, p=.40, \beta_{\text {Time } 2}=-.09, p=.48, \beta_{\text {Time3 }}=-.27, p<.01\right.$, $\left.\Delta R^{2}=.06\right)$. Week-level intrusions also significantly predicted self-regulation failure ( $\beta=$ $.24, p<.01, \Delta R^{2}=.06$ ), and intrusions measured on each day explained incremental 
variance over week-level intrusions $\left(\beta_{\text {Timel }}=.02, p=.84, \beta_{\text {Time } 2}=.03, p=.81, \beta_{\text {Time } 3}=.35\right.$, $\left.p<.01, \Delta R^{2}=.11\right)$. Week-level intrusions also significantly predicted cognitive failure $(\beta$ $\left.=.21, p<.05, \Delta R^{2}=.04\right)$, and intrusions measured on each day did not explain incremental variance over week-level intrusions $\left(\beta_{\text {Timel }}=-.23, p=.06, \beta_{\text {Time } 2}=-.03, p=\right.$ $\left..80, \beta_{\text {Times }}=.01, p=.94, \Delta R^{2}=.03\right)$. Finally, week-level intrusions also significantly predicted performance $\left(\beta=-.30, p<.01, \Delta R^{2}=.09\right)$, and intrusions measured on each day did not explain incremental variance over week-level intrusions $\left(\beta_{\text {Timel }}=.12, p=.32\right.$, $\left.\beta_{\text {Time } 2}=-.15, p=.23, \beta_{\text {Time } 3}=.07, p=.44, \Delta R^{2}=.02\right)$. See Table 9 for a summary of these results.

Past research has divided cognitive failure into three dimensions: Memory, attention, and behavior (Wallace \& Chen, 2005). I conducted a Confirmatory Factor Analysis, specifying three latent factors (five indicators per dimension), and found the model to have good fit $\chi^{2}=174.27, d f=87, \chi^{2} / d f=2.00$, RMSEA $=.08$, NFI $=.93$, CFI $=.94)$, and producing significantly better fit compared to the unidimensional model $\left(\chi^{2}=\right.$ 219.98, $\left.d f=90, \chi^{2} / d f=2.44, \mathrm{RMSEA}=.10, \mathrm{NFI}=.91, \mathrm{CFI}=.95\right)$ wherein all 15 items loaded onto a single Cognitive Failure latent variable $\left(\Delta \chi^{2}=45.71, \Delta d f=3, p<.001\right)$. See Figure 4 for a pictorial representation of this analysis.

The same procedures used to test Hypotheses 1 and 2 were repeated to determine whether intrusions experienced on a day-to-day basis were associated with each subdimension of cognitive failure. Specifically, I first specified a measurement model where Time 1, Time 2, and Time 3 intrusions loaded onto a single latent variable (i.e., week-level intrusions), and this latent variable was specified to predict a measurement 
model for the memory subdimension with the corresponding five items loading onto this latent factor. This model had adequate fit $\left(\chi^{2}=36.96, d f=19, \chi^{2} / d f=1.95, \mathrm{RMSEA}=\right.$ $.08, \mathrm{NFI}=.95, \mathrm{CFI}=.96)$, but the latent week-level intrusions variable was not a significant predictor of week-level cognitive failure memory $(r=-.05 ; \beta=-.08, S E=$ $.149, p=.577)$. Similarly, the week-level intrusions latent variable was specified to predict the measurement model for the attention subdimension with its corresponding five items loading onto this latent factor. This model had poor fit $\left(\chi^{2}=62.09, d f=19\right.$, $\left.\chi^{2} / d f=3.27, \mathrm{RMSEA}=.12, \mathrm{NFI}=.91, \mathrm{CFI}=.94\right)$, and the latent week-level intrusions variable was not a significant predictor of week-level cognitive failure attention $(r=-.03$; $\beta=-.04, S E=.122, p=.769)$. Finally, the week-level intrusions latent variable was specified to predict the measurement model for the behavior subdimension with its corresponding five items loading onto this latent factor. This model had adequate fit $\chi^{2}=$ $\left.33.68, d f=19, \chi^{2} / d f=1.77, \mathrm{RMSEA}=.07, \mathrm{NFI}=.96, \mathrm{CFI}=.98\right)$, but the latent weeklevel intrusions variable was not a significant predictor of week-level cognitive failure behavior $(r=.01 ; \beta=.01, S E=.167, p=.957)$. These additional analyses corroborate the findings from hypothesis 1c, such that week-level intrusions measured on a day-to-day basis are not associated with cognitive failure. Pictorial representations of these analyses can be found in Figure 5.

Several demographic variables were measured at Time 0 (i.e., Age, Gender, Managerial Status, Collaboration Hours, and Organization). All demographics were correlated with at least one study variable (see Table 10). However, given the power restrictions of adding control variables to Structural Regression models (Kline, 2010), 
and the lack of theory to guide my decision, managerial status and collaboration hours were selected as control variables in accordance with past research (i.e., Lin et al., 2013). All hypotheses were retested using including these variables (see Figures 6 and 7). By and large, results remained unchanged. Specifically, intrusions remained a significant predictor of fatigue $(r=.24 ; \beta=.21, S E=.085, p<.05)$, self-regulation failure $(r=.45 ; \beta$ $=.53, S E=.120, p<.01)$, and performance $(r=-.32 ; \beta=-.24, S E=.072, p<.01)$. Intrusions were not significantly associated with cognitive failure $(r=.09 ; \beta=.15, S E=$ $.130, p=.26)$. Time 4 surface acting and quantitative workload were also added as control variables and the results further remained unchanged. Specifically, after controlling for managerial status, collaboration hours, Time 4 surface acting, and quantitative workload, intrusions remained a significant predictor of fatigue $(r=.25 ; \beta=$ $.24, S E=.087, p<.01)$, self-regulation failure $(r=.45 ; \beta=.56, S E=.118, p<.01)$, and performance $(r=-.22 ; \beta=-.17, S E=.061, p<.01)$. Intrusions were not significantly associated with cognitive failure $(r=.08 ; \beta=.15, S E=.112, p=.17)$.

Finally, given that fatigue, self-regulation failure, and perceived performance were also measured on a day-to-day basis, the data was hierarchically structured, allowing a day-level examination of the relationship between intrusions and fatigue, selfregulation failure and perceived performance (micro-micro). It should be noted that cognitive failure was not measured on a daily basis due to the length of the measure (i.e., 15 items).To test these relationships, I restructured the data in SPSS 20.0 such that participants' scores on study variables over each day were "stacked" into a single variable corresponding to that variable. For example, Time 1, Time 2, and Time 3 
intrusions were "stacked" chronologically into a single intrusions variable to facilitate the transfer of data into HLM 7.0. A series of random effects regression models were specified wherein outcome variables (i.e., fatigue, self-regulation failure, perceived performance), were regressed on daily intrusions. Daily intrusions were grand mean centered to remain consistent with the between-subjects approach taken within this study. Additionally, heterogenous slopes were also specified to model the possibility that each participant experienced the intrusion-outcome relationship differently. Consistent with results from the micro-macro analyses, day-level intrusions were significantly associated with day-level fatigue $\left(\gamma_{10}=.38, S E=.08, p<.01\right)$, self-regulation failure $\left(\gamma_{10}=.33, S E=\right.$ $.07, p<.01)$, and perceived performance $\left(\gamma_{10}=-.13, S E=.05, p<.05\right)$. The heterogeneous slopes test was supported only for fatigue $\left(u_{1}=.28, p<.01\right)$, but not for self-regulation failure $\left(u_{1}=.20, p=.09\right)$ or perceived performance $\left(u_{1}=.04, p=.40\right)$. These results suggest that employees who experienced more frequent day-to-day intrusions also experienced greater fatigue, self-regulation failure, and lowered perceived performance. Additionally, the relationship between intrusions and fatigue tended to vary significantly across participants, but the relationship between intrusions and self-regulation failure and perceived performance did not vary significantly across participants. These results can be found in Table 11.

Quantitative workload and surface acting were also measured on a daily basis, and these day-level variables were also regressed onto grand mean centered daily intrusions. Consistent with the results of the between-subject correlations, intrusions were not a significant predictor of quantitative workload $\left(\gamma_{10}=.06, S E=.05, p=.20\right)$ or 
surface acting $\left(\gamma_{10}=.03, S E=.08, p=.72\right)$. Tests of heterogeneous slopes suggested that the nonsignificant slopes did vary across participants for both quantitative workload $\left(u_{1}=\right.$ $.11, p<.05)$ and surface acting $\left(u_{1}=.12, p<.05\right)$. These results suggest that participants who experienced more frequent intrusions were not more likely to report higher levels of quantitative workload and surface acting. However, this nonsignificant relationship does significantly vary across participants, suggesting future research should be devoted to uncovering these boundary conditions. These results can also be found in Table 11. 


\section{Chapter 8: Discussion}

The present study is the first to use a micro-macro design to examine naturally occurring intrusions measured on a day-to-day basis and their relationship with weeklevel strain and perceived performance. In summary, my results indicate that employees who experienced more day-to-day intrusions experienced higher levels of fatigue and self-regulation failure later in the week. Additionally, employees who experienced more intrusions were also likely to report lower levels of perceived performance for the week. However, participants who experienced more frequent intrusions were not found to have higher levels of cognitive failure - even when cognitive failure was broken down into its three subdimensions: memory, attention, and behavior. Detailed interpretation and exploration of each finding are below.

First, the present study found intrusions measured on a day-to-day basis were associated with higher levels of fatigue for the week. The results from the present study corroborate the notion that intrusions consume individuals' resources associated with fatigue. That is, assuming fatigue is a function of cognitive or physical resource depletion (Holmes, 1938), greater experience of intrusions is associated with higher levels of fatigue suggests that intrusions may alter these resources in some capacity. This may be either through the reduction of time, forcing employees to work harder and faster and exert more physical effort, or through greater exertion of cognitive effort during the shorter episodes employees have to complete their requisite work tasks while being intruded on by other employees. However, given the lack of a significant relationship between intrusions and cognitive failure (or any subdimension of cognitive failure), it 
may be that intrusions' association with fatigue may be solely driven through physical exertion. However, it should be noted that if consumption of time should be reflected in increased perceptions of quantitative workload, additional analyses from the present study dispute this assumption. That is, I found that daily intrusions were surprisingly not associated with daily quantitative workload, potentially disputing the assumption that intrusions perceptibly consume time. However, this assertion may be premature as quantitative workload may not be a valid operationalization of perceived loss of time. In the CIT industry, and particularly in start-up companies, staying late at work to complete work tasks is the norm. Thus, employees may not experience heightened quantitative workload when frequently intruded because employees have, ostensibly, all night to complete their remaining work tasks. Nevertheless, this prolonged exertion may still induce fatigue. Therefore, I suspect the relationship between intrusions and fatigue would be stronger and more apparent in blue collar positions, or hourly positions, where physical exertion to compensate for intrusions should be more of the norm, and staying overtime to compensate for displaced time due to intrusions is discouraged. Additional research should be aimed at clarifying these possibilities.

Second, results from the present study found intrusions measured on a day-to-day basis were associated with higher levels of self-regulation failure. These results corroborate the notion that intrusions consume self-regulatory resources. Specifically, participants who experienced more frequent intrusions on a day-to-day basis reported experiencing higher levels of self-regulation failure. However, the operating mechanism through which intrusions consumed self-regulatory resources remains unclear. That is, 
from the data from the present study it is not possible to disentangle whether selfregulatory resource decrements were due to a) the maintenance of outward displays of emotions consistent with display rules but inconsistent with genuine emotions (Grandey, 2003), or b) the engagement in frustrating tasks that hinder goal attainment (Adamcyk \& Bailey, 2004; Bailey \& Konstan, 2006; Bailey, Konstan \& Carlis, 2006), c) some other unexplored mechanism, or d) a combination of a) through c). Additional analyses examining the relationship between daily intrusions and daily surface acting may provide some initial evidence that intrusions do not consume self-regulatory resources through the maintenance of surface acting, rather through some other mechanism. Nevertheless, regardless of operating mechanism, intrusions ultimately do consume self-regulatory resources, indicating the importance of conceptualizing intrusions as a workplace stressor.

Third, intrusions measured on a day-to-day basis were associated with lower levels of perceived performance. Additionally, results from the present study also support the hypothesis that intrusions consume the resources required for successful job performance. That is, assuming job performance is a function of time, self-regulatory, and cognitive resource presence, intrusions clearly reduce resources, resulting in lowered job performance. However, similar to self-regulatory resources, determining the mechanism that triggered the alteration in job performance is beyond the scope of the present study, and might best be tested in a laboratory setting where self-regulatory resources and task performance can be tightly controlled and monitored. 
Finally, it should be noted that participants experiencing more intrusions were not more likely to experience more cognitive failure. These findings were consistent even when the cognitive failure construct was divided into memory, attention and behavioral subdimensions. These results raise several possible interpretations. First, it may be that intrusions consume cognitive resources, but cognitive resources may be too volatile to capture on a "chronic" level (i.e., week-level measured on a Thursday). That is, cognitive resources may have been consumed, but these decrements in cognitive failure may have occurred during the onset of each intrusion, and these effects may not have carried over to the Time 4 measurement occasion because cognitive resources were replenished by Time 4. Indeed past research has suggested that certain experiences during respite periods have the capacity to regenerate certain work-related resources (Sonnentag \& Fritz, 2007; Trougakos \& Hideg, 2009).

A second possibility may be that the items used to capture cognitive failure may not have been applicable to the CIT industry. That is, intrusions may consume cognitive resources, but the manifestation of low levels of cognitive resources may not have been captured in the Wallace and Chen (2005) measure. Wallace and Chen (2005) initially developed the measure for a variety of blue-collar occupations (e.g., production, manufacturing, or naval personnel), rather than for knowledge workers. It is conceivable that knowledge workers' cognitive failure is manifested as behaviors beyond that of the Wallace and Chen (2005) measure. However, in these instances, one would see a "floor effect" in item distributions, such that means and standard deviations for each item would be low. As presented in Table 4, the mean for cognitive failure $(2.69 ; \mathrm{SD}=.98)$ is higher 
than both fatigue (Mean=2.31, $\mathrm{SD}=.73$ ) and self-regulation failure (Mean=2.22, $\mathrm{SD}=.72$ ). Furthermore, the means for all fifteen items ranged between 2.41 and 2.92 , all values much higher than one would expect in a floor effect situation (see Table 12). Finally, a pictorial representation of these means (as found in Figure 8) further corroborates the unlikelihood of a floor effect as the means and standard deviations for each item tended to be closer to the mid-point (i.e., 3) of the five point scale.

A third possibility may be that intrusions simply do not consume cognitive resources, or consume a negligible amount of resources. Intrusions are thought to consume cognitive resources both because they are unpredictable and uncontrollable stimuli which force employees to quickly appraise threat and generate coping strategies. However, intrusions in the CIT industry may be expected phenomena simply because they are relatively frequent. For example, on average, participants experienced anywhere between zero and four intrusions per day, with some employees reporting up to 40 intrusions each day. For these participants, while the actual secondary tasks may have consumed cognitive resources, employees may have habituated to repeated intrusion exposure (Groves \& Thompson, 1970), thus minimizing the amount of cognitive resources required to cope. Indeed, over the course of the study, 54.19\% of employees reported the majority of the intrusions they experienced were expected (versus $45.81 \%$ reporting the majority of their intrusions were unexpected), lending credence to the likelihood of this final explanation.

\section{Contributions}


The present study contributes to organizational theory, research, and methodology, and further contributes to our understanding of the stressor-strain relationship. First, the present study is the first in organizational research to examine naturally occurring intrusions at work using a multi-wave design and survey methodology. This is significant as it provides insight into a new burgeoning work stressor and provides a holistic view of the demands characteristic of the $21^{\text {st }}$ century workplace that, to date, has received very little research (i.e., Zijlstra et al., 1999; Lin et al., 2013). With advances in technology, intrusions are becoming a norm, particularly in the CIT industry where information sharing speed is viewed as critical in agile work procedures. Additionally, building on Lin and colleagues (2013) study, the present study also reaffirms that intrusions can be measured with survey methods, and can be measured on a daily basis with adequate consistency. Second, the present study links this new workplace stressor with important work outcomes (i.e., fatigue, self-regulation failure, perceived performance). Although intrusions may be viewed as an organizational necessary evil (Grove, 1983), this study quantified the extent to which intrusions may impair healthy employee functioning. Third, the present study contributes to our understanding of the uses of the micro-macro approach in statistical analyses. While extant literature has focused on individual-level predictors of group-level outcomes, the current study is the first to use time-level data predicting individual-level outcomes. This is particularly important in occupational health psychology as daily stressors have dynamic relationships with strain outcomes. For example, the present study found inconsistent relationships between intrusions measured on each workday and strain 
reactions and perceived performance measured at the end of the week. Were intrusions only measured at a single measurement point, results from the present study would have yielded different findings depending on the day intrusions were measured. By measuring intrusions on multiple days, and applying the Croon and van Veldhoven (2007) method, the dynamic relationship between daily intrusions and week-level strain and perceived performance was adequately captured. Finally, to the my knowledge, the micro-macro statistical modeling approach put forth by Croon and van Veldhoven (2007) has never been applied to occupational health phenomena. This is particularly important given that occupational health psychologists often describe strain reactions as a result of repeated exposure to daily stressors. This study is the first to both explicitly test this assertion, and find support for it.

\section{Limitations}

While the present study provides several key contributions to organizational literature, internal validity limitations inherent in the study may limit the confidence in the conclusions drawn from the study. First, the present study relied solely on self-report survey measures of intrusions, strain reactions, and performance, thereby potentially inflating relationships and/or increasing the likelihood of finding "artificial" relationships between the constructs of interest (i.e., Common Method Variance; CMV; Podsakoff, MacKenzie, Lee \& Podsakoff, 2003). However, work stress research has suggested that not only do self-reported perceptions of stressors and strains produce the strongest relationships, but that perceptions of stressors are more practically important as it adjusts for personal tolerances for stressors (Lazarus \& Folkman, 1984). Additionally, given that 
all performance ratings provided by external members are largely influenced by extraneous factors, and that typically, in the CIT industry, the target employee is most capable of evaluating their own performance during a short time span, the use of selfreport measures is not only unavoidable, but likely to yield more internally valid measures of job performance. Nevertheless, several steps were taken to reduce the likelihood of Type I Errors. First, predictors and outcome variables were assessed on separate occasions, with intrusions measured once per day over the course of three days, and outcome variables (i.e., strain and performance) measured on a fourth day. This reduces the CMV resulting from temporal location of measurement. Second, structural equation modeling allows for estimations of CMV through the specification of correlated error terms of indicators. While this was not explicitly tested, modification indices did not recommend freeing covariance paths between error terms (typically a result of severe CMV), thus I assume CMV was not a likely culprit for the covariation between latent variables. Additionally, by not freeing the covariance paths between error terms for estimation, I essentially fixed the path to 0 , thereby testing a model in which CMV was not present. Nevertheless, future research will benefit from using alternate methods for measuring particular variables in an effort to reduce respondent biases. For example, past research has operationalized states of low self-regulatory capacity as one's ability to maintain a firm grip (e.g., Baumeister et al., 1998) or operationalized cognitive failure or fatigue using simple arithmetic problems (e.g., Glass \& Singer, 1972). Alternatively, using alternative sources for job performance (i.e., widgets produced in a manufacturing job) may provide more definitive evidence linking intrusions and job performance. 
Additionally, the present study examined week-level strain and performance by measuring these variables on Thursday. The lack of a measurement occasion on Friday casts some doubt on the construct validity of the week-level strain and performance variables as it is possible that the Thursday measure is deficient as participant responses lack the experience of strain on Friday. This was done primarily for reasons based in personal experience. First, in my experience as a former CIT employee, I noticed that employees often worked from home on Fridays, and were less likely to involve themselves in research. Thus, the Thursday measurement was used in part to minimize attrition rates during the critical final measurement point. Second, missing data on Fridays is unlikely to be missing at random, and important assumption in structural equation modeling. That is, missing data on the final day of the week may be moreso due to accumulated cognitive fatigue from the week, which is distinctly not random. Finally, measurement of strain and performance on Friday may be skewed due to anticipation effects. That is, given the weekend is impending, anticipation for the weekend may temper the results of the present study, artificially suppressing the findings.

Finally, the repeated reminder emails sent to increase compliance and reduce attrition within the study may have manipulated my primary construct of interest, intrusions. That is, by sending reminder emails every two hours, employees may have perceived my emails as an intrusion, thereby inflating levels of intrusions experienced by participants. However, given this was an observational study, using survey methods, the levels of intrusions (post-inflation) were probably captured in my results given that the 
inflation in experienced intrusions occurred prior to participants' completion of the surveys.

In addition to internal validity concerns inherent in the study, the sole sampling from CIT employees may hinder external validity such that effect sizes obtained within the present study may not be generalizable to other occupations. For example, in customer service occupations, intrusions by students are not only expected, but part of one's in-role job performance. Thus successfully addressing these "intrusions" may actually positively contribute to one's job performance. However, the results from the present study were consistent with a cross-sectional study by Lin and colleagues (2013) whose sampling strategy included a greater variety of occupations. Nevertheless, future research combining the internal validity strengths of the present study with the external validity strengths of the Lin and colleagues (2013) study could confirm these findings. Additionally, given the heavy demands of diary designs, it is possible the employees who completed all surveys had special motive to do so, potentially making them distinct from the population (Shrout, 2013), further jeopardizing external validity. That is, it is possible only employees who felt strongly about interruptions or intrusions chose to comply with the rigorous demands of the study, thereby biasing the results. However, given that the results from the present study are somewhat consistent with Lin and colleagues (2013) who used a less demanding design, these concerns may be slightly assuaged.

\section{Practical Applications}


Although intrusions, for the purposes of instantaneous information sharing, may be necessary for organizational survival, the results from this study indicate these intrusions can impair employee well-being and performance. With advancements in technology, the avenues by which employees can intrude on their co-workers have grown in recent years. By conceptualizing intrusions as stressors, I also assume that individuals can also cope with intrusions through a variety of strategies to a) prevent intrusions, b) reduce the damage intrusions induce, and c) reverse the damage intrusions incur. Indeed, past research has examined the various strategies employees implement to cope with intrusions, although the term coping has never been explicitly used. For example, Eyrolle and Cellier (2000) found that when confronted with customer intrusions, telephone operators used one of four strategies for managing performance on their primary tasks while coping with the secondary demands: 1) complete the primary task before attending to the secondary task; 2) ask the intruder to wait a few minutes while completing the primary task (e.g., "please hold for a few minutes") before attending to the secondary task; 3) identify the content of the secondary task, complete the primary task, and then complete the secondary task; 4) immediately complete the secondary task before completing the primary task. The most commonly used management strategy was to immediately perform the secondary task, and delay completion of the primary task (i.e., strategy $4 ; 77 \%)$, followed by strategies $1(10 \%), 2(7 \%)$, and $3(6 \%)$. All four strategies could be considered coping strategies; some more helpful to the employee than others. Although strategies 1 and 2 have been demonstrated to have the smallest effects on employee outcomes, they are consistently shown to be used the most infrequently (Cades, 
Boehm-Davis \& Trafton, in preparation as cited in Trafton \& Monk, 2008; Eyrolle \& Cellier, 2000). However, when intrusions are customer-driven, because of the customeroriented nature of many occupations, employees may feel obligated to address customerdriven secondary tasks before addressing their own primary tasks. Moreover, in some customer-service oriented organizations, this may not only be acceptable, but an obligatory component of in-role performance. Nonetheless, in situations where intrusions are inevitable, employees can implement certain strategies to minimize the disruption caused by intrusions. For example, past research has suggested using small visual reminders indicating where the employee left off on the primary task can shorten resumption lags upon completion of the secondary task (McDaniel, Einstein, Graham, \& Rall, 2004). Other research has suggested using two seconds during the adjustment lag to mentally "rehearse" how to resume performance on the primary task (Oulasvirta \& Saariluoma, 2006).

However, in situations where intrusions are coworker-driven, there may be fewer guidelines on the speed with which secondary tasks must be completed, thus potentially allowing for a delay in the completion of the secondary task. In these instances, research has suggested delaying secondary task completion to a "coarse breaking point" (i.e., between primary performance episodes) reduces the deleterious effects of interruptions (Adamczyk \& Bailey, 2004; Monk, Boehm-Davis \& Trafton, 2004). This not only reduces cognitive and self-regulatory resources consumed by addressing a secondary task while completing a primary task, but also provides the intruder with an opportunity to potentially address the inquiry themselves. Additionally, advances in technology, email, 
instant messaging, and text messages have increased the vehicles by which coworkers can intrude on each other. Turning off email, IM or text messaging alerts and periodically checking these devices at planned intervals can further aid employees in minimizing the effects of intrusions on performance and strain. Finally, simply recognizing that one will be interrupted multiple times per day can facilitate scheduling the completion of core primary work tasks, thereby reducing the strain experienced when intrusions are frequent.

Finally, it should be noted that intrusions may inherently be displeasing, exhausting, and ultimately affect an employee's performance, but they may not impair employees' cognitive functioning (i.e., result in cognitive failure). Thus, while the efficiency of employees may be impaired in situations where they experience frequent intrusions employees' overall decision-making accuracy may not be impaired. This may be pertinent for employees who must make high-stakes decisions in their organizations while managing routine day-to-day tasks, such as managers or executives who must routinely manage their own tasks, but also make high-stakes decisions with long-term consequences, such as personnel decisions (e.g., hiring, firing, promoting, training) or organizational re-structuring decisions (e.g., mergers, acquisitions).In these instances, intrusions may have a detrimental effect on the employees' wellness and overall performance, but these large-scale decisions may remain unaffected. Additional research must be conducted to replicate these findings.

\section{Future Research}


While this study presents a large step in the study of intrusions, it also introduces additional avenues for research. Nine avenues for future research are presented and discussed.

First, additional employee outcomes may be worth exploring as consequences of intrusions (e.g., burnout, turnover intentions, and organizational citizenship behaviors). Furthermore, although this study presents intrusions as an overwhelmingly negative event in the workplace, this may not always be the case. For example, Jett and George (2003) do suggest intrusions can have positive influences such as increases in morale. Past theories (e.g., Contact Hypothesis; Amir, 1969; Mere Exposure Effect; Bornstein \& D'Agostino, 1992) suggest that repeated interactions between employees may also increase ones' satisfaction with coworkers. Repeatedly being intruded may also increase one's network centrality, or the frequency with which one is contacted by others within a network (Gest, Graham-Bermann \& Hartup, 2001). Centrality in organizations affords individuals more power and opportunities for creativity (Ibarra, 1993). Additionally, when employees address intrusions, they may be perceived as more altruistic within the organization, yielding greater received altruism from members of the organizations based on Social Exchange Theory (Levinson, 1965). In the case of jobs wherein the employee is required to complete relatively monotonous tasks, intrusions may reduce boredom (Fisher, 1998). Finally, intrusions, depending $\mathrm{n}$ the content of the secondary task may also increase employee engagement. Engagement is defined as the extent to which employees invest themselves fully in their work roles (Kahn, 1990). When employees experience more frequent work-related intrusions, they may be more fully exposed to 
various tasks, duties, and responsibilities related to their work roles, thus immersing themselves further into their jobs, increasing engagement. When employees experience more frequent non-work intrusions, this may decrease engagement as employees invest themselves into roles outside of work (e.g., husband role, father role, friend role). Thus experiencing more frequent work-related intrusions may actually be beneficial for employee productivity. As intrusions are expected to continue to penetrate the workforce, understanding the positive effects of intrusions can facilitate a holistic understanding of tomorrow's workforce.

Nevertheless, given the negative findings regarding intrusions in this study and past research (e.g., Lin et al., 2013), investigating predictors of intrusions may be a second avenue for future research as knowledge of predictors is paramount for developing methods for prevention. Intra-individual characteristics such as extraversion or agreeableness may play a role in increasing the number of intrusions employees may experience. For example, employees with higher levels of extraversion may have a more expansive coworker network, thereby increasing the number of intrusions employees may experience. On the other hand, employees lower on extraversion may have a smaller network of coworkers to intrude on them. Employees who are highly agreeable may appear more inviting to intrusions given their affable and empathetic nature, whereas employees may be less willing to intrude on a coworker who appears unsympathetic or unfriendly such as the case with employees low in agreeableness. Job-related predictors such as past job performance or tenure may also contribute to the frequency of intrusions experienced. Employees with stronger past records of job performance or longer job 
tenure are perceived as being experts at the job (e.g., Goldstein \& Ford, 2002; Jackson \& Schuler, 1985). Employees with greater perceived expertise are likely to experience more frequent intrusions, particularly from those employees whose primary purpose for intruding is help-seeking.

Third, because intrusions are inherently a dyadic process whereby an intruder intrudes on a victim, investigations of predictors surrounding the intruder are imperative for gaining a holistic understanding of intrusions. For example, new employees may be encouraged to proactively ask senior employees questions in an effort to facilitate socialization (Gruman, Saks \& Zweig, 2006). If these questions occur when senior employees are completing job tasks, newcomers may become intruders and a prime audience for targeting training regarding intrusions. Similarly, employees with high levels of role ambiguity or role conflict may seek help from their colleagues in an effort to effectively navigate their job. Moreover, perpetrating intrusions may have vastly different effects on the intruder than on the victim. For example, particularly in the case where intrusions are aimed towards seeking help, intrusions may actually increase role clarity and subsequently improve job performance for intruders, providing an interesting duality in the sense that intrusions are beneficial for intruders but detrimental for victims.

Fourth, consistent with previous stress (Lazarus \& Folkman, 1984) and intrusions literature (Lin et al., 2013), the present study demonstrates the viability of using selfreported perceptions of intrusions through survey methodology. Nevertheless, objective measures of intrusions still hold a great deal of value from both a conceptual and methodological standpoint. Objectively documenting the number of intrusions 
experienced and then measuring intrusion frequency using survey methods can address the perceptual question: How many intrusions does it take for an employee to perceive intrusions as occurring frequently, and how many intrusions is too many intrusions? Furthermore, when intrusions are counted objectively and other study variables are measured using traditional Likert-type scales, this can further reduce common method bias.

Fifth, although the present study provides support for a relationship between intrusions and strain reactions, there may be boundary conditions under which intrusions are more harmful. For example, intrusions may be particularly harmful to employees when they already have little time to complete their job-related tasks (Jett \& George, 2003). Intrusions may also be less harmful for job performance when the information shared during intrusions is related to the job task being performed. Other moderators of the intrusions-employee outcome relationships may include individual differences, such as extraversion, agreeableness, proactive personality. That is, certain employees may have a particular disposition making them more resilient to intrusion exposure, or even preferential towards organizations or industries that have intrusions. Organizations in industries where frequent intrusions are the norm should identify these individual differences for staffing or training purposes to either hire or promote employees who possess these dispositions, or train the characteristics that promote intrusion resilience.

In addition to the boundary conditions (i.e., moderators), further research into the operating mechanisms (i.e., mediators) linking intrusions with employee outcomes can further shed understanding on intrusions. For example, intrusions may influence 
employee strain reactions because they induce greater perceptions of workload. That is, intrusions may only be linked with employee outcomes because they create perceptions of having too many work tasks to complete with too little time left. This explanation has been embraced in popular press outlets (e.g., Joyce, 2005), but is unlikely to be the case. For example, in the present study we found no link between intrusions experienced on a day-to-day basis and increases in quantitative workload, one requirement for establishing mediational relationships (Baron \& Kenny, 1986). Nevertheless, further investigation into the possible moderators and mediators of the intrusion and strain relationship could provide an understanding of what are "good" or "bad" intrusions.

Sixth, future research should extend theory regarding the use of micro-macro methodology in multi-wave designs. In other words, how many consecutive days must employees experience a stressor event for the event to produce negative "chronic outcomes?" Further understanding the relationship between short-term events and longterm consequences can provide further knowledge into the role of time in psychological phenomena.

Seventh, the present study briefly discussed an episodic framework in regard to intrusions, such that each intrusion includes an adjustment lag, secondary task performance, and resumption lags (Trafton \& Monk, 2008). Using experience sampling methodology or experimental designs may afford researchers the ability to conduct fined grained examinations of intrusions, possibly uncovering at what point during the intrusion episode self-regulatory and cognitive resources are consumed. 
Eighth, additional research investigating intrusions in other occupations may also contribute to our understanding of the phenomenon. That is, intrusions in the CIT industry are likely distinct from intrusions in the law enforcement industry as intrusions by police dispatchers are often aimed to enhance police officers' job performance, and protect the well-being of police officers. These intrusions are then also likely distinct from intrusions in construction equipment operators, where a single distraction from the task at hand can result in serious injury to oneself and coworkers.

Finally, it may be critical to examine the source of the intrusion. The present study examined intrusions from workplace colleagues, but intrusions from nonwork sources may have differential implications for employees. Although intrusions intersect task performance and may elicit frustration, intrusions from nonwork sources may be pleasurable, and immediately replenish lost self-regulatory resources. Additionally, even the source of the work-related intrusion may play a key role in the resources consumed. For example, intrusions from supervisors or upper management may be extremely rare in some occupations, thus consume more cognitive resources as they are highly unexpected. On the other hand, intrusions from coworkers who work next the employee may be extremely common, thus consume fewer cognitive resources as they are more expected.

\section{Conclusions}

The present study used a resource-based framework to link intrusions at work to strain and job performance. Results suggested that intrusions consume certain resources (e.g., self-regulatory resources), but not others (e.g., cognitive resources). Specifically, week-level intrusions (as measured on a day-to-day basis) were positively associated with 
fatigue, and self-regulation failure, but not cognitive failure. Intrusions were also negatively associated with perceived job performance, suggesting the importance of further investigating the phenomenon. The present study was also the first to explicitly test the assertion that events experienced on a day-to-day basis are associated with weeklevel outcomes. 
Table 1. Sample sizes and response rates for each company

\begin{tabular}{lccccccc}
\hline & \multicolumn{7}{c}{ Company } \\
\cline { 2 - 8 } & $\mathrm{A}^{\mathrm{a}}$ & $\mathrm{B}$ & $\mathrm{C}^{\mathrm{a}}$ & $\mathrm{D}^{\mathrm{a}}$ & $\mathrm{E}^{\mathrm{b}}$ & $\mathrm{F}^{\mathrm{a}}$ & Total \\
\hline Company Size & 25 & $\sim 35$ & $\sim 50$ & $\sim 40$ & $\sim 9$ & $\sim 70$ & $\sim 229$ \\
Interested & 25 & 35 & 40 & 33 & 9 & 54 & 196 \\
T0 Sample Size & 16 & 35 & 36 & 25 & 9 & 46 & 167 \\
T0 Resp. Rate A & $64.00 \%$ & $100.00 \%$ & $72.00 \%$ & $62.50 \%$ & $100.00 \%$ & $65.71 \%$ & $72.93 \%$ \\
T0 Resp. Rate B & $64.00 \%$ & $100.00 \%$ & $90.00 \%$ & $75.76 \%$ & $100.00 \%$ & $85.19 \%$ & $85.20 \%$ \\
T1 Sample Size & 16 & 35 & 34 & 20 & 9 & 36 & 150 \\
T1 Resp. Rate A & $64.00 \%$ & $100.00 \%$ & $68.00 \%$ & $50.00 \%$ & $100.00 \%$ & $51.00 \%$ & $51.00 \%$ \\
T1 Resp. Rate B & $100.00 \%$ & $100.00 \%$ & $94.44 \%$ & $80.00 \%$ & $100.00 \%$ & $78.26 \%$ & $89.82 \%$ \\
T2 Sample Size & 16 & 29 & 31 & 20 & 9 & 36 & 141 \\
T2 Resp. Rate A & $64.00 \%$ & $82.86 \%$ & $62.00 \%$ & $50.00 \%$ & $100.00 \%$ & $51.43 \%$ & $61.57 \%$ \\
T2 Resp. Rate B & $100.00 \%$ & $82.86 \%$ & $91.18 \%$ & $100.00 \%$ & $100.00 \%$ & $100.00 \%$ & $94.00 \%$ \\
T3 Sample Size & 16 & 31 & 34 & 19 & 9 & 36 & 145 \\
T3 Resp. Rate A & $64.00 \%$ & $88.57 \%$ & $68.00 \%$ & $47.50 \%$ & $100.00 \%$ & $51.43 \%$ & $63.32 \%$ \\
T3 Resp. Rate B & $100.00 \%$ & $88.57 \%$ & $100.00 \%$ & $95.00 \%$ & $100.00 \%$ & $100.00 \%$ & $96.67 \%$ \\
T4 Sample Size & 16 & 35 & 34 & 20 & 9 & 36 & 150 \\
T4 Resp. Rate A & $64.00 \%$ & $100.00 \%$ & $68.00 \%$ & $50.00 \%$ & $100.00 \%$ & $51.43 \%$ & $65.50 \%$ \\
T4 Resp. Rate B & $100.00 \%$ & $100.00 \%$ & $100.00 \%$ & $100.00 \%$ & $100.00 \%$ & $100.00 \%$ & $100.00 \%$ \\
& & & & & & & \\
\hline
\end{tabular}

Note. "Interested" refers to those employees who sent me an email expressing interest in participating; "Resp. Rate A" refers to the percentage of employees who participated out of the number of company employees; "Resp. Rate B" refers to the percentage of employees who participated out of those who were contacted; "Sample Size" refers to the total number of participants who completed surveys at the respective time point.

${ }^{a}$ Denote companies that have been acquired since data collection

${ }^{\mathrm{b}}$ Denotes the company that has dissolved since data collection 





Table 3. Perceived Performance Items Original Item

I adequately completed assigned duties.

I fulfilled responsibilities specified in my job description.

I performed tasks that are expected of me. I met formal performance requirements of the job.

I engaged in activities that will directly affect my performance evaluation.

I neglected aspects of the job that I am obligated to perform.

I failed to perform essential duties.

\section{Adapted Item}

I adequately completed assigned duties relative to my own expectations.

I fulfilled responsibilities from my job description up to my expectations.

I performed the tasks that I expected of myself. I met formal performance requirements of the job to my expectations.

I neglected aspects of the job that I expected myself to perform.

I failed to perform the essential duties I wanted to perform.

Note. Modifications to the original item are in italics. 


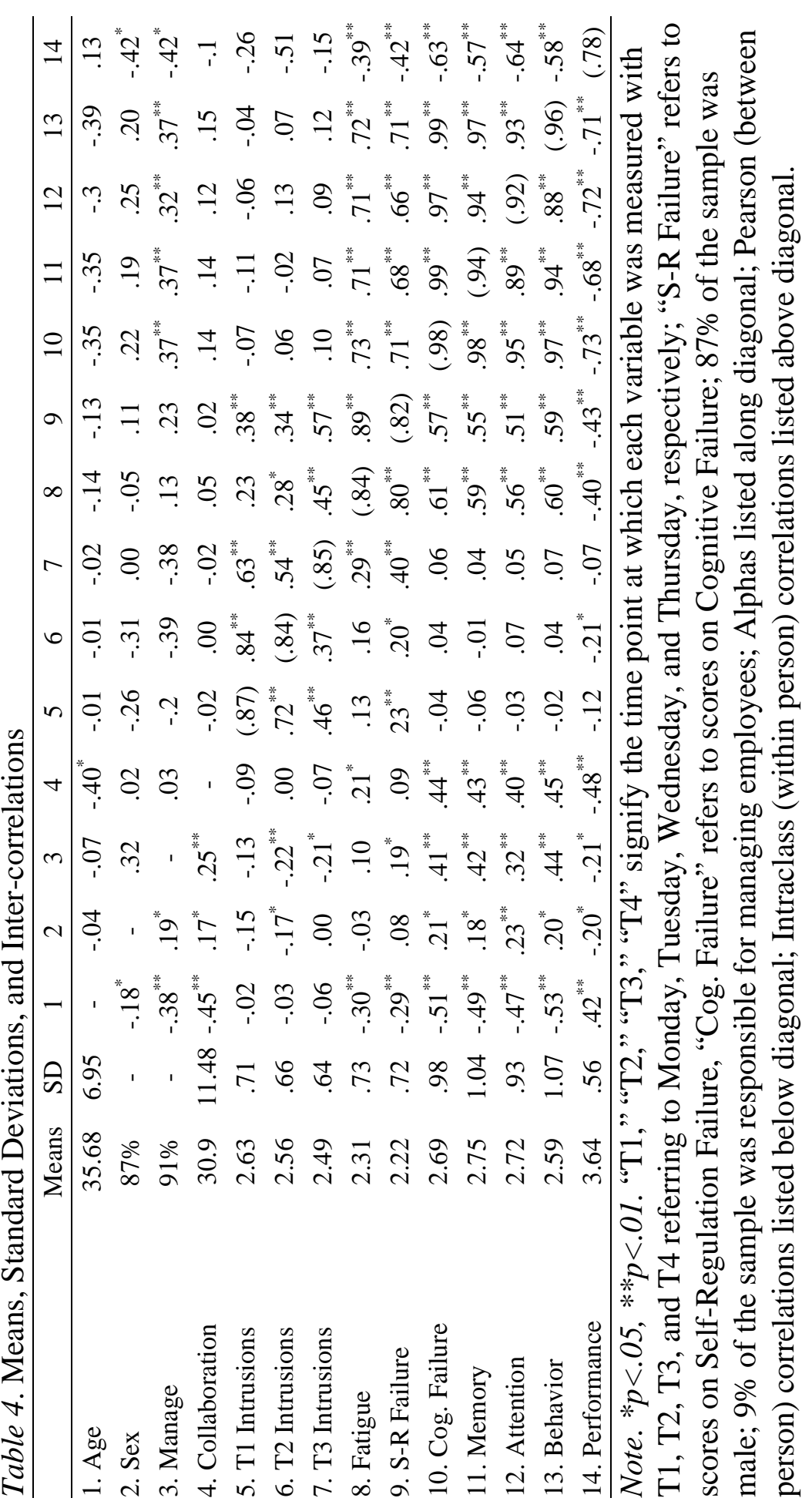


Table 5. Variable means and standard deviations for each company

\begin{tabular}{lcccccc}
\hline & $\mathrm{M}_{\mathrm{A}}\left(\mathrm{SD}_{\mathrm{A}}\right)$ & $\mathrm{M}_{\mathrm{B}}\left(\mathrm{SD}_{\mathrm{B}}\right)$ & $\mathrm{M}_{\mathrm{C}}\left(\mathrm{SD}_{\mathrm{C}}\right)$ & $\mathrm{M}_{\mathrm{D}}\left(\mathrm{SD}_{\mathrm{D}}\right)$ & $\mathrm{M}_{\mathrm{E}}\left(\mathrm{SD}_{\mathrm{E}}\right)$ & $\mathrm{M}_{\mathrm{F}}\left(\mathrm{SD}_{\mathrm{F}}\right)$ \\
\hline T1 Intrusions & $3.21(.78)$ & $2.75(1.05)$ & $2.66(.66)$ & $2.60(.73)$ & $2.33(.13)$ & $2.44(.38)$ \\
T2 Intrusions & $3.05(.74)$ & $2.64(.88)$ & $2.52(.74)$ & $2.71(.62)$ & $2.42(.22)$ & $2.40(.42)$ \\
T3 Intrusions & $2.93(.77)$ & $2.30(.81)$ & $2.66(.71)$ & $2.36(.70)$ & $2.47(.23)$ & $2.42(.31)$ \\
T4 Fatigue & $2.05(1.22)$ & $1.95(.81)$ & $2.38(.76)$ & $2.38(.71)$ & $2.64(.18)$ & $2.45(.47)$ \\
T4 S-R Failure & $2.16(1.40)$ & $1.94(.88)$ & $2.45(.72)$ & $2.17(.59)$ & $2.33(.13)$ & $2.25(.40)$ \\
T4 Cog. Failure & $1.58(.83)$ & $1.97(.78)$ & $2.58(.99)$ & $2.72(.96)$ & $3.50(.06)$ & $3.29(.60)$ \\
$\quad$ T4 Memory & $1.44(.76)$ & $2.03(.84)$ & $2.71(1.05)$ & $2.79(1.06)$ & $3.53(.10)$ & $3.38(.62)$ \\
$\quad$ T4 Attention & $1.84(.81)$ & $2.13(.84)$ & $2.55(.97)$ & $2.72(.89)$ & $3.49(.11)$ & $3.25(.62)$ \\
$\quad$ T4 Behavior & $1.45(1.00)$ & $1.77(.84)$ & $2.47(1.08)$ & $2.66(1.02)$ & $3.49(.11)$ & $3.24(.66)$ \\
T4 Performance & $3.97(.74)$ & $4.04(.56)$ & $3.72(.63)$ & $3.47(.54)$ & $3.39(.14)$ & $3.39(.29)$ \\
& & & & & &
\end{tabular}

Note. "T1," "T2," "T3," "T4" signify the time point at which each variable was measured with T1, T2, T3, and T4 referring to Monday, Tuesday, Wednesday, and Thursday, respectively; "S-R Failure" refers to scores on Self-Regulation Failure, "Cog. Failure" refers to scores on Cognitive Failure. 
Table 6. Descriptive statistics of characteristics of intrusions for each time point.

\begin{tabular}{|c|c|c|c|c|}
\hline & Time 1 & Time 2 & Time 3 & Aggregate \\
\hline \multicolumn{5}{|l|}{ Duration } \\
\hline$\%$ Short & 67.12 & 68.35 & 29.50 & 67.46 \\
\hline Moderate & 30.82 & 27.34 & 66.91 & 29.22 \\
\hline Long & 2.06 & 4.32 & 3.60 & 3.33 \\
\hline \multicolumn{5}{|l|}{ Difficulty } \\
\hline$\%$ Simple & 60.96 & 28.06 & 64.03 & 40.22 \\
\hline Moderate & 34.25 & 69.06 & 31.65 & 55.78 \\
\hline Complex & 4.79 & 2.88 & 4.32 & 4.00 \\
\hline \multicolumn{5}{|l|}{ Expectedness } \\
\hline$\%$ Expected & 57.53 & 53.24 & 48.20 & 54.19 \\
\hline Unexpected & 42.47 & 46.76 & 51.80 & 45.81 \\
\hline \multicolumn{5}{|l|}{ Welcomeness } \\
\hline$\%$ Welcome & 11.64 & 10.79 & 17.39 & 13.27 \\
\hline Neutral & 71.23 & 62.59 & 48.55 & 60.79 \\
\hline Unwanted & 17.12 & 26.62 & 34.06 & 25.93 \\
\hline \multicolumn{5}{|l|}{ Medium } \\
\hline$\%$ In person & 44.03 & 47.70 & 48.40 & 46.71 \\
\hline Email & 18.67 & 15.17 & 13.88 & 15.91 \\
\hline Instant message & 10.19 & 10.15 & 12.32 & 10.89 \\
\hline Phone & 20.94 & 18.64 & 18.11 & 19.23 \\
\hline Text message & 6.16 & 8.35 & 7.29 & 7.27 \\
\hline \multicolumn{5}{|l|}{ Valence } \\
\hline$\%$ Positive & 58.68 & 57.40 & 58.39 & 58.17 \\
\hline Neutral & 27.83 & 28.95 & 30.20 & 28.99 \\
\hline Negative & 13.49 & 13.65 & 11.41 & 12.84 \\
\hline
\end{tabular}

Note. All numbers in this table are percentages; the "Aggregate" score was calculated based on the sum of all frequencies (as opposed to the arithmetic mean between the three time points) 
Table 7. Means, Standard Deviations, and Intercorrelations between Week-Level Intrusions, Intrusions Measured at Each Time Point, and Intrusions Aggregated Over Time

\begin{tabular}{lccccccc}
\hline & Mean & SD & 1 & 2 & 3 & 4 & 5 \\
\hline 1. Week-Level & 2.50 & .668 & $(.85)$ & & & & \\
2. Time 1 & 2.63 & .711 & $.52^{* *}$ & $(.87)$ & & & \\
3. Time 2 & 2.56 & .664 & $.57^{* *}$ & $.72^{* *}$ & $(.84)$ & & \\
4. Time 3 & 2.49 & .636 & $.44^{* *}$ & $.46^{* *}$ & $.37^{* *}$ & $(.85)$ & \\
5. Time 1-3 & 2.55 & .570 & $.63^{* *}$ & $.89^{* *}$ & $.86^{* *}$ & $.74^{* *}$ & $(.75)$ \\
Aggregated & & & & & & & \\
\hline
\end{tabular}

Note. $* p<.05, * * p<.01$. Alphas listed along diagonal 
Table 8. Week-level Intrusions Regressed on Intrusions Measured at Each Time Point

\begin{tabular}{ccc}
\hline & \multicolumn{2}{c}{ Week-Level Intrusions } \\
\cline { 2 - 3 } & $\beta$ & $\Delta \mathrm{R}^{2}$ \\
\hline Time 1 Intrusions & \multicolumn{1}{c}{$.38^{* *}$} \\
Time 2 Intrusions & $.37^{* *}$ & \\
Time 3 Intrusions & $.26^{* *}$ & \\
\hline
\end{tabular}

Note. $* p<.05, * * p<.01$. 
Table 9. Outcome Variables Regressed on Intrusions at the Week-Level and each Measurement Point.

\begin{tabular}{|c|c|c|c|c|c|c|c|c|}
\hline & \multicolumn{2}{|c|}{ Fatigue } & \multicolumn{2}{|c|}{ S-R Failure } & \multicolumn{2}{|c|}{ Cog. Failure } & \multicolumn{2}{|c|}{ Performance } \\
\hline & $\beta$ & $\Delta \mathrm{R}^{2}$ & $\beta$ & $\Delta \mathrm{R}^{2}$ & $\beta$ & $\Delta \mathrm{R}^{2}$ & $\beta$ & $\Delta \mathrm{R}^{2}$ \\
\hline Step 1 & & $.037 *$ & & $.059 * *$ & & $.044 *$ & & $.091 * *$ \\
\hline $\begin{array}{l}\text { Week- } \\
\text { Level }\end{array}$ & $.19 *$ & & $.24 * *$ & & $.21 *$ & & $-.30 * *$ & \\
\hline Step 2 & & $.057 *$ & & $.107 * *$ & & .034 & & .016 \\
\hline Time 1 & -.10 & & .02 & & -.23 & & .12 & \\
\hline Time 2 & .09 & & .03 & & .03 & & -.15 & \\
\hline Time 3 & $.27 * *$ & & $.35 * *$ & & .01 & & .07 & \\
\hline
\end{tabular}


Table 10. Between-Subjects Correlations between Demographic Variables and Study Variables

\begin{tabular}{lccccc}
\hline & Organization & Age & Sex & $\begin{array}{c}\text { Managerial } \\
\text { Status }\end{array}$ & $\begin{array}{c}\text { Collaboration } \\
\text { Hours }\end{array}$ \\
\hline T1 Intrusions & $-.27^{* * *}$ & -.02 & -.15 & -.13 & -.09 \\
T2 Intrusions & $-.21^{*}$ & -.03 & $-.17^{*}$ & $-.22^{* *}$ & .00 \\
T3 Intrusions & -.11 & -.06 & .00 & $-.21^{*}$ & -.07 \\
Fatigue & $.23^{* *}$ & $-.30^{* *}$ & -.03 & .10 & $.21^{*}$ \\
S-R Failure & .08 & $-.29^{* *}$ & .08 & $.19^{*}$ & .09 \\
Cog. Failure & $.59^{* *}$ & $-.51^{* *}$ & $.21^{*}$ & $.41^{* *}$ & $.44^{* *}$ \\
Performance & $-.44^{* *}$ & $.42^{* *}$ & $-.20^{*}$ & $-.21^{*}$ & $-.48^{* *}$ \\
\hline
\end{tabular}

Note. $* p<.05, * * p<.01$. "S-R Failure" refers to scores on Self-Regulation Failure, "Cog. Failure" refers to scores on Cognitive Failure 
Table 11. Results of Day-Level Fatigue, Self-Regulation Failure, Perceived Performance, Quantitative Workload, and Surface Acting Regressed on Day-Level Intrusions.

\begin{tabular}{lrrrrr}
\hline & \multicolumn{1}{c}{ Fatigue } & \multicolumn{1}{c}{ S-R Failure } & Performance & \multicolumn{1}{c}{ QWL } & \multicolumn{1}{c}{ Surf. Acting } \\
\cline { 2 - 6 } & \multicolumn{1}{c}{ Estimate } & \multicolumn{1}{c}{ Estimate } & \multicolumn{1}{c}{ Estimate } & Estimate & \multicolumn{1}{c}{ Estimate } \\
\hline Intercept, $\beta_{0}$ & & & & & \\
Fixed $\left(\gamma_{00}\right)$ & $2.25(.05)^{* *}$ & $2.26(.05)^{* *}$ & $3.56(.04)^{* *}$ & $3.48(.04)^{* *}$ & $2.99(.05)^{* *}$ \\
$\quad$ Random $\left(u_{0}\right)$ & $.25^{* *}$ & $.22^{* *}$ & $.21^{* *}$ & $.17^{* *}$ & .16 \\
Slope, $\beta_{1}$ & & & & & \\
$\quad$ Fixed $\left(\gamma_{10}\right)$ & $.38(.08)^{* *}$ & $.33(.07)^{* *}$ & $-.13(.05)^{*}$ & $.06(.05)$ & $.03(.08)$ \\
Random $\left(u_{1}\right)$ & $.28^{* *}$ & .20 & .04 & $.11^{*}$ & $.12^{*}$ \\
Deviance & & & & & \\
\hline
\end{tabular}

Note. $* p<.05, * * p<.01$. "S-R Failure" refers to scores on Self-Regulation Failure, "Performance" refers to scores on Perceived Performance, "QWL" refers to scores on Quantitative Workload, "Surf. Acting" refers to scores on Surface Acting 
Table 12. Means and Standard Deviations for Cognitive Failure Items

\begin{tabular}{lcc}
\hline & Means & SD \\
\hline $\begin{array}{l}\text { How often were you unable to remember whether you have or } \\
\text { have not turned off work equipment at work? }\end{array}$ & 2.92 & 1.16 \\
$\begin{array}{l}\text { How often did you fail to recall work procedures at work? } \\
\text { How often were you unable to remember work-related contact }\end{array}$ & 2.71 & 1.17 \\
$\begin{array}{l}\text { information at work? } \\
\text { How often were you unable to remember what materials were }\end{array}$ & 2.68 & 1.13 \\
$\begin{array}{l}\text { required to complete a particular task at work? } \\
\text { How often did you forget where you have put something you use } \\
\text { in your job at work? }\end{array}$ & 2.81 & 1.21 \\
\hline $\begin{array}{l}\text { How often did you fail to notice postings or notices on the } \\
\text { facilities bulletin board(s) or email system at work? }\end{array}$ & 2.65 & 1.03 \\
$\quad \begin{array}{l}\text { How often did you not fully listen to instructions at work? } \\
\text { How often did you day-dream when you ought to be listening to }\end{array}$ & 2.84 & 1.25 \\
$\begin{array}{l}\text { somebody at work? } \\
\text { How often did you not focus your attention on work activities at }\end{array}$ & 2.55 & .95 \\
$\begin{array}{l}\text { work? } \\
\text { How often were you easily distracted by co-workers at work? }\end{array}$ & 2.71 & 1.14 \\
\hline $\begin{array}{l}\text { How often did you accidentally drop objects or things at work? } \\
\text { How often did you throw away something you meant to keep }\end{array}$ & 2.81 & 1.25 \\
$\begin{array}{l}\text { (e.g., memos) at work? } \\
\text { How often did you say things to others that you did not mean to }\end{array}$ & 2.43 & 1.09 \\
$\begin{array}{l}\text { say at work? } \\
\text { How often did you unintentionally press buttons on machines at }\end{array}$ & 2.67 & 1.18 \\
$\begin{array}{l}\text { work? } \\
\text { How often did you accidentally start or stop the wrong machine at } \\
\text { work? }\end{array}$ & 2.64 & 1.24 \\
\hline
\end{tabular}

Note. Scores are based on a 5-point Likert scale. 
Figure 1

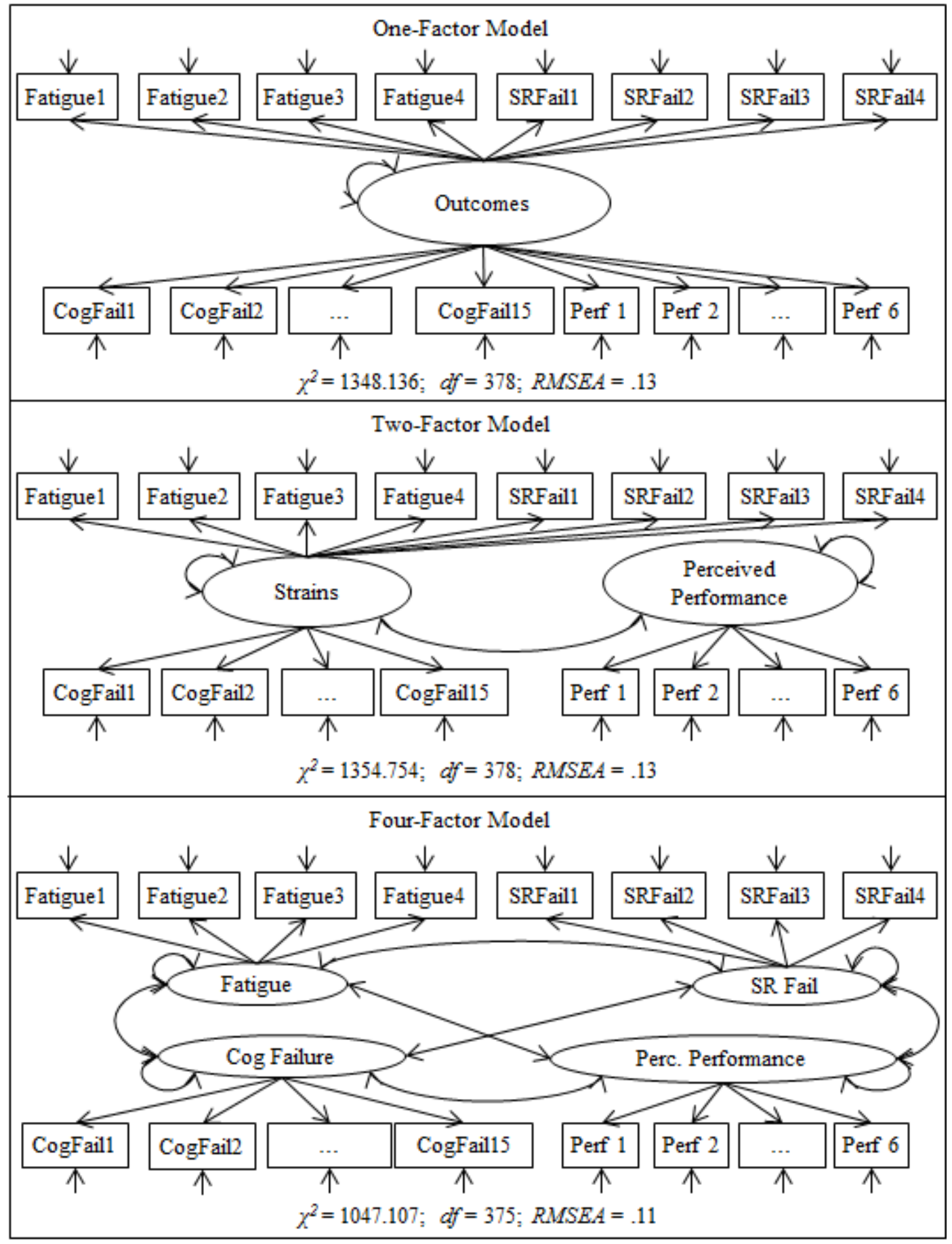

Figure 1. Nested measurement models comparing a 4-, 2-, and 1-factor model of outcome variables. The 1 -factor $\left(\chi^{2}=1348.14, d f=378, \chi^{2} / d f=3.57, \mathrm{RMSEA}=.13, \mathrm{NFI}=.68, \mathrm{CFI}=.74\right)$ and 2-factor $\left(\chi^{2}=1354.75, d f=378, \chi^{2} / d f=3.58\right.$, RMSEA $\left.=.13, \mathrm{NFI}=.68, \mathrm{CFI}=.74\right)$ models fit poorly, but the 4 -factor model had acceptable fit $\left(\chi^{2}=1047.11, d f=375, \chi^{2} / d f=2.79\right.$, RMSEA $=$ 
$.11, \mathrm{NFI}=.75, \mathrm{CFI}=.82$ ). The 4-factor model fit the data significantly better than the 2-factor model $\left(\Delta \chi^{2}=307.65, \Delta d f=3, \mathrm{p}<.001\right)$ 
Figure 2

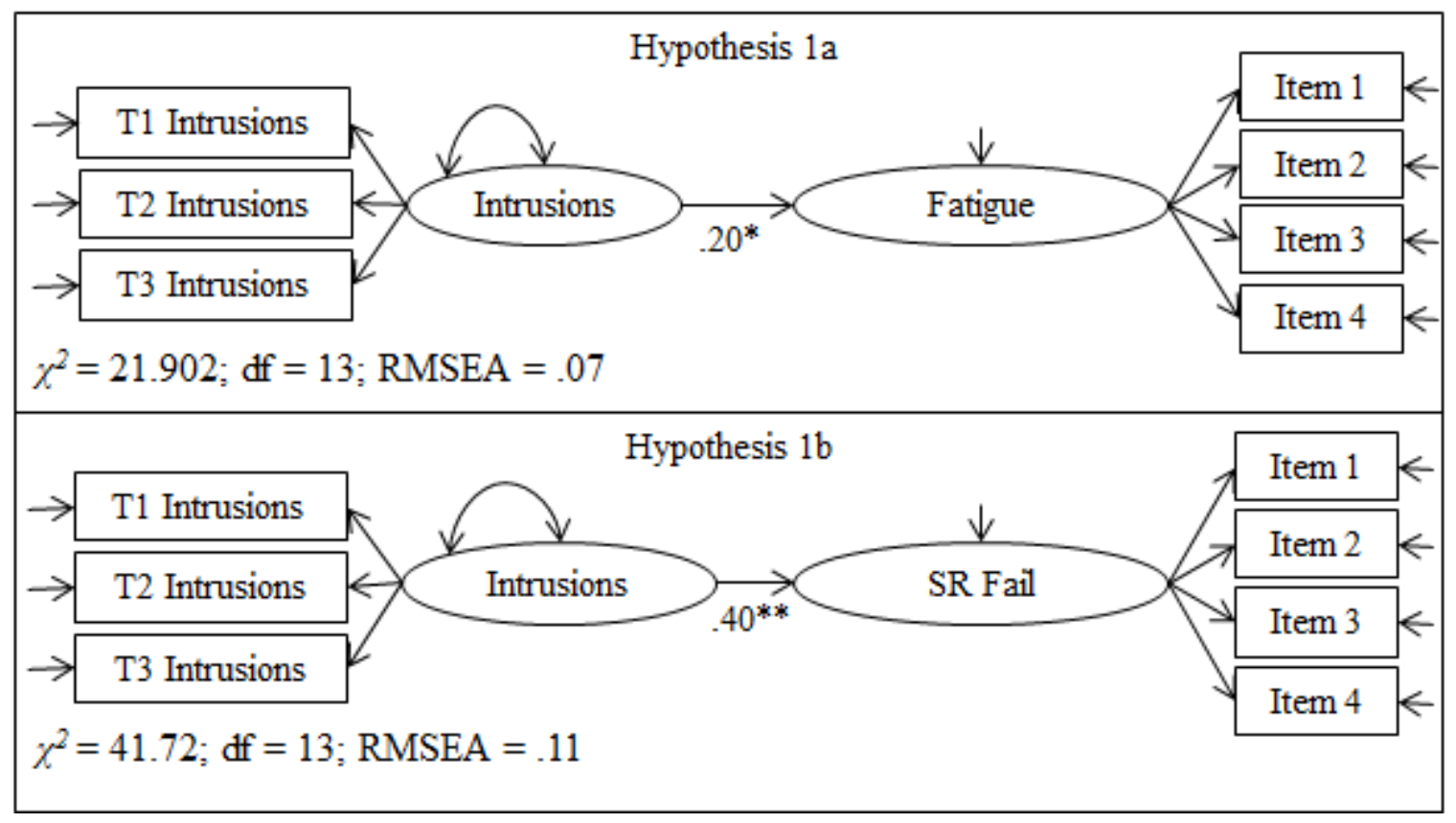

Figure 2. Structural regression model specified to test Hypothesis 1a and 1b. Values listed in the figure represent standardized loadings (i.e., correlation coefficients), with values significant at the .05 level indicated by a single asterisks $(*)$, and values significant at the .01 level indicated by two asterisks $(* *)$. Both models yielded acceptable fit. Day-to-day intrusions were significantly associated with week-level fatigue $(r=.20 ; \beta=.17, S E=.083, p<.05)$ and self-regulation failure $(r=.40 ; \beta=.45, S E=.114, p<.01)$. 
Figure 3



Figure 3. Structural regression model specified to test Hypothesis 1c and 2. Values listed in the figure represent standardized factor loadings, with values significant at the .05 level indicated by a single asterisks $(*)$, and values significant at the .01 level indicated by two asterisks $(* *)$. Both models yielded acceptable fit. Day-to-day intrusions were not significantly associated with weeklevel cognitive failure $(r=-.02 ; \beta=-.06, S E=.285, p=.842)$, but were significantly associated with performance $(r=-.27 ; \beta=-.20, S E=.079, p<.05)$. 
Figure 4

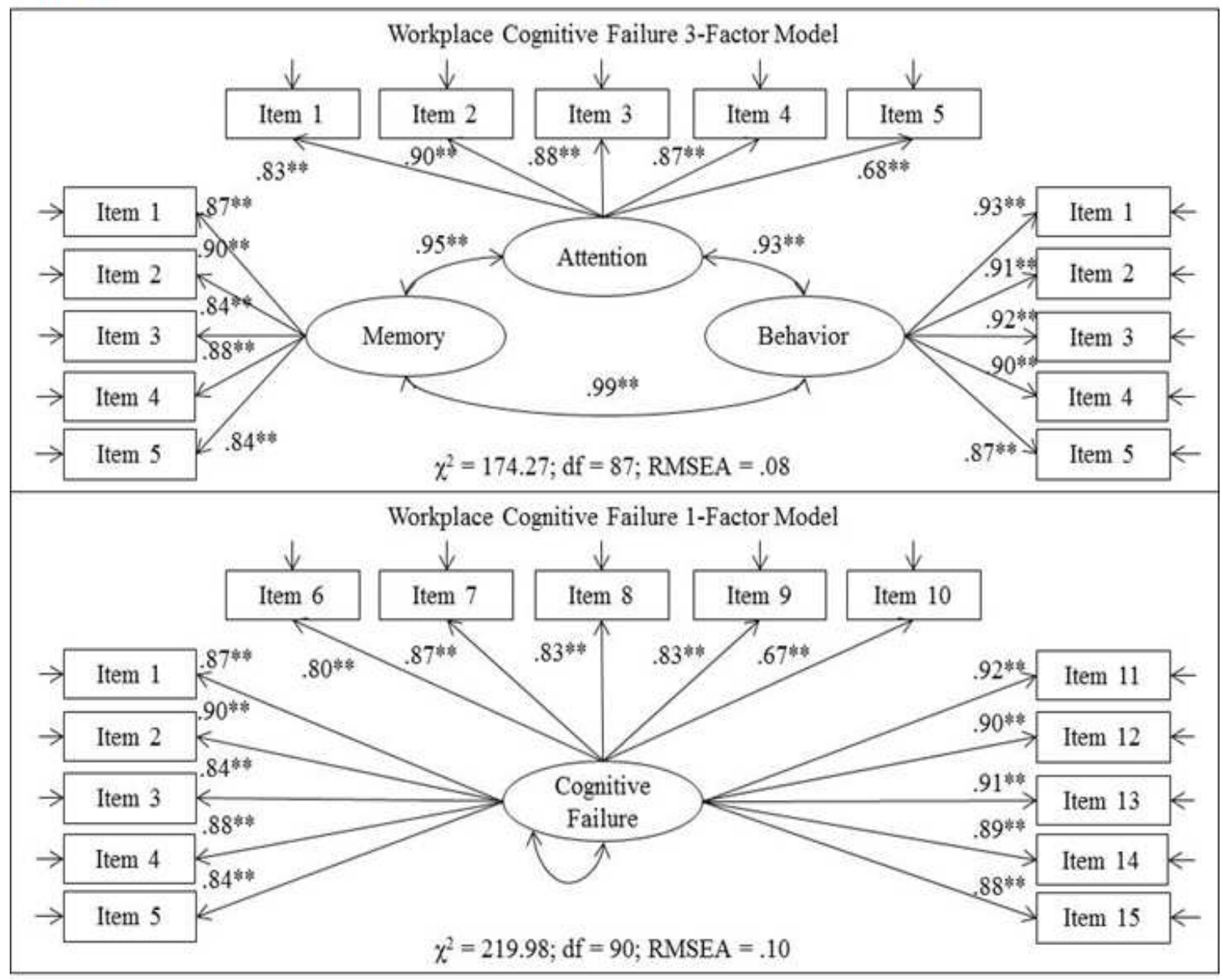

Figure 4. Nested measurement models comparing a 3- and 1-factor model of cognitive failure. Values listed in the figure represent standardized factor loadings, with values significant at the .05 level indicated by a single asterisks $(*)$, and values significant at the .01 level indicated by two asterisks $(* *)$. Both the 3 -factor $\left(\chi^{2}=174.27, \mathrm{df}=87, \chi^{2} / \mathrm{df}=2.00, \mathrm{RMSEA}=.08, \mathrm{NFI}=.93, \mathrm{CFI}\right.$ $=.94)$ and 1 -factor $\left(\chi^{2}=219.98, \mathrm{df}=90, \chi^{2} / \mathrm{df}=2.44, \mathrm{RMSEA}=.10, \mathrm{NFI}=.91, \mathrm{CFI}=.95\right)$ models yielded acceptable fit, but the 3 -factor model fit the data significantly better $\left(\Delta \chi^{2}=45.71\right.$, $\Delta \mathrm{df}=3, \mathrm{p}<.001)$. 
Figure 5

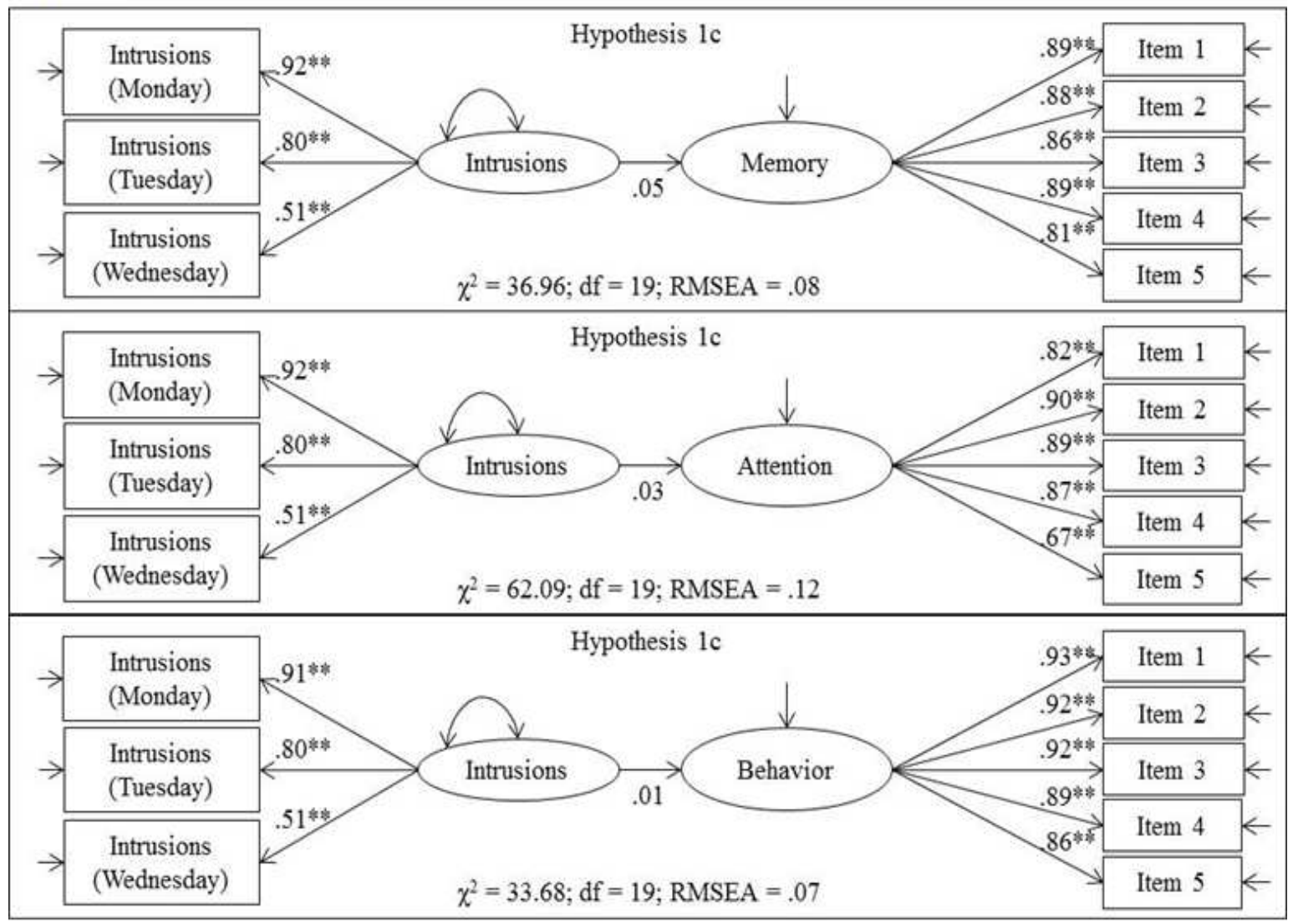

Figure 5. Structural regression model specified to test Hypothesis 1c with cognitive failure being broken into three sub dimensions. Values listed in the figure represent standardized factor loadings, with values significant at the .05 level indicated by a single asterisks $(*)$, and values significant at the .01 level indicated by two asterisks $(* *)$. Both models yielded acceptable fit. Day-to-day intrusions were not significantly associated with week-level cognitive failure memory $(r=-.05 ; \beta=-.08, S E=.149, p=.577)$, cognitive failure attention $(r=-.03 ; \beta=-.04, S E=.122, p$ $=.769)$, or cognitive failure behavior $(r=.01 ; \beta=.01, S E=.167, p=.957)$. 
Figure 6

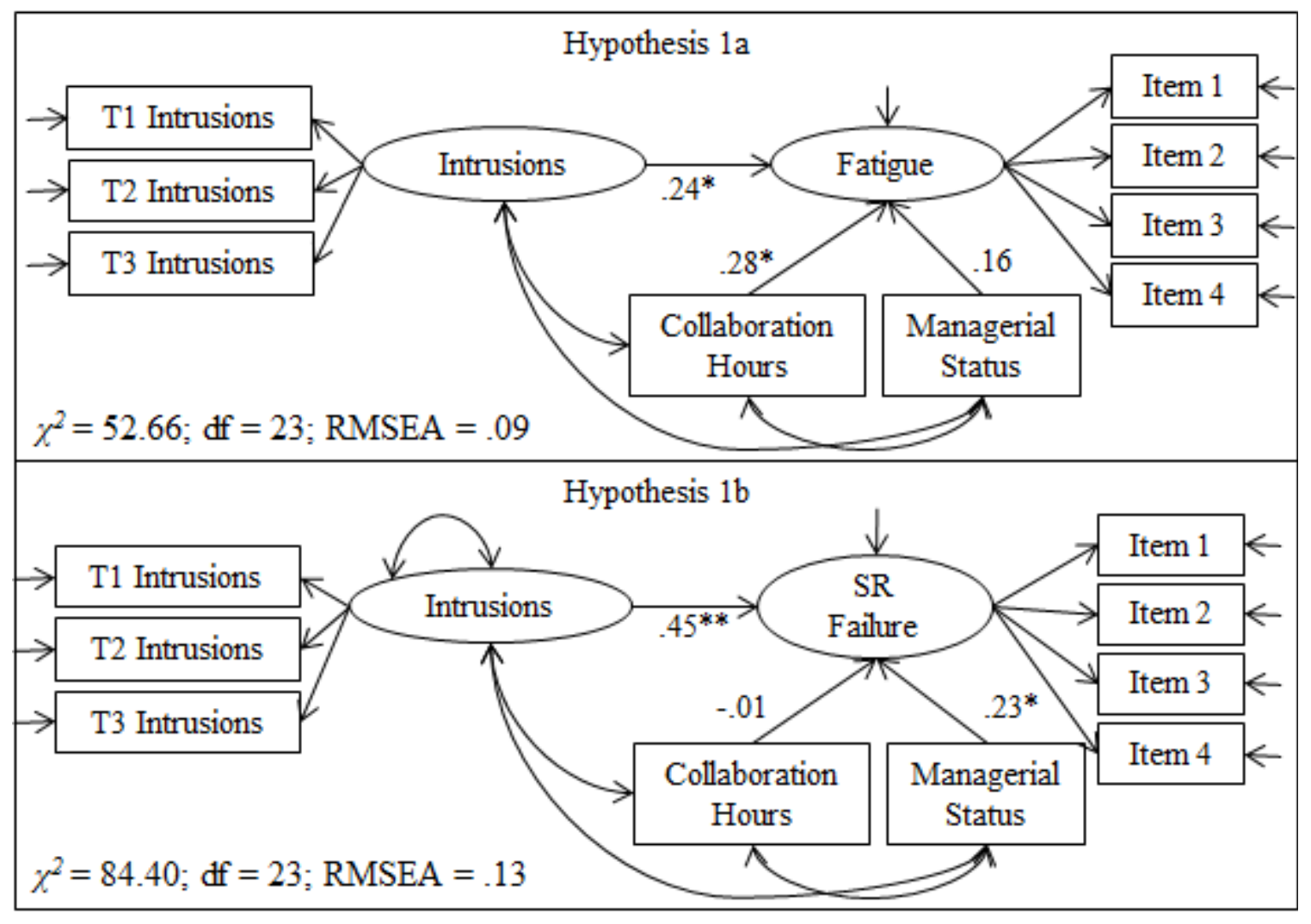

Figure 6. Structural regression model specified to test Hypothesis 1a and $1 \mathrm{~b}$ while controlling for collaboration hours and managerial status. Values listed in the figure represent standardized paths (i.e., correlations), with values significant at the .05 level indicated by a single asterisks $(*)$, and values significant at the .01 level indicated by two asterisks $(* *)$. The model for hypothesis 1a yielded good fit, whereas the model for hypothesis $1 \mathrm{~b}$ yielded poor fit. Day-to-day intrusions were significantly associated with week-level fatigue $(r=.24 ; \beta=.21, S E=.085, p<.05)$ and self-regulation failure $(r=$ $.45 ; \beta=.53, S E=.120, p<.01)$ after controlling for collaboration hours and managerial status. 
Figure 7

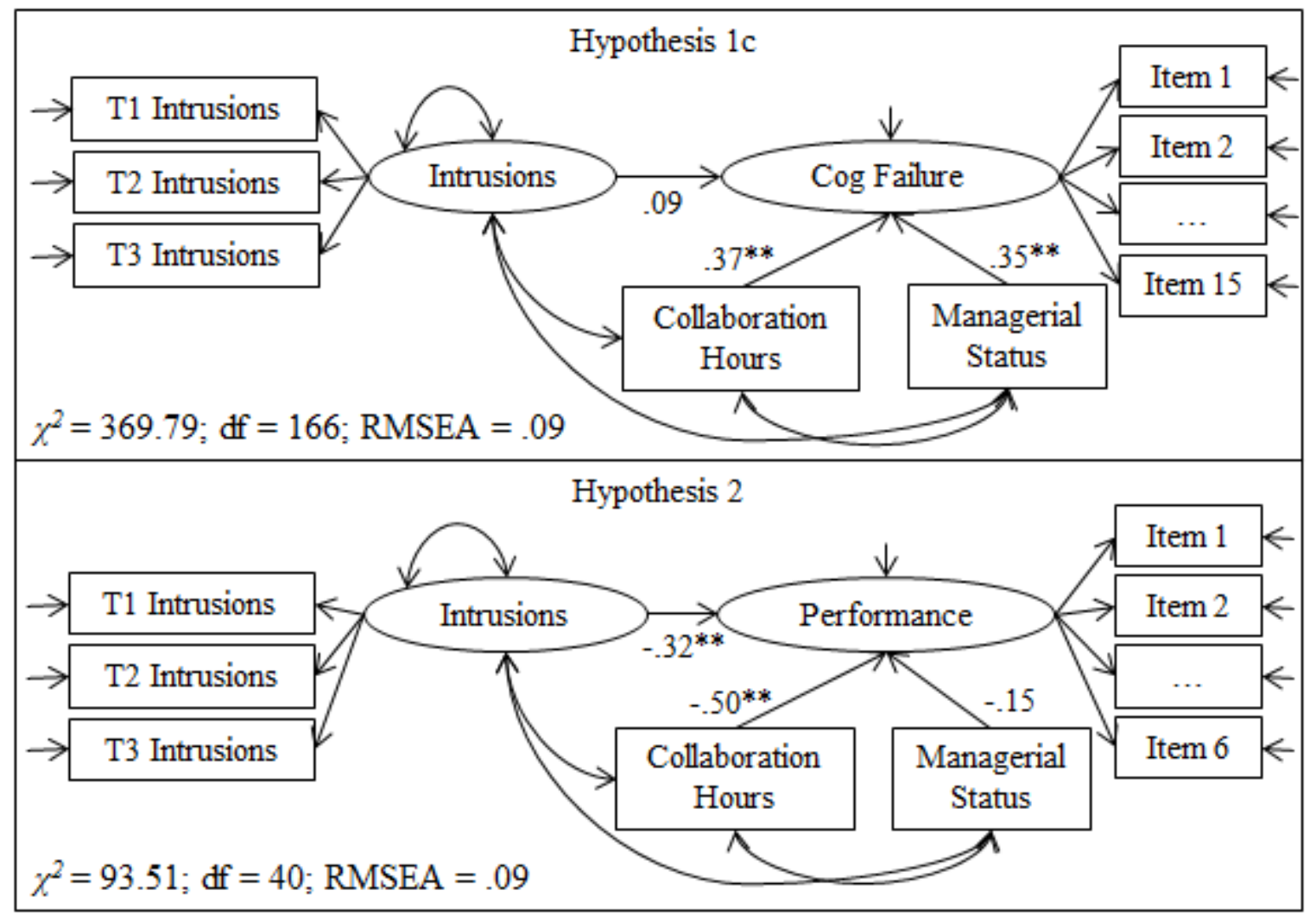

Figure 7. Structural regression model specified to test Hypothesis 1c and 2 while controlling for collaboration hours and managerial status. Values listed in the figure represent standardized paths (i.e., correlations), with values significant at the .05 level indicated by a single asterisks $(*)$, and values significant at the .01 level indicated by two asterisks $(* *)$. Both models yielded good fit. Day-to-day intrusions were not significantly associated with week-level cognitive failure $(r=.09 ; \beta=.15, S E=.130, p=.26)$, but were significantly associated with week-level performance $(r=-.32 ; \beta=-.24, S E=.072$, $p<.01)$ after controlling for collaboration hours and managerial status. 
Figure 8

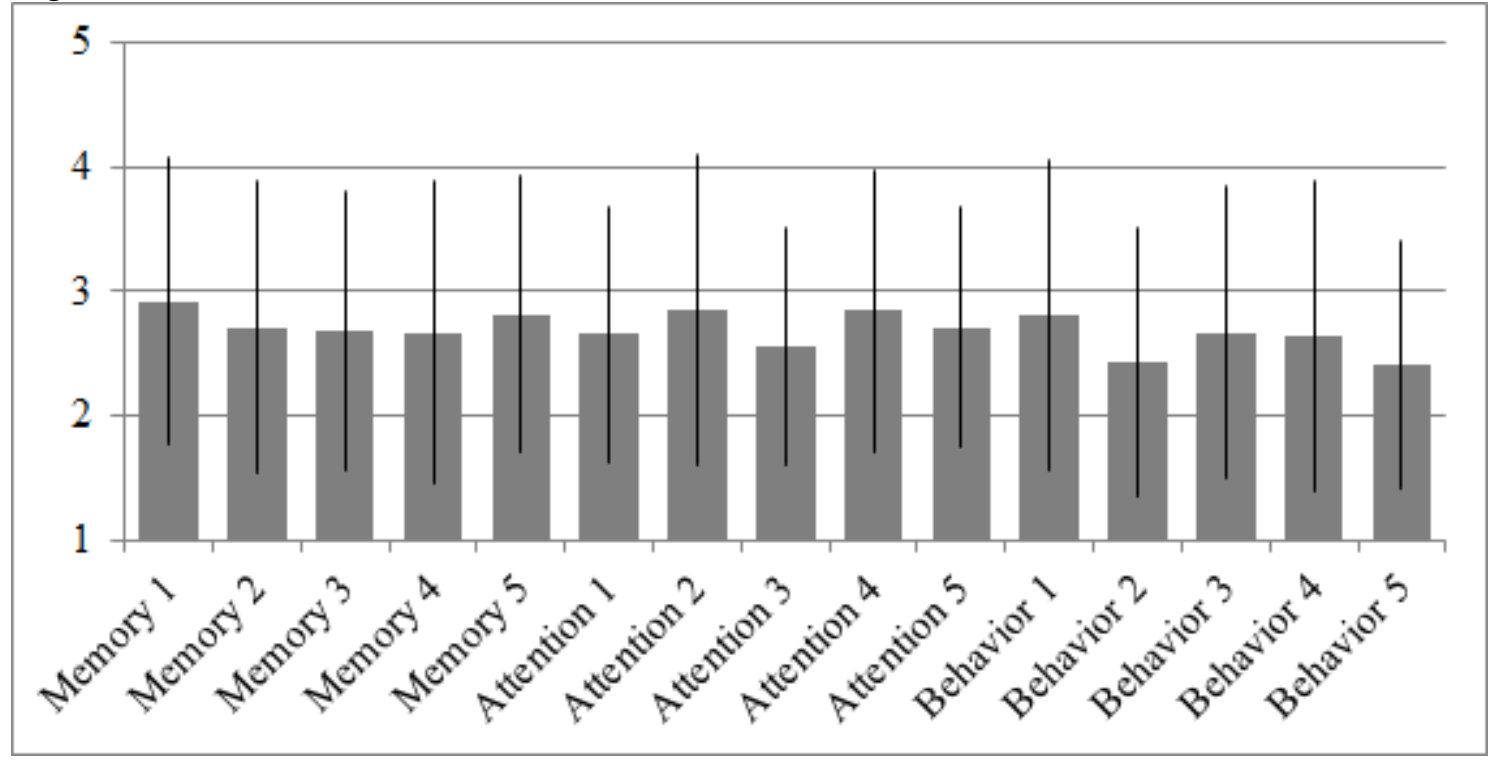

Figure 8. Means and standard deviations for all items on the Workplace Cognitive Failure. Means for the items ranged from 2.41 ("How often did you start or stop the wrong machine at work?") and 2.92 ("How often were you unable to remember whether you have or have not turned off work equipment at work?"). The average mean and standard deviation across items was 2.69 and 1.13 , respectively. Given the relatively high scores on these items, the measure likely did not suffer from a floor effect. 


\section{References}

Adamczyk, P. D., \& Bailey, B. P. (2004). If not now, when? The effects of interruption at different moments within task execution. In Human factors in computing systems: proceedings of CHI’04 (pp. 271-278). New York: Association for Computing Machinery Press.

Allen, M. J. \& Yen, W. M. (2002). Introduction to Measurement Theories. Long Grove, IL: Waveland Press, Inc.

Amir, Y. (1969). Contact hypothesis in ethnic relations. Psychological Bulletin, 71, 319342.

Anderson, N. H. \& Butzin, C. A. (1974). Performance = motivation $\times$ ability: An integration-theoretical analysis. Journal of Personality and Social Psychology, 30, 598-604.

Ashforth, B. E., \& Humphrey, R. H. (1993). Emotional labor in service roles: The influence of identity. Academy of Management Review, 18, 88-115.

Bailey, B. P., \& Konstan, J. A. (2006). On the need for attention-aware systems: Measuring effects of interruption on task performance, error rate, and affective state. Computers in Human Behavior, 22, 685-708.

Bailey, B. P., Konstan, J. A., \& Carlis, J. V. (2006). The effect of interruptions on task performance, annoyance, and anxiety in the user interface. IEEE Conference on Systems, Man, and Cybernetics (pp. 757-762). Los Alamitos, CA: IEEE Press. 
Baron, R. M., \& Kenny, D. A. (1986). The moderator-mediator variable distinction in social psychological research: Conceptual, strategic, and statistical considerations. Journal of Personality and Social Psychology, 51, 1173-1182.

Baumeister, R. F., Bratslavsky, E., Muraven, M., \& Tice, D. M. (1998). Ego depletion: Is the active self a limited resource? Personality Processes and Individual Differences, 74, 1252-1265.

Beal, D. J., Weiss, H. M., Barros, E. \& MacDermid, S. M. (2005). An episodic process model of affective influences on performance. Journal of Applied Psychology, 90, 1105-1068.

Beck, K., Beedle, M., van Bennekum, A., Cockburn, A., Cunningham, W., Fowler, M., ... Thomas, D. (2001). Manifesto for agile software development. Retrieved from http://agilemanifesto.org/

Becker, T. E. (2005). Potential problems in the statistical control of variables in organizational research: A qualitative analysis with recommendations. Organizational Research Methods, 8, 274-289.

Benington, H. D. (1983). Production of large computer programs. IEEE Annals of the History of Computing, 5, 350-361.

Berger, F., \& Merritt, E. A. (1998). No time left for you. Cornell Hotel and Restaurant Administration Quarterly, 39, 32-40.

Bergqvist, U., Wolgast, E., Nilsson, B., \& Voss, M. (1995). Musculoskeletal disorders among visual display terminal workers: Individual, ergonomic, and work organizational factors. Ergonomics, 38, 763-776. 
Berkowitz, L. (1989). Frustration-Aggression Hypothesis: Examination and reformulation. Psychological Bulletin, 106, 59-73.

Bornstein, R. F., \& D’Agostino, P. R. (1992). Stimulus recognition and the mere exposure effect. Journal of Personality and Social Psychology, 63, 545-552.

Brewer, E. W., \& Shapard, L. (2004). Employee burnout: A meta-analysis of the relationship between age or years of experience. Human Resource Development Review, 3, 102-123.

Brotheridge, C. M., \& Grandey, A. A. (2002). Emotional labor and burnout: Comparing two perspectives of “people work.” Journal of Vocational Behavior, 60, 17-39.

Brotheridge, C. M., \& Lee, R. T. (2003). Development and validation of the Emotional Labour Scale. Journal of Occupational and Organizational Psychology, 76, 365379.

Cades, D. M., Trafton J. G., Boehm-Davis, D. A., \& Monk, C. A. (2007). Does the difficulty of an interruption affect our ability to resume? Proceedings of the $51^{\text {st }}$ annual meeting of the Human Factors and Ergonomics Society (pp. 234-238). Santa Monica, CA: HFES.

Carver, C. S., \& Sheier, M. F. (1982). Control Theory: A useful conceptual framework for personality-social, clinical, and health psychology. Psychological Bulletin, 92, 111-135. 
Cattell, R. B. (1978). The Scientific Use of Factor Analysis in Behavioral and Life Sciences. New York: Plenum Press.

Chrisholm, C. D., Collison, E. K., Nelson, D. R., \& Cordell, W. H. (2000). Emergency department workplace interruptions: Are emergency physicians "interrupt-driven" and “multitasking?" Academic Emergency Medicine, 7, 1239-1243.

Ciarocco, N. J., Twenge, J. M., Muraven, M., \& Tice, D. M. (2011). The state selfcontrol capacity scale: Reliability, validity, and correlations with physical and psychological stress. Paper presented at Society for Personality and Social Psychology, San Diego, CA.

Cohen, S. (1980). After effects of stress on human performance and social behavior: A review of research and theory. Psychological Bulletin, 88, 82-108.

Cohen, S., \& Herbert, T. B. (1996). Health psychology: Psychological factors and physical disease from the perspective of human psychoneuroimmunology. Annual Review of Psychology, 47, 113-142.

Cohen, S. \& Spacapan, S. (1978). The aftereffects of stress: An attentional interpretation. Environmental Psychology and Nonverbal Behavior, 3, 43-57.

Cohen, S., Tyrell, D. A. J., \& Smith, A. P. (1991). Psychological stress and susceptibility to the common cold. New England Journal of Medicine, 325, 606-612.

Croon, M. A. \& van Veldhoven, M. J. P. M. (2007). Predicting group-level outcome variables from variables measured at the individual level: A latent variable multilevel model. Psychological Methods, 12, 45-57. 
Dababneh, A.J, Swanson, N., \& Shell, R.L. (2001). Impact of added rest breaks on the productivity and well being of workers. Ergonomics, 44, p. $164-74$.

Deese, J., \& Kaufman, R. A. (1957). Serial effects in recall of unorganized and sequentially organized verbal material. Journal of Experimental Psychology, 54, $180-187$.

Demerouti, E., Bakker, A.B., Nachreiner, F., \& Schaufeli, W.B. (2001). The Job Demands-Resources Model of Burnout. Journal of Applied Psychology, 86, p. 499-512.

DeShon, R. P., \& Gillespie, J. Z. (2003). A Motivated Action Theory account for Goal Orientation. Journal of Applied Psychology, 90, 1096-1127.

Dismukes, R. K., Young, G. E., \& Sumwalt, R. L. (1998). Cockpit interruptions and distractions: Effective management requires a careful balancing act. ASRS Directline, 10, 4-9

Duffy, M. K., Ganster, D. C. \& Pagon, M. (2002). Social undermining in the workplace. Academy of Management Journal, 45, 331-351.

Edwards, M. B., \& Gronlund, S. D. (1998). Task interruption and its effects on memory. Memory, 6, 665-687.

Einstein, G. O., McDaniel, M. A., Williford, C. L., Pagan, J. L., \& Dismukes, R. K. (2003). Forgetting of intentions in demanding situations is rapid. Journal of Experimental Psychology: Applied, 9, 147-162. 
Ekman, P. \& Friesen, W. V. (1975). Unmasking the face. Englewood Cliffs, NJ: PrenticeHall.

Emerson, R. M. (1976). Social exchange theory. Annual Review of Sociology, 2, 335-362.

Enders, C. K. \& Bandalos, D. L. (2001). The relative performance of full information maximum likelihood estimation for missing data in structural equation models. Structural Equation Modeling, 8, 430-457.

Eyrolle, H. \& Cellier, J-M. (2000). The effects of interruptions in work activity: Field and laboratory results. Applied Ergonomics, 31, 537-543.

Farh, J-L., \& Dobbins, G. H. (1989). Effects of self-esteem on leniency bias in selfreports of performance: A structural equation model analysis. Personnel Psychology, 42, 835-850.

Fiske, S. T. \& Taylor, S. E. (1984). Social Cognition. New York: McGraw-Hill.

Fisher, C. D. (1998). Effects of external and internal interruptions on boredom at work: Two studies. Journal of Organizational Behavior, 19, 503-522.

Fox, S., \& Spector, P. E. (1999). A model of work frustration-aggression. Journal of Organizational Behavior, 20, 915-931.

Fritz, C., Lam, C. F., \& Spreitzer, G. M. (2011). It's the little things that matter. Academy of Management Perspectives, 25, 28-39. 
Fritz, C., Lin, B. C., \& Trougakos, J. (2009). Recovery at work: Explicating the need for research attention. Professional Development Workshop presented at Academy of Management, Chicago, IL.

Fritz, C., \& Sonnentag, S. (2006). Recovery, well-being, and performance-related outcomes: The role of workload and vacation experiences. Journal of Applied Psychology, 91, 936-945.

Fritz, C., \& Sonnentag, S. (2005). Recovery, health, and job performance: Effects of weekend experiences. Journal of Occupational Health Psychology, 10, 187-199.

Frone, M. R., Yardley, J. K., \& Markel, K. S. (1997). Developing and testing an integrative model of the work-family interface. Journal of Vocational Behavior, $50,145-167$.

Gest, S. D., Graham-Bermann, S. A., \& Hartup, W. W. (2001). Peer experience: Common and unique features of number of friendships, social network centrality, and sociometric status. Social Development, 10, 23-40.

Gillie, T. \& Broadbent, D. E. (1989). What makes interruptions disruptive? A study of length, similarity, and complexity. Psychological Research, 50, 243-250.

Glass, D. C., \& Singer, J. E. (1972). Urban Stress: Experiments on Noise and Social Stressors. New York: Academic Press.

Goldstein, I., \& Ford, K. (2002). Training in organizations: Needs assessment, development, and evaluation. California: Wadsworth. 
Grandey, A. A. (2000). Emotion regulation in the workplace: A new way to conceptualize emotional labor. Journal of Occupational Health Psychology, 5, 95-110.

Grandey, A. A. (2003). When "the show must go on": Surface acting and deep acting as determinants of emotional exhaustion and peer-rated service delivery. Academy of Management Journal, 46, 86-96.

Grove, A. S. (1983). High output management. New York: Random House.

Gruman, J. A., Saks, A. M. \& Zweig, D. I. (2006). Organizational socialization tactics and newcomer proactive behaviors: An integrative study. Journal of Vocational Behavior, 69, 90-104.

Hakanen, J. J., Schaufeli, W. B., \& Ahola, K. (2008). The Job Demands-Resources model: A three-year cross-lagged study of burnout, depression, commitment, and work engagement. Work \& Stress, 22, 224-241.

Halbesleben, J. R. B. (2006). Sources of social support and burnout: A meta-analytic test of the conservation of resources model. Journal of Applied Psychology, 91, 11341145.

Hartley, L. R. (1973). Effect of prior noise or prior performance on serial reaction. Journal of Experimental Psychology, 101, 255-261.

Henning, R.A., Jacques, P., Kissel, G.V., Sullivan, A.B., \& Alteras-Webb, A.M. (1997). Frequent short rest breaks from computer work: Effects on productivity and wellbeing at two field sites. Ergonomics, 40, p. 78-91. 
Hobfoll, S. E. (1989). Conservation of resources: a new attempt at conceptualizing stress. American Psychologist, 44, p. 513-524.

Hochschild, A. R. (1979). Emotion work, feeling rules, and social structure. American Journal of Sociology, 85, 551-575.

Hochschild, A. R. (1983). The managed heart: Commercialization of human feeling. Berkeley: University of California Press.

Hodgetts, H. M., \& Jones, D. M. (2006). Interruption of the Tower of London task: Support for a Goal-Activation approach. Journal of Experimental Psychology: General, 135, 103-115.

Holmes, W.G. (1938). Applied time and motion study. New York: Ronald.

Holms, T. H., \& Rahe, R. H. (1967). The social readjustment rating scale. Journal of Psychosomatic Research, 11, 213-218.

Hutcheson, G. \& Sofroniou, N. (1999). The Multivariate Social Scientist. Sage Publications Ltd: London.

Ibarra, H. (1993). Network centrality, power, and innovation involvement: Determinants of technical and administrative roles. Academy of Management Journal, 35, 471501.

Jackson, S. E. \& Schuler, R. S. (1985). A meta-analysis and conceptual critique of research on role ambiguity and role conflict in work settings. Organizational Behavior and Human Decision Processes, 36, 16-78. 
Jett, Q. R., \& George, J. M. (2003). Work interrupted: A closer look at the role of interruptions in organizational life. Academy of Management Review, 28, 494507.

Jex, S. M., \& Britt, T. W. (2008). Organizational Psychology: A Scientist-Practitioner Approach. Hoboken, NJ: John Wiley \& Sons, Inc.

Johansson, G. \& Aronsson, G. (1984). Stress reactions in computerized administrative work. Journal of Occupational Behavior, 5, 159-181.

Joyce, A. (2005, January 2). Your interruption strategy: Set priorities and plan on unplanned events. Retrieved from http://www.washingtonpost.com/wpdyn/articles/A36722-2004Dec30.html

Judge, T. A., \& Ilies, R. (2004). Affect and job satisfaction: A study of their relationship at work and at home. Journal of Applied Psychology, 89, 661-673.

Kahn, W. A. (1990). Psychological conditions of personal engagement and disengagement at work. Academy of Management Journal, 33, 692-724.

Kanfer, R. (2009). Work motivation: Identifying use-inspired research directions. Industrial and Organizational Psychology, 2, 77-93.

Karasek, R. A. (1979). Job demands, job decision latitude, and mental strain: Implications for job redesign. Administrative Science Quarterly, 24, 285-308. 
van Katwyk, P. T., Fox, S., Spector, P. E., \& Kelloway, E. K. (2000). Using the jobrelated affective well-being scale (JAWS) to investigate affective responses to work stressors. Journal of Occupational Health Psychology, 5, 219-230.

Kirmeyer, S. L. (1988). Coping with competing demands: Interruption and the Type A pattern. Journal of Applied Psychology, 73, 621-629.

Kline, R. B. (2010). Principles and Practice of Structural Equation Modeling ( $3^{\text {rd }}$ Ed). New York: Guilford Press.

de Lange, A. H., Taris, T. W., Kompier, M. A. J., Houtman, I. L. D., \& Bongers, P. M. (2003). "The very best of the millennium": Longitudinal research and the demand-control-(support) model. Journal of Occupational Health Psychology, 8, 282-305.

Lazarus, R. S., \& Folkman, S. (1984). Stress, Appraisal, and Coping. New York: Springer.

Lee, R. T., \& Ashforth, B. E. (1996). A meta-analytic examination of the correlates of the three dimensions of job burnout. Journal of Applied Psychology, 81, 123-133.

LePine, J. A., Podsakoff, N. P., \& LePine, M. A. (2005). A meta-analytic test of the challenge stressor-hindrance stressor framework: An explanation for inconsistent relationships among stressors and performance. Academy of Management Journal, 48, 765-775. 
Levinson, H. (1965). Reciptrocation: The relationship between man and organization. Administrative Science Quarterly, 9, 370-390.

Lin, B. C., \& Fritz, C. (under review). Give me a break! The effects of lunch break unwinding on employee well-being. Journal of Applied Psychology.

Lin, B. C., Kain, J. M. \& Fritz, C. (Unpublished manuscript). Don't interrupt me! Examining the relationship between intrusions at work and employee strain and job performance.

Lin, B. C., Kain, J. M. \& Fritz, C. (2013). Don't interrupt me! An examination of the relationship between intrusions at work and employee strain. International Journal of Stress Management, 20, 77-94.

Lindell, M. K., \& Whitney, D. J. (2001). Accounting for common method variance in cross-sectional research designs. Journal of Applied Psychology, 86, 114-121.

Longenecker, C. O., Sims, H. P. Jr., \& Gioia, D. A. (1987). Behind the mask: The politics of employee appraisal. The Academy of Management Executive, 1, 183-193.

Markels, A. (1997, April 8). Memo 4/8/97, FYI: Messages inundate offices. Wall Street Journal, p. B1.

Maslach, C. \& Jackson, S. E. (1981). The measurement of experienced burnout. Journal of Occupational Behavior, 2, 99-113.

Maslach, C., Schaufeli, W. B., \& Leiter, M. P. (2001). Job burnout. Annual Review of Psychology, 52, 397-422. 
McDaniel, M. A., Einstein, G. O., Graham, T. \& Rall, E. (2004). Delaying execution of intentions: Overcoming the costs of interruptions. Applied Cognitive Psychology, $18,533-547$.

Meyer, H. H. (1991). A solution to the performance appraisal feedback enigma. Academy of Management Executive, 5, 68-76.

Mintzberg, H. (1990). The manager's job: Folklore and fact. Harvard Business Review, $68,163-176$.

Monk, C. A., Boehm-Davis, D., \& Trafton, J. G. (2004). Recovering from interruptions: Implications for driver-distraction research. Human Factors, 46, 650-663.

Monk, C. A., Trafton, J. G., \& Boehm-Davis, D. A. (2008). The effect of interruption duration and demand on resuming suspended goals. Journal of Experimental Psychology: Applied, 14, 299-313.

Morris, J. A., \& Feldman, D. (1996). The dimensions, antecedents, and consequences of emotional labor. Academy of Management Review, 21, 986-1010.

Motowidlo, S. J. (2003). Job performance. In W. C. Borman, D. R. Ilgen, \& R. Klimoski (Eds.), Handbook of Psychology, Volume 12: Industrial and Organizational Psychology (pp. 39-53). Hoboken, NJ: John Wiley \& Sons, Inc.

Muraven, M., Tice, D. M., \& Baumeister, R. F. (1998) Self-control as limited resource: Regulatory depletion patterns. Journal of Personality and Social Psychology, 74, 774-789. 
Muraven, M., Baumeister, R. F. \& Tice, D. M. (1999). Longitudinal improvement of selfregulation through practice: Building self-control strength through repeated exercise. Journal of Social Psychology, 139, 446-457.

National Institute for Occupational Safety and Health (2002). The Changing Organization of Work and the Safety and Health of Working People (DHHS2002-116).

Ones, D. S., \& Viswesvaran, C. (1998). The effects of social desirability and faking on personality and integrity assessment for personnel selection. Human Performance, $11,245-269$.

Oulasvirta, A., \& Saarilouma, P. (2004). Long-term working memory and interrupting messages in human-computer interaction. Behavior \& Information Technology, $23,53-64$.

Outlasvirta, A., \& Saariluoma, P. (2006). Surviving task interruptions: Investigating the implications of long-term working memory theory. International Journal of Human-Computer Studies, 64, 941-961.

Palliser, C. R., Firth, H. M., Feyer, A. M., \& Paulin, S. M. (2005). Musculoskeletal discomfort and work-related stress in New Zealand dentists. Work \& Stress, 19, 351-359. 
Peters, L. H., \& O'Connor, E. J. (1980). Situational constraints and work outcomes: The influences of a frequently overlooked construct. Academy of Management Review, $5,1980$.

Podsakoff, P. M., MacKenzie, S. B., Lee, J-Y. \& Podsakoff, N. P. (2003). Common method biases in behavioral research: A critical review of the literature and recommended remedies. Journal of Applied Psychology, 88, 879-903.

Quick, J. C. (1998). Introduction to the measurement of stress at work. Journal of Occupational Health Psychology, 3, 291-293.

Quick, J. C. (1999). Occupational health psychology: Historical roots and future directions. Health Psychology, 18, 82-88.

Quick, J. C., Quick, J. D., Nelson, D. L., \& Hurrell, J. J. Jr. (1997). Preventative stress management in organizations. Washington D. C.: American Psychological Association.

Robinson, W. S. (1950) Ecological correlations and the behavior of individuals. American Sociological Review, 15, 351-357.

Rogers, A. E., Hwang, W-T., \& Scott, L. D. (2004). The effects of work breaks on staff nurse performance. Journal of Nursing Administration, 34, 512-519.

Rotton, J., Olszewski, D., Charleton, M., \& Soler, E. (1978). Loud speech, conglomerate noise, and behavioral aftereffects. Journal of Applied Psychology, 63, 360-365. 
Royce, W. (1970). Managing the development of large software systems. Proceedings of IEEE WESCON, 26, 1-9.

Sackett, P. R., \& DeVore, C. J. (2001). Counterproductive behaviors at work. In N. Anderson, D. S. Ones, H. K. Sinangil and C. Viswesvaran (eds) Handbook of Industrial, Work and Organizational Psychology: Personnel Psychology. Vol. 1. London: Sage.

Schaufeli, W. B., \& Bakker, A. B. (2004). The demands, job resources, and their relationship with burnout and engagement: A multi-sample study. Journal of Organizational Behavior, 25, 293-315.

Shrout, P. E. (2013, Spring). Implementing multilevel analyses of daily diary data. Center for the Advancement of Research methods and Analysis (CARMA). Lecture conducted from Wayne State University, Detroit, MI.

Smith, P. C., Kendall, L. M., \& Hulin, C. L. (1969). The measurement of satisfaction in work and retirement. Chicago: Rand McNally.

Spector, P.E., \& Jex, S.M. (1998). Development of four self-report measures of job stressors and strain: Interpersonal Conflict at Work Scale, Organizational Constraints Scale, Quantitative Workload Inventory, and Physical Symptoms Inventory. Journal of Occupational Health Psychology, 3, p. 356-367.

Spira, J.B., \& Feintuch, J. B. (2005). The cost of not paying attention: How interruptions impact knowledge worker productivity. New York, New York: Basex, Inc. 
Stanton, J. M., Balzer, W. K., Smith, P. C., Parra, L. F., \& Ironson, G. (2001). A general measure of work stress: The Stress in General Scale. Educational and Psychological Measurement, 61, 866-888.

Sweeny, K., Melnyk, D., Miller, W. \& Shepperd, J. A. (2010). Information avoidance: Who, what, when, and why. Review of General Psychology, 14, 340-353.

Taris, T. W. \& Schreurs, P. J. G. (2009). Well-being and organizational performance: An organizational-level test of the happy-worker hypothesis. Work \& Stress, 23, 120 136.

Tepper, B. J. (2007). Abusive supervision in work organizations: Review, synthesis, and research agenda. Journal of Management, 33, 261-289.

Tice, D. M., Baumeister, R. F., Schmueli, D. \& Muraven, R. F. (2007). Restoring the self: Positive affect helps improve self-regulation following ego depletion. Journal of Experimental Social Psychology, 43, 379-384.

Tucker, P., Folkard, S., \& Macdonald, I. (2003). Rest breaks and accident risk. The Lancet, 361, p. 680.

Trafton, J. G., \& Monk, C. A. (2008). Task interruptions. In D. A. Boehm-Davis (Ed.), Reviews of human factors and ergonomics (Vol. 3, pp. 111-126). Santa Monica, CA: Human Factors and Ergonomics Society. 
Trougakos, J.P., Beal, D.J., Green, S.G., \& Weiss, H.M. (2008). Making the break count: An episodic examination of recovery, activities, emotional experiences, and positive affective displays. Academy of Management Journal, 51, p. 131-146.

Trougakos, J. P. \& Hideg, I. (2009). Momentary work recovery: The role of within-day work breaks. In S. Sonnentag, P. L. Perrewe, \& D. C. Ganster (Eds.), Research in occupational stress and well-being (Vol. 7, pp. 37-84). Emerald Group Publishing Limited.

United States Department of Labor, Bureau of Labor Statistics. (2011). American time use survey - 2010 results (USDL-11-0919). Retrieved from http://www.bls.gov/news.release/ atus.nr0.htm

United States Department of Labor, Wage and Hour Division. (2010). Handy reference guide to the Fair Labor Standards Act (WH Publication 1282). Retrieved from http://www.dol.gov/whd/regs/compliance/wh1282.pdf

van Veldhoven, M., \& Broersen, S. (2003). Measurement quality and validity of the “Need for recovery scale". Occupational and Environmental Medicine, 60, 3-9.

Vroom, V. H. (1964). Work and Motivation. Oxford, England: Wiley.

Wallace, J. C., \& Chen, G. (2005). Development and validation of a work-specific measure of cognitive failure: Implications for occupational safety. Journal of Occupational and Organizational Psychology, 78, 615-632. 
Wallis, C., \& Steptoe, S. (2006, January 16). Help! I've lost my focus.” Time, 167, pp. $72-79$.

Watson, D., \& Clark, L.A. (1994). The PANAS-X: Manual for the Positive and Negative Affect Schedule- Expanded form. Unpublished Manuscript, University of Iowa, Iowa City, IA.

Williams, L. J., \& Anderson, S. E. (1991). Job satisfaction and organizational commitment as predictors of organizational citizenship and in-role behaviors. Journal of Management, 17, 601-617.

Yerkes, R. M. \& Dodson, J. D. (1908). The relation of strength of stimulus to rapidity of habit-formation. Journal of Comparative Neurology and Psychology, 18, 459482.

Zapf, D., Dormann, C. \& Frese, M. (1996). Longitudinal studies in organizational stress research: A review of the literature with reference to methodological issues. Journal of Occupational Health Psychology, 1, 145-169.

Zijlstra, F. R. H., Roe, R. A., Leonora, A. B., \& Krediet, I. (1999). Temporal factors in mental work: Effects of interrupted activities. Journal of Occupational and Organizational Psychology, 72, 163-185. 


\section{Appendix A. Time 0 Survey}

(This survey can be found here: https://www.surveymonkey.com/s/T0)

Thank you for choosing to participate in this study! The following survey will inquire about your general workplace experiences. This online survey should take no longer than 15 minutes to complete. We would like to remind you that participation in this study is completely voluntary, and you are free to withdraw from the study at any point. Responses will remain anonymous, so please feel free to be as honest as possible.

By clicking "continue," you indicating that you a) are at least 18 year old, b) understand your rights as a participant, and c) consenting to participate in this study.

\section{-PAGE BREAK-}

In the textbox below please enter your 11-digit Security Code. Your security code is the first two letters of your first name, last two letters of your last name, first two letters of your city of birth, last two letters of your current city of residence, and last three digits of your social security number. This code will be used to link all of your responses together and subsequently discarded.

What is your age?

What is your sex?

What company do you work for?

$\overline{\text { Male Female }}$

Job title

Is managing other employees part of your job? Yes

No

How many hours do you spend collaborating with your coworkers per week?

hours

Can you briefly describe what your job entails?

\section{-PAGE BREAK-}

The following survey questions were designed to assess your typical emotions, and the way you perceive various characteristics of your workplace, your job, or the work you do. Please take a few seconds to think about your job, in general, and respond to the following survey questions.

Please indicate the extent to which the following statements applied to you in the past three months.

NOTE: In the following survey questions, "coworkers" refer to anyone you work with (including supervisors, subordinates, colleagues). "Interruptions" can include others either stopping by your workplace, email, instant messaging, or phone and text messages.

\begin{tabular}{|c|c|c|c|c|}
\hline 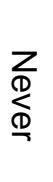 & $\begin{array}{l}\text { D } \\
\stackrel{D}{\mathbb{D}} \\
\stackrel{2}{<}\end{array}$ & 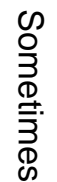 & 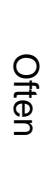 & 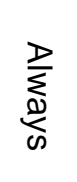 \\
\hline & 2 & 3 & 4 & 5 \\
\hline & 2 & 3 & 4 & \\
\hline & 2 & 3 & 4 & 5 \\
\hline & 2 & 3 & 4 & \\
\hline
\end{tabular}

I was interrupted by other coworkers.

My work flow was halted by other coworkers.

I had to stop working to attend to interruptions from coworkers.

My coworkers stopped me while I was working. 


\begin{tabular}{|c|c|c|c|c|c|}
\hline $\begin{array}{l}\text { NOTE: In the following survey questions, "nonwork members" refer to } \\
\text { anyone you know from outside of work. "Interruptions" can include } \\
\text { others either stopping by your workplace, email, instant messaging, or } \\
\text { phone and text messages. }\end{array}$ & $\underset{\mathbb{\Phi}}{\underset{\mathbb{Q}}{Z}}$ & 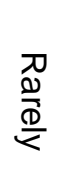 & 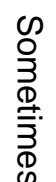 & $\underset{\stackrel{\mathbb{D}}{\stackrel{O}{D}}}{ }$ & \\
\hline $\begin{array}{l}\text { I was interrupted by other nonwork members. } \\
\text { My work flow was halted by other nonwork members. } \\
\text { I had to stop working to attend to interruptions from nonwork } \\
\text { members. } \\
\text { Nonwork members stopped me while I was working. }\end{array}$ & $\begin{array}{l}1 \\
1 \\
1 \\
1\end{array}$ & $\begin{array}{l}2 \\
2 \\
2 \\
2\end{array}$ & $\begin{array}{l}3 \\
3\end{array}$ & $\begin{array}{l}4 \\
4\end{array}$ & $\begin{array}{l}5 \\
5\end{array}$ \\
\hline
\end{tabular}

\section{-PAGE BREAK-}

The following questions are designed to measure certain characteristics of your work. Please indicate the extent to which you agree with each of the following by using the response scale provided

The job requires me to accomplish my job before other complete their job.

Other jobs depend directly on my job.

Unless my job gets done, other jobs cannot be completed.

My job activities are greatly affected by the work of other people.

My job depends on the work of many different people for its completion.

My job cannot be done unless others do their work.

The job requires that I only do one task or activity at a time.

The tasks on the job are simple and uncomplicated.

The job comprises relatively uncomplicated tasks.

The job involves performing relatively simple tasks.

The job involves solving problems that have no obvious correct answer.

The job requires me to be creative.

The job often involves dealing with problems that I have not met before.

The job requires unique ideas or solutions to problems.

The job allows me to make my own decisions about how to

The job allows me to make my own decisions about how to schedule my work.

The job allows me to decide on the order in which things are done on the job.

The job allows me to plan how I do my work.

The job gives me a chance to use my personal initiative or judgment in carrying out the work.

The job allows me to make a lot of decisions on my own.

The job provides me with significant autonomy in making decisions.

The job allows me to make decisions about what methods I use to complete my work.

The job gives me considerable opportunity for independence and freedom in how I do the work.

The job allows me to decide on my own how to go about doing my work.

\begin{tabular}{|c|c|c|c|c|}
\hline 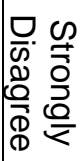 & 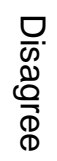 & 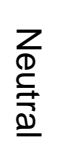 & $\frac{\vec{b}}{\mathbb{D}}$ & 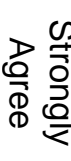 \\
\hline 1 & 2 & 3 & 4 & 5 \\
\hline 1 & 2 & 3 & 4 & 5 \\
\hline 1 & 2 & 3 & 4 & 5 \\
\hline 1 & 2 & 3 & 4 & 5 \\
\hline 1 & 2 & 3 & 4 & 5 \\
\hline 1 & 2 & 3 & 4 & 5 \\
\hline 1 & 2 & 3 & 4 & 5 \\
\hline 1 & 2 & 3 & 4 & 5 \\
\hline 1 & 2 & 3 & 4 & 5 \\
\hline 1 & 2 & 3 & 4 & 5 \\
\hline 1 & 2 & 3 & 4 & 5 \\
\hline 1 & 2 & 3 & 4 & 5 \\
\hline 1 & 2 & 3 & 4 & 5 \\
\hline 1 & 2 & 3 & 4 & 5 \\
\hline 1 & 2 & 3 & 4 & 5 \\
\hline 1 & 2 & 3 & 4 & 5 \\
\hline 1 & 2 & 3 & 4 & 5 \\
\hline 1 & 2 & 3 & 4 & 5 \\
\hline 1 & 2 & 3 & 4 & 5 \\
\hline 1 & 2 & 3 & 4 & 5 \\
\hline 1 & 2 & 3 & 4 & 5 \\
\hline 1 & 2 & 3 & 4 & 5 \\
\hline 1 & 2 & 3 & 4 & 5 \\
\hline 1 & 2 & 3 & 4 & 5 \\
\hline
\end{tabular}


The following survey questions consist of a number of words and phrases that describe different feelings and emotions. Please indicate the extent you have felt the following in general.

\begin{tabular}{|c|c|c|c|c|c|c|c|c|c|c|c|}
\hline & $\begin{array}{l}Z \underset{Z}{O} \\
\stackrel{9}{0} \\
\stackrel{0}{=}\end{array}$ & 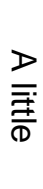 & $\begin{array}{l}\frac{3}{0} \\
\frac{0}{\mathbb{D}} \\
\frac{0}{0} \\
\frac{\mathbb{D}}{\alpha}\end{array}$ & 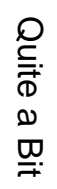 & 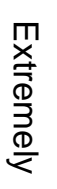 & & $\begin{array}{l}Z \\
\stackrel{+}{+} \\
\stackrel{2}{0} \\
\stackrel{0}{\equiv}\end{array}$ & $\frac{D}{\frac{D}{\bar{D}}}$ & $\begin{array}{l}3 \\
\frac{0}{0} \\
\frac{0}{\mathbb{D}} \\
\frac{\mathbb{D}}{\mathbb{D}} \\
\stackrel{\mathbb{D}}{<}\end{array}$ & 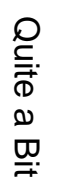 & 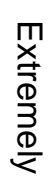 \\
\hline Active & 1 & 2 & 3 & 4 & 5 & Afraid & 1 & 2 & 3 & 4 & 5 \\
\hline Alert & 1 & 2 & 3 & 4 & 5 & Scared & 1 & 2 & 3 & 4 & 5 \\
\hline Attentive & 1 & 2 & 3 & 4 & 5 & Nervous & 1 & 2 & 3 & 4 & 5 \\
\hline Determined & 1 & 2 & 3 & 4 & 5 & Jittery & 1 & 2 & 3 & 4 & 5 \\
\hline Enthusiastic & 1 & 2 & 3 & 4 & 5 & Irritable & 1 & 2 & 3 & 4 & 5 \\
\hline Excited & 1 & 2 & 3 & 4 & 5 & Hostile & 1 & 2 & 3 & 4 & 5 \\
\hline Inspired & 1 & 2 & 3 & 4 & 5 & Guilty & 1 & 2 & 3 & 4 & 5 \\
\hline 2Interested & 1 & 2 & 3 & 4 & 5 & Ashamed & 1 & 2 & 3 & 4 & 5 \\
\hline Proud & 1 & 2 & 3 & 4 & 5 & Upset & 1 & 2 & 3 & 4 & 5 \\
\hline Strong & 1 & 2 & 3 & 4 & 5 & Distressed & 1 & 2 & 3 & 4 & 5 \\
\hline
\end{tabular}

The following survey questions are designed to inquire about things your job and work environment require of you. Please indicate, on average, how often you experience these things at work.

\begin{tabular}{|c|c|c|c|c|c|}
\hline & 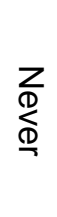 & $\sum_{0}$ & 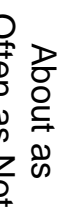 & 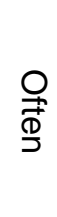 & 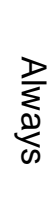 \\
\hline How often does your job require you to work very fast? & 1 & 2 & 3 & 4 & 5 \\
\hline How often does your job require you to work very hard? & 1 & 2 & 3 & 4 & 5 \\
\hline How often does your job leave you with little time to get things done? & 1 & 2 & 3 & 4 & 5 \\
\hline How often is there a great deal to be done? & 1 & 2 & 3 & 4 & \\
\hline How often do you have to do more work than you can do well? & 1 & 2 & 3 & 4 & \\
\hline How often do you resist expressing your true feelings? & 1 & 2 & 3 & 4 & 5 \\
\hline How often do you pretend to have emotions that you don't really have? & 1 & 2 & 3 & 4 & 5 \\
\hline How often do you hide your true feelings about a situation? & 1 & 2 & 3 & 4 & \\
\hline I help others who have heavy workloads. & 1 & 2 & 3 & 4 & \\
\hline I help orient new people even though it is not required. & 1 & 2 & 3 & 4 & \\
\hline I willingly help others who have work-related problems. & 1 & 2 & 3 & 4 & \\
\hline I am always ready to lend a helping hand to those around me. & 1 & 2 & 3 & 4 & \\
\hline
\end{tabular}

Please indicate the frequency in which you generally experience the following statements.

\begin{tabular}{|c|c|c|c|c|c|}
\hline & $\underset{\mathbb{\mathbb { N }}}{\underset{\mathbb{N}}{Z}}$ & $\begin{array}{l}\stackrel{D}{D} \\
\stackrel{\mathbb{D}}{<}\end{array}$ & 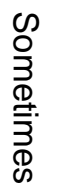 & $\begin{array}{l}\stackrel{\mathrm{O}}{ \pm} \\
\stackrel{\mathbb{D}}{J}\end{array}$ & $\sum_{\infty}^{\infty}$ \\
\hline $\begin{array}{l}\text { I had trouble falling asleep. } \\
\text { I had trouble staying asleep (including waking up too early). } \\
\text { I woke up several times during the night. } \\
\text { I woke up after my usual amount of sleep feeling tired and worn out. }\end{array}$ & $\begin{array}{l}1 \\
1 \\
1 \\
1\end{array}$ & $\begin{array}{l}2 \\
2 \\
2 \\
2\end{array}$ & $\begin{array}{l}3 \\
3 \\
3 \\
3\end{array}$ & $\begin{array}{l}4 \\
4 \\
4 \\
4\end{array}$ & $\begin{array}{l}5 \\
5 \\
5 \\
5\end{array}$ \\
\hline
\end{tabular}


During the past three months, how would you rate your sleep quality overall?
Very Bad
$\mathrm{Bad}$
Average
Good
Very Good
-PAGE BREAK-

Thank you for completing this portion of the study!

Please email the researcher (bclin@pdx.edu) to continue with the study. On the coming Monday, we will email you to begin the daily portion of this study. It is generally recommended that you complete the survey as soon as we send it to you, but you may complete the survey any time before you leave work. 


\section{Appendix B. Time 1 Survey}

(This survey can be found here: https://www.surveymonkey.com/s/T1_Monday)

Thank you for choosing to participate in the daily portion of the study! The following survey will inquire about the various things you have experienced today. This online survey should take no longer than 10 minutes to complete. We would like to remind you that participation in this study is completely voluntary, and you are free to withdraw from the study at any point. Responses will remain anonymous, so please feel free to be as honest as possible.

By clicking "continue," you indicating that you a) are at least 18 year old, b) understand your rights as a participant, and c) consenting to participate in this study.

\section{-PAGE BREAK-}

In the textbox below please enter your 11-digit Security Code. Your security code is the first two letters of your first name, last two letters of your last name, first two letters of your city of birth, last two letters of your current city of residence, and last three digits of your social security number. This code will be used to link all of your responses together and subsequently discarded.

\section{-PAGE BREAK-}

The following survey questions are designed to measure how often you experience interruptions at work (be they from coworkers, supervisors, or subordinates), and the nature of the interruptions you experience.

Please indicate the frequency with which the following statements applied to you today by circling the corresponding response.

NOTE: In the following survey questions, "coworkers" refer to anyone you work with (including supervisors, subordinates, colleagues). "Interruptions" can include others either stopping by your workplace, email, instant messaging, or phone and text messages.

I was interrupted by other coworkers.

My work flow was halted by other coworkers.

I had to stop working to attend to interruptions from coworkers.

My coworkers stopped me while I was working.

NOTE: In the following survey questions, "nonwork members" refer to anyone you know from outside of work. "Interruptions" can include others either stopping by your workplace, email, instant messaging, or phone and text messages.

I was interrupted by other nonwork members.

My work flow was halted by other nonwork members. I had to stop working to attend to interruptions from nonwork members.

Nonwork members stopped me while I was working.

\begin{tabular}{|c|c|c|c|c|}
\hline$\underset{\mathbb{Q}}{Z}$ & $\begin{array}{l}\text { D } \\
\stackrel{D}{\bar{D}} \\
\stackrel{\sim}{<}\end{array}$ & 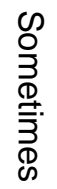 & $\begin{array}{l}\text { O } \\
\stackrel{\mathbb{D}}{D}\end{array}$ & $\sum_{\infty}^{\infty}$ \\
\hline 1 & 2 & 3 & 4 & 5 \\
\hline 1 & 2 & 3 & 4 & 5 \\
\hline 1 & 2 & 3 & 4 & 5 \\
\hline 1 & 2 & 3 & 4 & 5 \\
\hline$\underset{\mathbb{D}}{Z}$ & $\begin{array}{l}\stackrel{D}{D} \\
\stackrel{D}{\mathbb{D}}\end{array}$ & 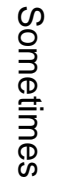 & $\begin{array}{l}\stackrel{\bigcirc}{\mathbb{D}} \\
\stackrel{\mathbb{D}}{3}\end{array}$ & $\sum_{\infty}^{\infty}$ \\
\hline 1 & 2 & 3 & 4 & 5 \\
\hline r & 2 & 3 & 4 & 5 \\
\hline 1 & 2 & 3 & 4 & 5 \\
\hline & 2 & 3 & 4 & 5 \\
\hline
\end{tabular}

What percentage of the interruptions you experienced today were...
... in person?
$\%$
... via phone? 
... via email?

... via instant messaging?

$\%$

... via text message?

$\%$

The majority of interruptions I experienced were... (please circle one)

Short
Simple/Easy
$\quad$ Unexpected

Moderate

Moderate

Upsetting

Unwanted

Negative

Neutral

Neutral

Neutral

\section{Long \\ Complex/Difficult \\ Expected \\ Pleasant \\ Welcome \\ Positive}

What percentage of the interruptions you experienced today were positive?

What percentage of the interruptions you experienced today were

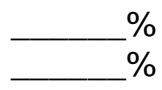

negative?

What percentage of the interruptions you experienced today were neutral?

Please provide an estimate of...

... the number of interruptions you experienced at work today:

$\ldots$ the average amount of time each interruption took up

times today:

minutes

What was the majority of your interruptions about today?

Please indicate the extent to you feel each of the below statements right now.

\begin{tabular}{|c|c|c|c|c|c|}
\hline & $\begin{array}{l}Z \\
\stackrel{Z}{+} \\
\stackrel{0}{0} \\
\supseteqq\end{array}$ & $\frac{D}{\frac{D}{\bar{D}}}$ & $\begin{array}{l}\frac{3}{0} \\
\frac{\mathrm{d}}{\mathbb{D}} \\
\frac{\mathbb{D}}{\mathbb{D}} \\
\frac{1}{<}\end{array}$ & 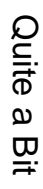 & 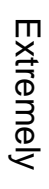 \\
\hline Alert & 1 & 2 & 3 & 4 & 5 \\
\hline Attentive & 1 & 2 & 3 & 4 & 5 \\
\hline Concentrating & 1 & 2 & 3 & 4 & 5 \\
\hline Determined & 1 & 2 & 3 & 4 & 5 \\
\hline Sleepy & 1 & 2 & 3 & 4 & 5 \\
\hline Tired & 1 & 2 & 3 & 4 & 5 \\
\hline Sluggish & 1 & 2 & 3 & 4 & 5 \\
\hline Drowsy & 1 & 2 & 3 & 4 & 5 \\
\hline I feel drained. & 1 & 2 & 3 & 4 & 5 \\
\hline My mind feels unfocused right now. & 1 & 2 & 3 & 4 & 5 \\
\hline $\begin{array}{l}\text { It would take a lot of effort for me to concentrate on something right } \\
\text { now. }\end{array}$ & 1 & 2 & 3 & 4 & 5 \\
\hline I can't absorb any information. & 1 & 2 & 3 & 4 & 5 \\
\hline
\end{tabular}

Please indicate the extent to you agree with each of the following statements regarding your work for today. 


\begin{tabular}{|c|c|c|c|c|c|}
\hline & 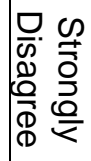 & $\begin{array}{l}\frac{\square}{\omega} \\
\frac{0}{0} \\
\frac{0}{\Phi} \\
\frac{1}{D}\end{array}$ & $\begin{array}{l}\text { Z } \\
\stackrel{\mathbb{D}}{\mathbf{C}} \\
\stackrel{+}{\underline{D}}\end{array}$ & $\frac{\vec{D}}{\mathbb{D}}$ & 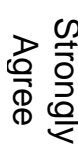 \\
\hline $\begin{array}{l}\text { Today I adequately completed assigned duties relative to my own } \\
\text { expectations. }\end{array}$ & 1 & 2 & 3 & 4 & 5 \\
\hline $\begin{array}{l}\text { Today I fulfilled responsibilities from my job description up to my } \\
\text { expectations. }\end{array}$ & 1 & 2 & 3 & 4 & 5 \\
\hline Today I performed the tasks that I expected of myself. & 1 & 2 & 3 & 4 & 5 \\
\hline $\begin{array}{l}\text { Today I met formal performance requirements of the job to my } \\
\text { expectations. }\end{array}$ & 1 & 2 & 3 & 4 & 5 \\
\hline I neglected aspects of the job that I expected myself to perform today. & 1 & 2 & 3 & 4 & 5 \\
\hline I failed to perform the essential duties I wanted to perform today. & 1 & 2 & 3 & 4 & 5 \\
\hline
\end{tabular}

Please indicate, on average, how often you experienced these things at work today.

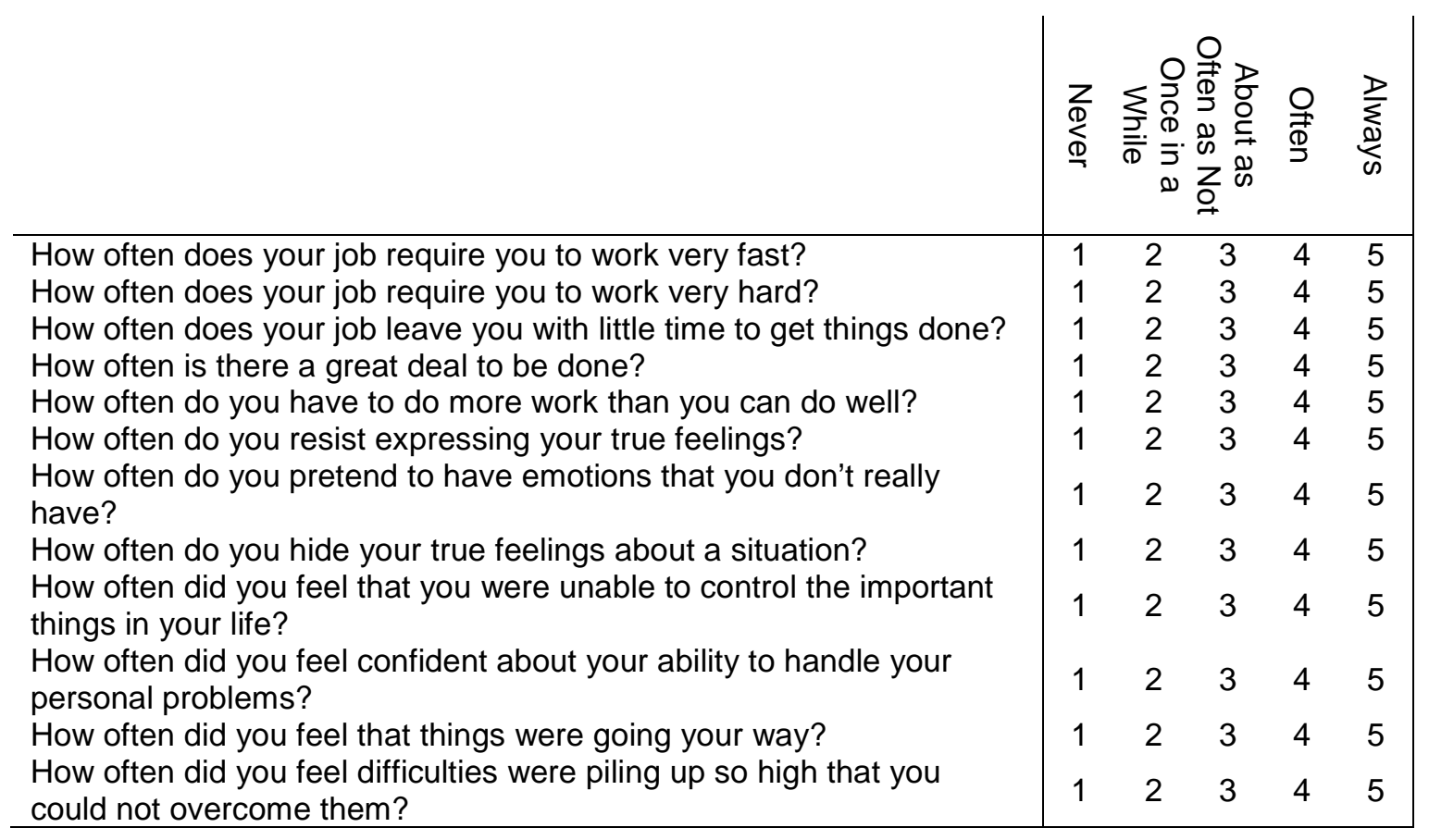

-PAGE BREAK-

Thank you for participating in this study!

Please email the researcher (bclin@pdx.edu) to continue with the study. If you are interested in continuing, you should receive another email tomorrow to proceed with the TUESDAY SURVEY. 
Appendix $C$. Time 2 Survey

(This survey can be found here: https://www.surveymonkey.com/s/T2_Tuesday)

Thank you for choosing to participate in the daily portion of the study! The following survey will inquire about the various things you have experienced today. This online survey should take no longer than 10 minutes to complete. We would like to remind you that participation in this study is completely voluntary, and you are free to withdraw from the study at any point. Responses will remain anonymous, so please feel free to be as honest as possible.

By clicking "continue," you indicating that you a) are at least 18 year old, b) understand your rights as a participant, and c) consenting to participate in this study.

\section{-PAGE BREAK-}

In the textbox below please enter your 11-digit Security Code. Your security code is the first two letters of your first name, last two letters of your last name, first two letters of your city of birth, last two letters of your current city of residence, and last three digits of your social security number. This code will be used to link all of your responses together and subsequently discarded.

\section{-PAGE BREAK-}

The following survey questions are designed to measure how often you experience interruptions at work (be they from coworkers, supervisors, or subordinates), and the nature of the interruptions you experience.

Please indicate the frequency with which the following statements applied to you today by circling the corresponding response.

NOTE: In the following survey questions, "coworkers" refer to anyone you work with (including supervisors, subordinates, colleagues). "Interruptions" can include others either stopping by your workplace, email, instant messaging, or phone and text messages.

\begin{tabular}{|c|c|c|c|c|}
\hline$\underset{\mathbb{Q}}{Z_{0}}$ & 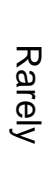 & 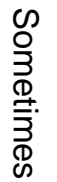 & $\begin{array}{l}\stackrel{0}{\stackrel{D}{D}} \\
\stackrel{D}{J}\end{array}$ & $\underbrace{N}_{\infty}$ \\
\hline & 2 & 3 & 4 & \\
\hline & 2 & 3 & 4 & \\
\hline & 2 & 3 & 4 & \\
\hline & 2 & 3 & 4 & \\
\hline
\end{tabular}

I was interrupted by other coworkers.

My work flow was halted by other coworkers.

I had to stop working to attend to interruptions from coworkers.

My coworkers stopped me while I was working.

NOTE: In the following survey questions, "nonwork members" refer to anyone you know from outside of work. "Interruptions" can include others either stopping by your workplace, email, instant messaging, or phone and text messages.

I was interrupted by other nonwork members. My work flow was halted by other nonwork members. I had to stop working to attend to interruptions from nonwork members.

Nonwork members stopped me while I was working.

\begin{tabular}{|c|c|c|c|c|}
\hline$\underset{\mathbb{\mathbb { D }}}{Z}$ &  & 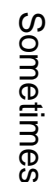 & $\frac{\stackrel{\mathrm{O}}{\mathbb{D}}}{\stackrel{\mathbb{D}}{J}}$ & $\underbrace{\stackrel{D}{\infty}}_{\infty}$ \\
\hline 1 & 2 & 3 & 4 & 5 \\
\hline 1 & 2 & 3 & 4 & 5 \\
\hline 1 & 2 & 3 & 4 & 5 \\
\hline 1 & 2 & 3 & 4 & 5 \\
\hline
\end{tabular}

What percentage of the interruptions you experienced today were...

... in person?

... via email?
$\%$

$\%$
... via phone?

... via text message?
$\%$ $\%$ 
... via instant messaging? $\%$

The majority of interruptions I experienced were... (please circle one)

$\begin{array}{ll}\text { Short } & \text { Moderate } \\ \text { Simple/Easy } & \text { Moderate }\end{array}$
Unexpected

$\begin{array}{ll}\text { Upsetting } & \text { Neutral } \\ \text { Unwanted } & \text { Neutral } \\ \text { Negative } & \text { Neutral }\end{array}$

\author{
Long \\ Complex/Difficult \\ Expected
}

Pleasant
Welcome
Positive

What percentage of the interruptions you experienced today were positive?

What percentage of the interruptions you experienced today were negative?

What percentage of the interruptions you experienced today were neutral?

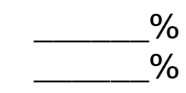

$\%$

$\%$

Please provide an estimate of...

... the number of interruptions you experienced at work today:

$\ldots$ the average amount of time each interruption took up today:

What was the majority of your interruptions about today?

Please indicate the extent to you feel each of the below statements right now.

\begin{tabular}{|c|c|c|c|c|c|}
\hline & 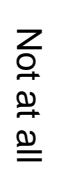 & $\frac{D}{\stackrel{\bar{\equiv}}{\bar{D}}}$ & $\begin{array}{l}3 \\
\frac{3}{0} \\
\frac{D}{D} \\
\mathbb{D} \\
\stackrel{\mathbb{D}}{<}\end{array}$ & 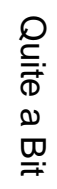 & $\begin{array}{l}\text { T. } \\
\stackrel{\times}{\mathbb{D}} \\
\stackrel{\mathbb{D}}{3} \\
\stackrel{\mathbb{D}}{<}\end{array}$ \\
\hline Alert & 1 & 2 & 3 & 4 & 5 \\
\hline Attentive & 1 & 2 & 3 & 4 & 5 \\
\hline Concentrating & 1 & 2 & 3 & 4 & 5 \\
\hline Determined & 1 & 2 & 3 & 4 & 5 \\
\hline Sleepy & 1 & 2 & 3 & 4 & 5 \\
\hline Tired & 1 & 2 & 3 & 4 & 5 \\
\hline Sluggish & 1 & 2 & 3 & 4 & 5 \\
\hline Drowsy & 1 & 2 & 3 & 4 & 5 \\
\hline I feel drained. & 1 & 2 & 3 & 4 & 5 \\
\hline My mind feels unfocused right now. & 1 & 2 & 3 & 4 & 5 \\
\hline $\begin{array}{l}\text { It would take a lot of effort for me to concentrate on something right } \\
\text { now. }\end{array}$ & 1 & 2 & 3 & 4 & 5 \\
\hline I can't absorb any information. & 1 & 2 & 3 & 4 & 5 \\
\hline
\end{tabular}

Please indicate the extent to you agree with each of the following statements regarding your work for today. 
DO NOT DISTURB

\begin{tabular}{l|lllll}
\hline $\begin{array}{l}\text { Today I adequately completed assigned duties relative to my own } \\
\text { expectations. }\end{array}$ & 1 & 2 & 3 & 4 & 5 \\
$\begin{array}{l}\text { Today I fulfilled responsibilities from my job description up to my } \\
\text { expectations. }\end{array}$ & 1 & 2 & 3 & 4 & 5 \\
Today I performed the tasks that I expected of myself. & 1 & 2 & 3 & 4 & 5 \\
Today I met formal performance requirements of the job to my & 1 & 2 & 3 & 4 & 5 \\
expectations. & 1 & 2 & 3 & 4 & 5 \\
I neglected aspects of the job that I expected myself to perform today. & 1 & 2 & 3 & 4 & 5 \\
\hline I failed to perform the essential duties I wanted to perform today. &
\end{tabular}

Please indicate, on average, how often you experienced these things at work today.

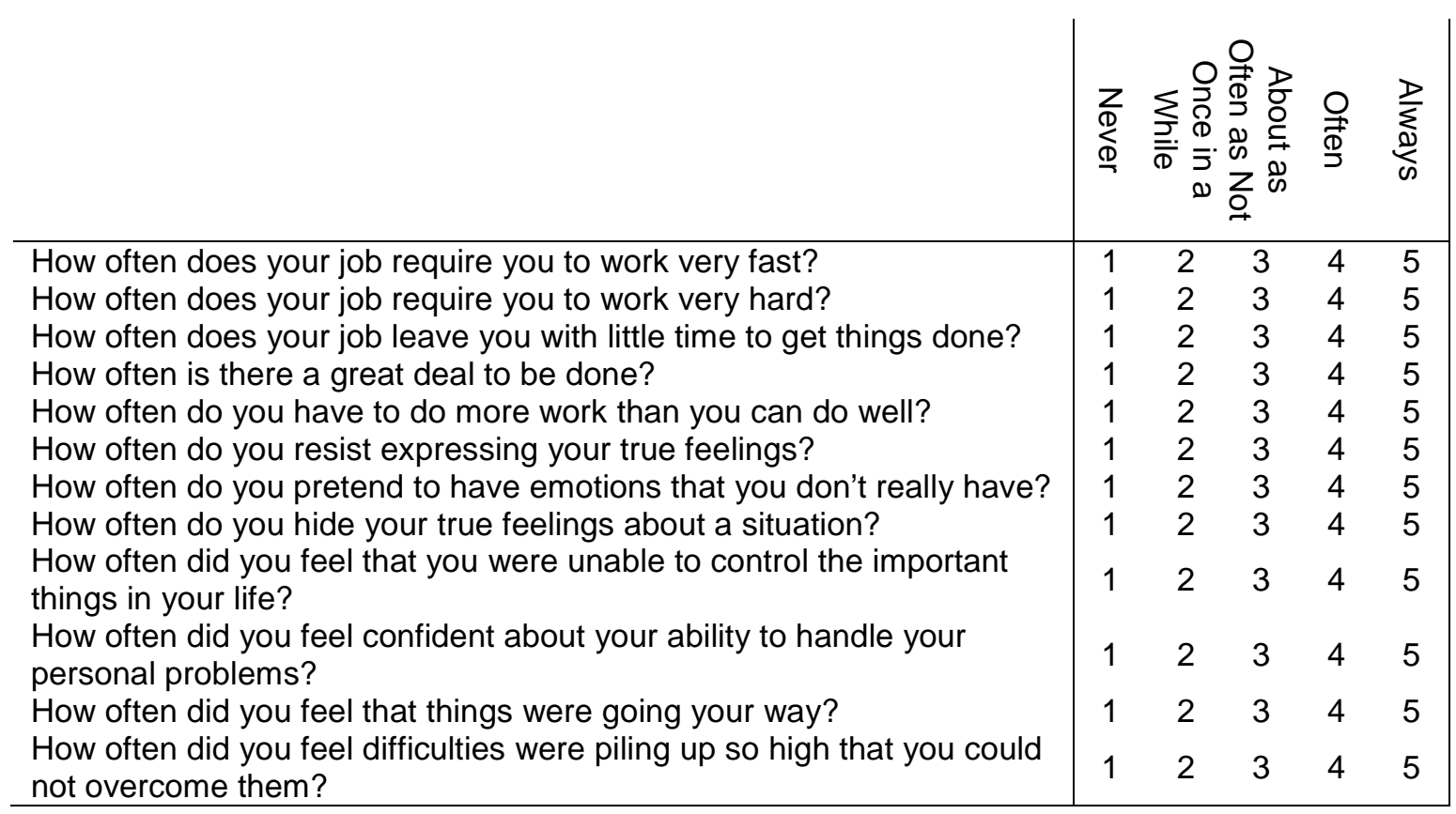

-PAGE BREAK-

Thank you for participating in this study!

Please email the researcher (bclin@pdx.edu) to continue with the study. If you are interested in continuing, you should receive another email tomorrow to proceed with the WEDNESDAY SURVEY. 
Appendix D. Time 3 Survey

(This survey can be found here: https://www.surveymonkey.com/s/T3_Wednesday)

Thank you for choosing to participate in the daily portion of the study! The following survey will inquire about the various things you have experienced today. This online survey should take no longer than 10 minutes to complete. We would like to remind you that participation in this study is completely voluntary, and you are free to withdraw from the study at any point. Responses will remain anonymous, so please feel free to be as honest as possible.

By clicking "continue," you indicating that you a) are at least 18 year old, b) understand your rights as a participant, and c) consenting to participate in this study.

\section{-PAGE BREAK-}

In the textbox below please enter your 11-digit Security Code. Your security code is the first two letters of your first name, last two letters of your last name, first two letters of your city of birth, last two letters of your current city of residence, and last three digits of your social security number. This code will be used to link all of your responses together and subsequently discarded.

\section{-PAGE BREAK-}

The following survey questions are designed to measure how often you experience interruptions at work (be they from coworkers, supervisors, or subordinates), and the nature of the interruptions you experience.

Please indicate the frequency with which the following statements applied to you today by circling the corresponding response.

NOTE: In the following survey questions, "coworkers" refer to anyone you work with (including supervisors, subordinates, colleagues). "Interruptions" can include others either stopping by your workplace, email, instant messaging, or phone and text messages.

I was interrupted by other coworkers.

My work flow was halted by other coworkers.

I had to stop working to attend to interruptions from coworkers.

My coworkers stopped me while I was working.

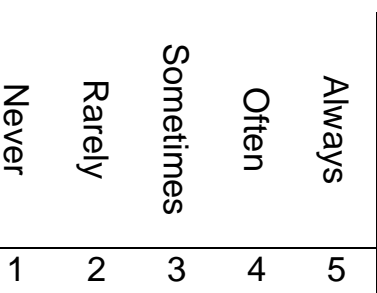

NOTE: In the following survey questions, "nonwork members" refer to anyone you know from outside of work. "Interruptions" can include others either stopping by your workplace, email, instant messaging, or phone and text messages.

I was interrupted by other nonwork members. My work flow was halted by other nonwork members. I had to stop working to attend to interruptions from nonwork members.

Nonwork members stopped me while I was working.

$\begin{array}{lllll}1 & 2 & 3 & 4 & 5 \\ 1 & 2 & 3 & 4 & 5\end{array}$

$\begin{array}{lllll}1 & 2 & 3 & 4 & 5\end{array}$

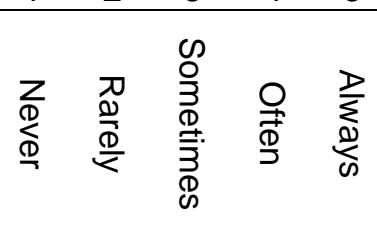

What percentage of the interruptions you experienced today were...

... in person?

... via email?
$\%$

$\%$
... via phone?

... via text message?

$\begin{array}{lllll}1 & 2 & 3 & 4 & 5 \\ 1 & 2 & 3 & 4 & 5 \\ 1 & 2 & 3 & 4 & 5 \\ 1 & 2 & 3 & 4 & 5\end{array}$

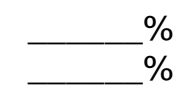


... via instant messaging? $\%$

The majority of interruptions I experienced were... (please circle one)

$\begin{array}{ll}\text { Short } & \text { Moderate } \\ \text { Simple/Easy } & \text { Moderate }\end{array}$

\begin{tabular}{ll}
\multicolumn{2}{c}{ Unexpected } \\
Upsetting & Neutral \\
Unwanted & Neutral \\
Negative & Neutral
\end{tabular}

\author{
Long \\ Complex/Difficult \\ Expected
}

\section{Pleasant \\ Welcome \\ Positive}

What percentage of the interruptions you experienced today were positive?

What percentage of the interruptions you experienced today were negative?

What percentage of the interruptions you experienced today were neutral?



Please provide an estimate of...

$\ldots$ the number of interruptions you experienced at work today:

$\ldots$ the average amount of time each interruption took up today:

times

minutes

What was the majority of your interruptions about today?

Please indicate the extent to you feel each of the below statements right now.

\begin{tabular}{|c|c|c|c|c|c|}
\hline & 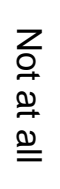 & $\frac{D}{\stackrel{\bar{\equiv}}{\bar{D}}}$ & $\begin{array}{l}3 \\
\frac{3}{0} \\
\frac{D}{D} \\
\mathbb{D} \\
\stackrel{\mathbb{D}}{<}\end{array}$ &  & $\begin{array}{l}\text { T. } \\
\stackrel{\times}{\mathbb{D}} \\
\stackrel{\mathbb{D}}{3} \\
\stackrel{\mathbb{D}}{<}\end{array}$ \\
\hline Alert & 1 & 2 & 3 & 4 & 5 \\
\hline Attentive & 1 & 2 & 3 & 4 & 5 \\
\hline Concentrating & 1 & 2 & 3 & 4 & 5 \\
\hline Determined & 1 & 2 & 3 & 4 & 5 \\
\hline Sleepy & 1 & 2 & 3 & 4 & 5 \\
\hline Tired & 1 & 2 & 3 & 4 & 5 \\
\hline Sluggish & 1 & 2 & 3 & 4 & 5 \\
\hline Drowsy & 1 & 2 & 3 & 4 & 5 \\
\hline I feel drained. & 1 & 2 & 3 & 4 & 5 \\
\hline My mind feels unfocused right now. & 1 & 2 & 3 & 4 & 5 \\
\hline $\begin{array}{l}\text { It would take a lot of effort for me to concentrate on something right } \\
\text { now. }\end{array}$ & 1 & 2 & 3 & 4 & 5 \\
\hline I can't absorb any information. & 1 & 2 & 3 & 4 & 5 \\
\hline
\end{tabular}

Please indicate the extent to you agree with each of the following statements regarding your work for today. 
DO NOT DISTURB

\begin{tabular}{l|lllll}
\hline $\begin{array}{l}\text { Today I adequately completed assigned duties relative to my own } \\
\text { expectations. }\end{array}$ & 1 & 2 & 3 & 4 & 5 \\
$\begin{array}{l}\text { Today I fulfilled responsibilities from my job description up to my } \\
\text { expectations. }\end{array}$ & 1 & 2 & 3 & 4 & 5 \\
Today I performed the tasks that I expected of myself. & 1 & 2 & 3 & 4 & 5 \\
Today I met formal performance requirements of the job to my & 1 & 2 & 3 & 4 & 5 \\
expectations. & 1 & 2 & 3 & 4 & 5 \\
Ineglected aspects of the job that I expected myself to perform today. & 1 & 2 & 3 & 4 & 5 \\
\hline
\end{tabular}

Please indicate, on average, how often you experienced these things at work today.

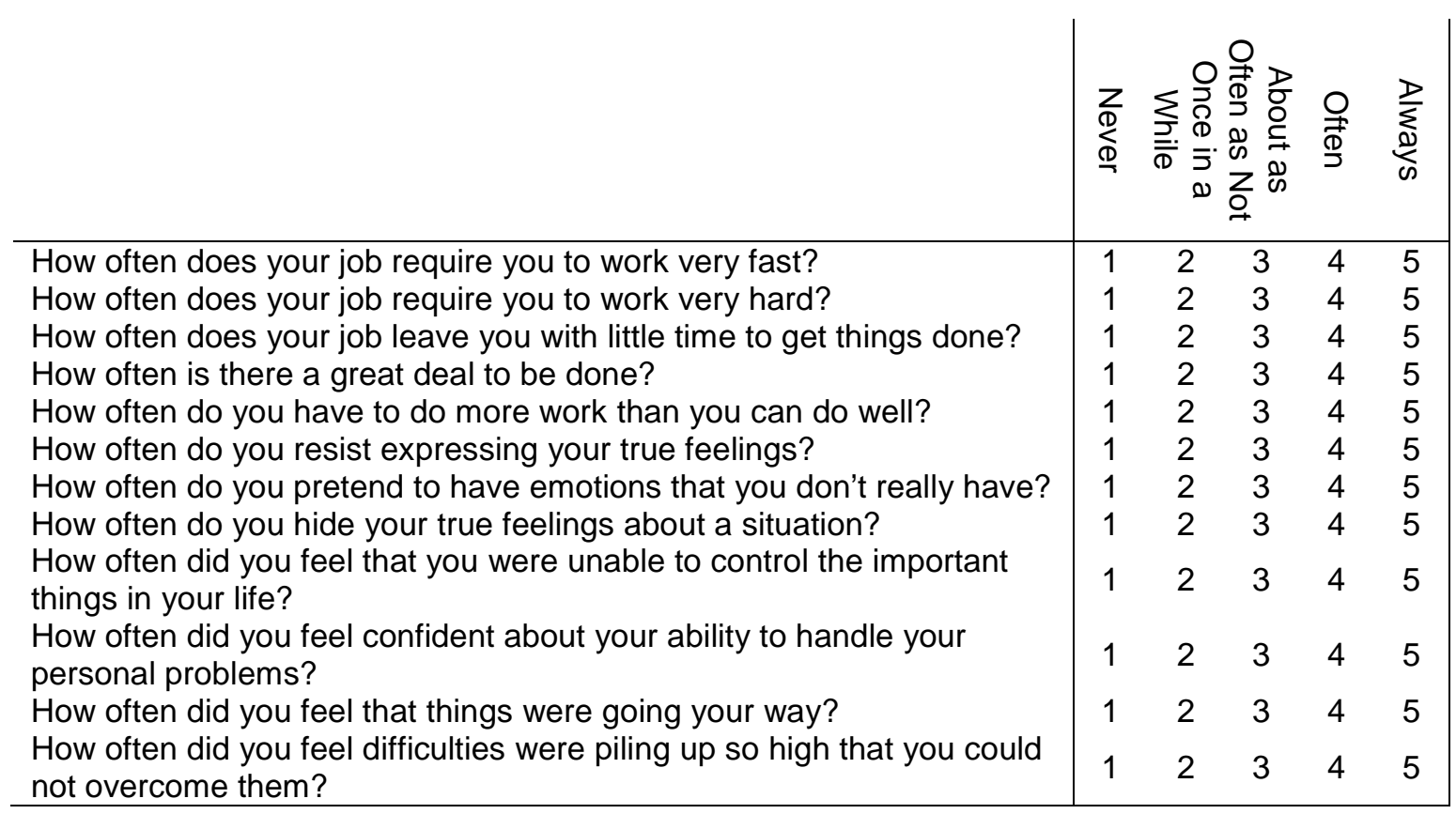

-PAGE BREAK-

Thank you for participating in this study!

Please email the researcher (bclin@pdx.edu) to continue with the study. If you are interested in continuing, you should receive another email tomorrow to proceed with the THURSDAY SURVEY. 
Appendix E. Time 4 Survey

(This survey can be found here: https://www.surveymonkey.com/s/T4_Thursday)

Thank you for continuing to participate in this study! This survey is the last survey you need to complete for the purposes of this study. This survey is designed to gain an understanding of your experiences from THIS ENTIRE WEEK. This online survey should take no longer than 20 minutes to complete. We would like to remind you that participation in this study is completely voluntary, and you are free to withdraw from the study at any point. Responses will remain anonymous, so please feel free to be as honest as possible.

By clicking "continue," you indicating that you a) are at least 18 year old, b) understand your rights as a participant, and c) consenting to participate in this study.

\section{-PAGE BREAK-}

In the textbox below please enter your 11-digit Security Code. Your security code is the first two letters of your first name, last two letters of your last name, first two letters of your city of birth, last two letters of your current city of residence, and last three digits of your social security number. This code will be used to link all of your responses together and subsequently discarded.

\section{-PAGE BREAK-}

The following survey questions are designed to measure how often you experience interruptions at work (be they from coworkers, supervisors, or subordinates), and the nature of the interruptions you experience.

Please indicate the frequency with which the following statements applied to you THIS WEEK by circling the corresponding response.

NOTE: In the following survey questions, "coworkers" refer to anyone you work with (including supervisors, subordinates, colleagues). "Interruptions" can include others either stopping by your workplace, email, instant messaging, or phone and text messages.

I was interrupted by other coworkers. My work flow was halted by other coworkers. I had to stop working to attend to interruptions from coworkers. My coworkers stopped me while I was working.

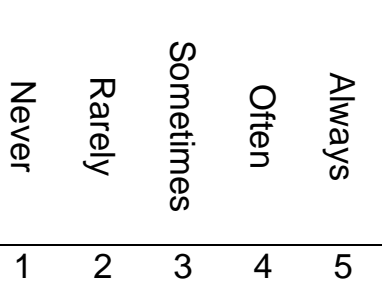

NOTE: In the following survey questions, "nonwork members" refer to anyone you know from outside of work. "Interruptions" can include others either stopping by your workplace, email, instant messaging, or phone and text messages.

I was interrupted by other nonwork members. My work flow was halted by other nonwork members. I had to stop working to attend to interruptions from nonwork members.

Nonwork members stopped me while I was working. What percentage of the interruptions you experienced THIS WEEK were... 
$\ldots$ in person?

... via email?

... via instant messaging?

$\begin{array}{r}\% \\ \hline \% \\ \hline\end{array}$

... via phone?

... via text message?

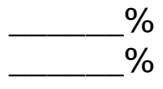

The majority of interruptions I experienced THIS WEEK were... (please circle one) Short Simple/Easy

Moderate

Moderate

Unexpected

Upsetting

Unwanted

Negative

Neutral

Neutral

Neutral
Long

Complex/Difficult

Expected

Pleasant

Welcome

Positive

What percentage of the interruptions you experienced today were positive?

What percentage of the interruptions you experienced today were

negative?

What percentage of the interruptions you experienced today were neutral?

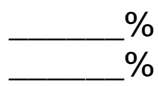

Please provide an estimate of...

... the number of interruptions you experienced at work THIS WEEK:

... the average amount of time each interruption took up THIS WEEK:

What was the majority of your interruptions about THIS WEEK?

Please indicate the extent to you feel each of the below statements THIS WEEK.

\begin{tabular}{|c|c|c|c|c|c|}
\hline & $\begin{array}{l}Z \\
\stackrel{Z}{+} \\
\stackrel{2}{\oplus} \\
\cong\end{array}$ & $\frac{D}{\stackrel{D}{\bar{D}}}$ & $\begin{array}{l}3 \\
\frac{0}{0} \\
\frac{\mathbb{D}}{\mathbb{D}} \\
\frac{\mathbb{D}}{\mathbb{D}} \\
\end{array}$ & 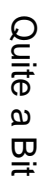 & 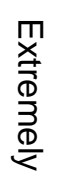 \\
\hline Alert & 1 & 2 & 3 & 4 & 5 \\
\hline Attentive & 1 & 2 & 3 & 4 & 5 \\
\hline Concentrating & 1 & 2 & 3 & 4 & 5 \\
\hline Determined & 1 & 2 & 3 & 4 & 5 \\
\hline Sleepy & 1 & 2 & 3 & 4 & 5 \\
\hline Tired & 1 & 2 & 3 & 4 & 5 \\
\hline Sluggish & 1 & 2 & 3 & 4 & 5 \\
\hline Drowsy & 1 & 2 & 3 & 4 & 5 \\
\hline I feel drained. & 1 & 2 & 3 & 4 & 5 \\
\hline My mind feels unfocused right now. & 1 & 2 & 3 & 4 & 5 \\
\hline $\begin{array}{l}\text { It would take a lot of effort for me to concentrate on something right } \\
\text { now. }\end{array}$ & 1 & 2 & 3 & 4 & 5 \\
\hline I can't absorb any information. & 1 & 2 & 3 & 4 & 5 \\
\hline
\end{tabular}

Please indicate the extent to you agree with each of the following statements regarding your work for THIS WEEK. 


\begin{tabular}{|c|c|c|c|c|c|}
\hline & 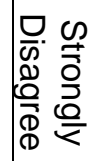 & $\begin{array}{l}\frac{\square}{\infty} \\
\stackrel{\mathscr{D}}{0} \\
\frac{0}{\mathbb{D}} \\
\mathbb{D}\end{array}$ & 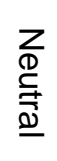 & $\frac{\mathbb{D}}{\stackrel{D}{\mathbb{D}}}$ & 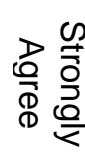 \\
\hline $\begin{array}{l}\text { This week I adequately completed assigned duties relative to my } \\
\text { own expectations. }\end{array}$ & 1 & 2 & 3 & 4 & 5 \\
\hline $\begin{array}{l}\text { This week I fulfilled responsibilities from my job description up to my } \\
\text { expectations. }\end{array}$ & 1 & 2 & 3 & 4 & 5 \\
\hline This week I performed the tasks that I expected of myself. & 1 & 2 & 3 & 4 & 5 \\
\hline $\begin{array}{l}\text { This week I met formal performance requirements of the job to my } \\
\text { expectations. }\end{array}$ & 1 & 2 & 3 & 4 & 5 \\
\hline $\begin{array}{l}\text { I neglected aspects of the job that I expected myself to perform this } \\
\text { week. }\end{array}$ & 1 & 2 & 3 & 4 & 5 \\
\hline I failed to perform the essential duties I wanted to perform this week. & 1 & 2 & 3 & 4 & 5 \\
\hline
\end{tabular}

Please indicate, on average, how often you experienced these things at work THIS WEEK.

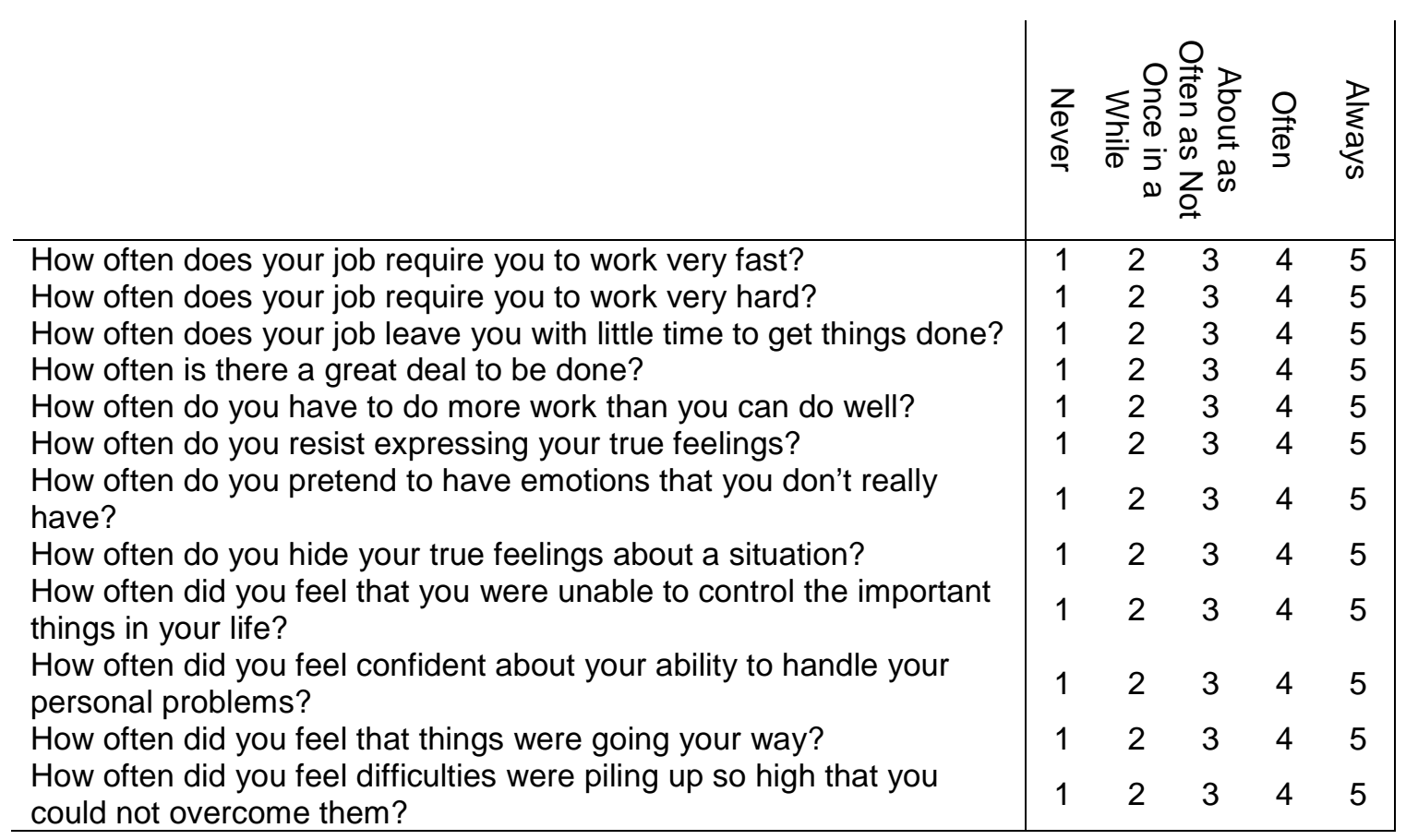

Please indicate how frequent you experienced each of these statements THIS WEEK.

\begin{tabular}{|c|c|c|c|c|c|}
\hline & $\begin{array}{l}\underset{\mathbb{Q}}{\mathbb{\Phi}} \\
\stackrel{\mathbb{D}}{-}\end{array}$ & & 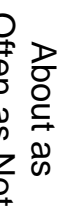 & $\frac{\stackrel{\mathrm{O}}{\mathrm{D}}}{\mathrm{D}}$ & \\
\hline \multirow{3}{*}{$\begin{array}{l}\text { How often were you unable to remember whether you have or have } \\
\text { not turned off work equipment at work? } \\
\text { How often did you fail to recall work procedures at work? } \\
\text { How often were you unable to remember work-related contact } \\
\text { information at work? }\end{array}$} & 1 & 2 & 3 & 4 & 5 \\
\hline & 1 & 2 & 3 & 4 & 5 \\
\hline & 1 & 2 & 3 & 4 & 5 \\
\hline
\end{tabular}


How often were you unable to remember what materials were required to complete a particular task at work?

How often did you forget where you have put something you use in your job at work?

How often did you fail to notice postings or notices on the facilities bulletin board(s) or email system at work?

How often did you not fully listen to instructions at work?

How often did you day-dream when you ought to be listening to somebody at work?

How often did you not focus your attention on work activities at work?

How often were you easily distracted by co-workers at work?

How often did you accidentally drop objects or things at work?

How often did you throw away something you meant to keep (e.g., memos) at work?

How often did you say things to others that you did not mean to say at work?

How often did you unintentionally press buttons on machines at work?

How often did you accidentally start or stop the wrong machine at work?

$\left|\begin{array}{lllll}1 & 2 & 3 & 4 & 5 \\ 1 & 2 & 3 & 4 & 5 \\ 1 & 2 & 3 & 4 & 5 \\ 1 & 2 & 3 & 4 & 5 \\ 1 & 2 & 3 & 4 & 5 \\ 1 & 2 & 3 & 4 & 5 \\ 1 & 2 & 3 & 4 & 5 \\ 1 & 2 & 3 & 4 & 5 \\ 1 & 2 & 3 & 4 & 5 \\ 1 & 2 & 3 & 4 & 5 \\ 1 & 2 & 3 & 4 & 5 \\ 1 & 2 & 3 & 4 & 5\end{array}\right|$

Please indicate the frequency in which you experienced the following statements THIS WEEK.

\begin{tabular}{|c|c|c|c|c|c|}
\hline & $\begin{array}{l}\underset{\mathbb{Q}}{\mathbb{\Phi}} \\
\underset{\mathbb{D}}{\mathbf{D}}\end{array}$ & $\begin{array}{l}\stackrel{D}{D} \\
\stackrel{\mathbb{D}}{=}\end{array}$ & 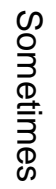 & $\begin{array}{l}\text { O } \\
\stackrel{\mathbb{D}}{\mathrm{D}}\end{array}$ & $\sum_{\infty}^{\infty}$ \\
\hline Most days I was enthusiastic about my work. & 1 & 2 & 3 & 4 & 5 \\
\hline I felt fairly satisfied with my present job. & 1 & 2 & 3 & 4 & 5 \\
\hline Each day at work seemed like it would never end for me. & 1 & 2 & 3 & 4 & 5 \\
\hline I found real enjoyment in my work. & 1 & 2 & 3 & 4 & 5 \\
\hline I considered my job rather unpleasant. & 1 & 2 & 3 & 4 & 5 \\
\hline I had trouble falling asleep. & 1 & 2 & 3 & 4 & 5 \\
\hline I had trouble staying asleep (including waking up & 1 & 2 & 3 & 4 & 5 \\
\hline I woke up several times during the night. & 1 & 2 & 3 & 4 & 5 \\
\hline I woke up after my usual amount of sleep feeling tired and worn out. & 1 & 2 & 3 & 4 & 5 \\
\hline
\end{tabular}

During the past three months, how would you rate your sleep quality overall?

$\begin{array}{llll}\text { Very Bad } & \text { Bad } & \text { Average } & \text { Good }\end{array}$

-PAGE BREAK-

Thank you for participating in our study of workplace interruptions!

Past laboratory studies on interruptions have shown demonstrated the disruptiveness of interruptions on performance on basic work tasks. However, research has yet to examine naturally occurring interruptions at work, nor how interruptions at work influence complex tasks, such as the work employees in the high tech industry perform. 
If you are interested in being entered into the drawing for the incentive, please email the researcher Bing Lin (bclin@pdx.edu).

Thank you again for participating. If you have any questions regarding the topic of interruptions, please feel free to contact the lead investigator, Bing Lin (bclin@pdx.edu). 
Appendix F. Company-wide Recruitment Email

Subject: Interruptions Research Invitation for <organization name>

Hi Everyone,

I am happy to announce our collaboration with a psychology research scientist at Portland State University and my former classmate from Purdue. The researcher, Bing Lin, is interested in investigating the consequences of interruptions at work particularly within the Computer and Information Technology (CIT) industry.

Initial research has shown that interruptions are costly in terms of time of productivity lost. However, Bing and his team of researchers suspect interruptions have additional psychological costs as well. This is where we need your help! Help our company be a part of scientific advancement by filling out a series of five surveys over the course of a week. Each survey should take between 10-15 minutes. Participation is both anonymous and voluntary, and refusing to participate will in no way impact your standing in our company or with Portland State University. However, if you agree to participate, please be certain to complete all time points. This will help us determine the types of hindrances our employees experience on a day-to-day basis, and determine the consequences of workplace interruptions.

If you're interested in helping out, please read the document below. After you have read through the informed consent, go ahead and contact Bing Lin (bclin@pdx.edu). Bing also mentioned that all participants will have a roughly one-in-three chance to win a prize for participating in this study.

Bing C. Lin, M.A., A.B.D.

Industrial \& Organizational Psychology

Department of Psychology

Portland State University

Portland, OR 97207-0751 


\section{INFORMED CONSENT}

\section{Background of Study}

We are studying the different types of interruptions employees in the High-Tech industry can experience, and the effects these interruptions have on employee productivity and stress. While some research has shown interruptions are disruptive, most of these studies have been conducted in the laboratory, rather than in the field. You have the unique opportunity to contribute to the first field study of interruptions at work.

To participate in this study, you must be at least 18 years of age. Should you agree to participate, your participation in this study will involve completing one initial survey and four surveys over the course of four days while at work. In all, participation in the entire study should require no more than 1.5 hours.

Your participation in this study is completely voluntary, and you are free to withdraw from the study at any point. Neither declining to participate nor withdrawing from this study will impact your standing in your organization or your standing with Portland State University.

\section{$\underline{\text { Participation Instructions }}$}

To be eligible for participation, we ask that you first complete a survey that should take no longer than 15 minutes. Once you complete this survey you will receive an invitation to participate in the study beginning the following Monday. Participation in this study involves completing four surveys over the course of four consecutive days (i.e., Monday through Thursday). Each survey should take no longer than 10 minutes. In all, participation in this study should take no longer than an hour.

\section{Potential Risks \& Safeguards}

While there are few risks involved in participation of this study, there are a few points during participation where you may be exposed to a low level of risk. As such, we have taken steps at different points to safeguard you from the potential risks of participating in the study.

It is possible that other employees or supervisors will be able to see your responses in the surveys. Therefore, we ask that you either complete the study during "low traffic periods" (where your coworkers are unlikely to be present), or minimize your window when coworkers and supervisors are present. In addition, we ask that you do not talk about the study to coworkers until after the study in order to minimize coworkers' curiosity.

\section{Potential Benefits}

My team of researchers will deliver the final results of our study to the management in each of your organizations after removing all identifying information. We will provide recommendations to reduce the number of interruptions employees in your organization experience based on the results of our study. Additionally, at the conclusion of the study roughly one out of three participants will receive an incentive for participating, should they choose to submit their eligibility.

\section{$\underline{\text { Additional Information }}$}


If you have any additional questions regarding this study, please feel free to email the principle investigator (bclin@ pdx.edu). This study has been approved by the Human Subjects Research and Review Committee at Portland State University

(http://www.rsp.pdx.edu/policies HSRRC.php). If you have any questions, comments, or complaints, please do not hesitate to contact us.

If you are interested in participating in this study, please email the principle investigator, Bing Lin (bclin@pdx.edu). By doing so, you are agreeing that you a) are at least 18 years of age, b) understand your rights as a participant, and c) consenting to participate in this study. 
Appendix G. Recruitment Email to Participate in Time 0

Subject: "Interruptions - PRE-STUDY SURVEY"

Dear Prospective Participant,

Thank you for your interest in participating in our study!

Prior to studying the types of interruptions you experience at work and the effects these interruptions have on your productivity and stress, we need to assess the various characteristics of your workplace. This will allow us to contextualize the interruptions you experience on a day-to-day basis.

The current online survey should take no more than 15 minutes. We would like to remind you that participation in this study is completely voluntary, and you are free to withdraw from the study at any point. Responses will remain anonymous, so please feel free to be as honest as possible.

If you are interested in continuing, please visit the link below. By doing so, you are agreeing that you a) are at least 18 year old, b) understand your rights as a participant, and c) consenting to participate in this study.

http://www.surveymonkey.com/s/T0

After you have completed this survey, please email me again notifying me of your completion, so that I can enroll you into the daily portion of the study.

Bing C. Lin, M.A., A.B.D.

Industrial \& Organizational Psychology

Department of Psychology

Portland State University

Portland, OR 97207-0751 
Appendix H. Reminder Recruitment Email for Time 0

Subject: "Interruptions - PRE-STUDY SURVEY Reminder"

Dear Prospective Participant,

This is a reminder that you have not yet completed the pre-study survey. If you are no longer interested in participating, please let me know.

The current online survey should take no more than 15 minutes. We would like to remind you that participation in this study is completely voluntary, and you are free to withdraw from the study at any point. Responses will remain anonymous, so please feel free to be as honest as possible.

If you are interested in continuing, please visit the link below. By doing so, you are agreeing that you a) are at least 18 year old, b) understand your rights as a participant, and c) consenting to participate in this study.

http://www.surveymonkey.com/s/T0

After you have completed this survey, please email me again notifying me of your completion, so that I can enroll you into the daily portion of the study.

Bing C. Lin, M.A., A.B.D.

Industrial \& Organizational Psychology

Department of Psychology

Portland State University

Portland, OR 97207-0751 
Appendix I. Recruitment Email to Participate in Time 1

Subject: "Interruptions - MONDAY SURVEY"

Dear Prospective Participant,

Thank you for your continued interest in participating in our study!

As you may recall, our study is focused on examining the different day-to-day interruptions people in your company experience, and how these interruptions affect employee productivity and stress. Today marks the first day we begin to understand the different interruptions you experience.

Today's online survey should take no more than 10 minutes. We would like to remind you that participation in this study is completely voluntary, and you are free to withdraw from the study at any point. Responses will remain anonymous, so please feel free to be as honest as possible.

If you are interested in continuing, please visit the link below. By doing so, you are agreeing that you a) are at least 18 year old, b) understand your rights as a participant, and c) consenting to participate in this study.

http://www.surveymonkey.com/s/T1 Monday

After you have completed this survey, please email me again notifying me of your completion.

Bing C. Lin, M.A., A.B.D.

Industrial \& Organizational Psychology

Department of Psychology

Portland State University

Portland, OR 97207-0751 
Appendix J. Reminder Recruitment Email for Time 1

Subject: "Interruptions - MONDAY SURVEY REMINDER"

Dear Prospective Participant,

This is a reminder that you have not yet completed the MONDAY survey. If you are no longer interested in participating, please let me know.

As you may recall, our study is focused on examining the different day-to-day interruptions people in your company experience, and how these interruptions affect employee productivity and stress. Today marks the first day we begin to understand the different interruptions you experience.

Today's online survey should take no more than 10 minutes. We would like to remind you that participation in this study is completely voluntary, and you are free to withdraw from the study at any point. Responses will remain anonymous, so please feel free to be as honest as possible.

If you are interested in continuing, please visit the link below. By doing so, you are agreeing that you a) are at least 18 year old, b) understand your rights as a participant, and c) consenting to participate in this study.

http://www.surveymonkey.com/s/T1 Monday

After you have completed this survey, please email me again notifying me of your completion.

Bing C. Lin, M.A., A.B.D.

Industrial \& Organizational Psychology

Department of Psychology

Portland State University

Portland, OR 97207-0751 
Appendix $K$. Recruitment Email to Participate in Time 2

Subject: "Interruptions - TUESDAY SURVEY"

Dear Prospective Participant,

Thank you for your continued interest in participating in our study!

As you may recall, our study is focused on examining the different day-to-day interruptions people in your company experience, and how these interruptions affect employee productivity and stress. Today's survey is completely identical to the survey you completed yesterday. However, it is imperative that you continue to complete these surveys because to understand how "day-to-day" interruptions impact you, we need to understand what "day-to-day" actually means.

Today's online survey should again take less than 10 minutes. We would like to remind you that participation in this study is completely voluntary, and you are free to withdraw from the study at any point. Responses will remain anonymous, so please feel free to be as honest as possible.

If you are interested in continuing, please visit the link below. By doing so, you are agreeing that you a) are at least 18 year old, b) understand your rights as a participant, and c) consenting to participate in this study.

http://www.surveymonkey.com/s/T2 Tuesday

Bing C. Lin, M.A., A.B.D.

Industrial \& Organizational Psychology

Department of Psychology

Portland State University

Portland, OR 97207-0751 
Appendix L. Reminder Recruitment Email for Time 2

Subject: "Interruptions - TUESDAY SURVEY REMINDER"

Dear Prospective Participant,

This is a reminder that you have not yet completed the TUESDAY survey. If you are no longer interested in participating, please let me know.

As you may recall, our study is focused on examining the different day-to-day interruptions people in your company experience, and how these interruptions affect employee productivity and stress. Today's survey is completely identical to the survey you completed yesterday. However, it is imperative that you continue to complete these surveys because to understand how "day-to-day" interruptions impact you, we need to understand what "day-to-day" actually means.

Today's online survey should again take less than 10 minutes. We would like to remind you that participation in this study is completely voluntary, and you are free to withdraw from the study at any point. Responses will remain anonymous, so please feel free to be as honest as possible.

If you are interested in continuing, please visit the link below. By doing so, you are agreeing that you a) are at least 18 year old, b) understand your rights as a participant, and c) consenting to participate in this study.

\section{http://www.surveymonkey.com/s/T2 Tuesday}

Bing C. Lin, M.A., A.B.D.

Industrial \& Organizational Psychology

Department of Psychology

Portland State University

Portland, OR 97207-0751 
Appendix M. Recruitment Email to Participate in Time 3

Subject: "Interruptions - WEDNESDAY SURVEY"

Dear Prospective Participant,

Thank you for your continued interest in participating in our study!

As you may recall, our study is focused on examining the different day-to-day interruptions people in your company experience, and how these interruptions affect employee productivity and stress. Today's survey is completely identical to the survey you completed Monday and Tuesday. Once again, it is imperative that you continue to complete these surveys because to understand how "day-to-day" interruptions impact you, we need to understand what "day-to-day" actually means.

Today's online survey should again take less than 10 minutes. We would like to remind you that participation in this study is completely voluntary, and you are free to withdraw from the study at any point. Responses will remain anonymous, so please feel free to be as honest as possible.

If you are interested in continuing, please visit the link below. By doing so, you are agreeing that you a) are at least 18 year old, b) understand your rights as a participant, and c) consenting to participate in this study.

http://www.surveymonkey.com/s/T3 Wednesday

Bing C. Lin, M.A., A.B.D.

Industrial \& Organizational Psychology

Department of Psychology

Portland State University

Portland, OR 97207-0751 
Appendix N. Reminder Recruitment Email for Time 3

Subject: "Interruptions - WEDNESDAY SURVEY REMINDER"

Dear Prospective Participant,

This is a reminder that you have not yet completed the WEDNESDAY survey. If you are no longer interested in participating, please let me know.

As you may recall, our study is focused on examining the different day-to-day interruptions people in your company experience, and how these interruptions affect employee productivity and stress. Today's survey is completely identical to the survey you completed Monday and Tuesday. Once again, it is imperative that you continue to complete these surveys because to understand how "day-to-day" interruptions impact you, we need to understand what "day-to-day" actually means.

Today's online survey should again take less than 10 minutes. We would like to remind you that participation in this study is completely voluntary, and you are free to withdraw from the study at any point. Responses will remain anonymous, so please feel free to be as honest as possible.

If you are interested in continuing, please visit the link below. By doing so, you are agreeing that you a) are at least 18 year old, b) understand your rights as a participant, and c) consenting to participate in this study.

\section{http://www.surveymonkey.com/s/T3 Wednesday}

Bing C. Lin, M.A., A.B.D.

Industrial \& Organizational Psychology

Department of Psychology

Portland State University

Portland, OR 97207-0751 
Appendix $O$. Recruitment Email to Participate in Time 4

Subject: "Interruptions - THURSDAY SURVEY"

Dear Prospective Participant,

Thank you for your continued interest in participating in our study!

As you may recall, our study is focused on examining the different day-to-day interruptions people in your company experience, and how these interruptions affect employee productivity and stress. This is the last survey you will complete for this study, and will help us understand how interruptions affect you.

Additionally, it is imperative you complete this survey so that you may redeem your incentive. We will also provide you some tips and tricks on how to minimize the number of interruptions you experience, and how to minimize the effects of interruptions on your productivity and stress.

Today's online survey should take less than 15 minutes. We would like to remind you that participation in this study is completely voluntary, and you are free to withdraw from the study at any point. Responses will remain anonymous, so please feel free to be as honest as possible.

If you are interested in continuing, please visit the link below. By doing so, you are agreeing that you a) are at least 18 year old, b) understand your rights as a participant, and c) consenting to participate in this study.

\section{http://www.surveymonkey.com/s/T4 Thursday}

After you have completed this survey, please email me again notifying me of your completion so that I can enter you into a drawing to win a small token of appreciation for participating in this study.

Bing C. Lin, M.A., A.B.D.

Industrial \& Organizational Psychology

Department of Psychology

Portland State University

Portland, OR 97207-0751 
Appendix $P$. Reminder Recruitment Email for Time 0

Subject: "Interruptions - THURSDAY SURVEY REMINDER"

Dear Prospective Participant,

This is a reminder that you have not yet completed the THURSDAY survey. If you are no longer interested in participating, please let me know.

As you may recall, our study is focused on examining the different day-to-day interruptions people in your company experience, and how these interruptions affect employee productivity and stress. This is the last survey you will complete for this study, and will help us understand how interruptions affect you.

Additionally, it is imperative you complete this survey so that you may redeem your incentive. We will also provide you some tips and tricks on how to minimize the number of interruptions you experience, and how to minimize the effects of interruptions on your productivity and stress.

Today's online survey should take less than 15 minutes. We would like to remind you that participation in this study is completely voluntary, and you are free to withdraw from the study at any point. Responses will remain anonymous, so please feel free to be as honest as possible.

If you are interested in continuing, please visit the link below. By doing so, you are agreeing that you a) are at least 18 year old, b) understand your rights as a participant, and c) consenting to participate in this study.

\section{http://www.surveymonkey.com/s/T4 Thursday}

After you have completed this survey, please email me again notifying me of your completion so that I can enter you into a drawing to win a small token of appreciation for participating in this study.

Bing C. Lin, M.A., A.B.D.

Industrial \& Organizational Psychology

Department of Psychology

Portland State University

Portland, OR 97207-0751 


\section{Appendix Q. Pilot Survey \\ INTERRUPTIONS AT WORK PILOT STUDY \\ Information \& Informed Consent Document}

\section{Participation Requirements}

Because this study centers on employee workplace experiences, only participants who are either currently employed (full or part-time) or have been employed in the past six months can participate in the present study. You must be over 18 years old to participate in this study.

\section{Background and the Present Study}

Interruptions at work are a common phenomenon in the modern workplace, and with increased adoption of instant messaging, email, and smartphones, interruptions at work will likely become more prevalent in the future. Preliminary evidence from Ergonomics and Cognitive Psychology has shown that interruptions are disruptive for workflow, and employee stress. To replicate these findings in organizational sciences, a valid measure of workplace interruptions is necessary.

My research team and I have developed a measure of workplace interruptions, but in order for this measure to be useful, we need to test its reliability and validity by recruiting participants like you to complete the measure first. If you choose to participate in this study, please complete the measure outside of class and in a location where your responses will not be seen by anyone else. Participation should not take you longer than 20 minutes to complete.

\section{Your Rights as a Participant}

As per your rights as a participant, your participation in this study is completely voluntary and declining participation will not affect your status as a student of this class or the Department of Psychology. Certain questions within the survey may be personal, or cause some unintentional distress. However, no identifying information will be asked of you. If you experience distress, you should immediately contact their respective Employee Assistance Programs (EAP) or the Center for Student Health and Counseling (SHAC; 503-725-2800).

If you do choose to participate in the study, you are free to withdraw from the study at anytime without any consequences. Finally, results of the study will only be reported in aggregate in the event that the study is published, so that no responses will be individually identifiable. If you have any questions, concerns, or complaints regarding your right as a participant, or the study, please email the researcher at bclin@pdx.edu, call (765) 414-2758, or you may visit his office at CH542. You may also contact the Human Subjects Research and Review Committee (hsrrc@lists.pdx.edu). The HSRRC is located at Research and Strategic Partnerships, Market Center Building Suite 620, 1600 SW $4^{\text {th }}$ Ave, Portland OR 97201. 
Instructions: Interruptions can include coworkers, supervisors, or subordinates either stopping by your workplace, email, instant messaging, or phone and text messages.

Please think about the interruptions you have experienced at work today, and indicate how frequently each of the following occurred by circling the appropriate response.

1. I was interrupted by others.

2. My work flow was halted by others.

3. I had to stop working to attend to others' interruptions.

4. I was able to work long periods without being interrupted.

5. Others stopped me while I was working.

\begin{tabular}{|c|c|c|c|c|}
\hline 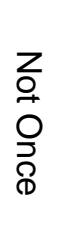 & 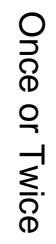 & $\begin{array}{l}D \\
D \\
\sum^{\mathbb{D}} \\
\stackrel{-1}{3} \\
\stackrel{\mathbb{D}}{\infty}\end{array}$ & 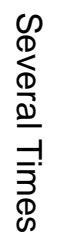 & 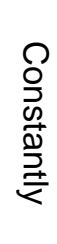 \\
\hline 1 & 2 & 3 & 4 & 5 \\
\hline 1 & 2 & 3 & 4 & 5 \\
\hline 1 & 2 & 3 & 4 & 5 \\
\hline 1 & 2 & 3 & 4 & 5 \\
\hline 1 & 2 & 3 & 4 & 5 \\
\hline
\end{tabular}

What percentage of the interruptions you experienced today were...
6. ... in person? $\%$
9. ... via phone? $\%$
7. ... via email? $\%$
8. ... via instant messaging? 10. ... via text message? $\%$

The majority of interruptions I experienced were... (please circle one)

\begin{tabular}{lccc} 
11. & Short & Moderate & \multicolumn{1}{c}{$\begin{array}{c}\text { Long } \\
\text { Complex/Difficult }\end{array}$} \\
12. & Simple/Easy & Moderate & $\begin{array}{c}\text { Unexpected } \\
\text { Expected }\end{array}$ \\
13. & Pleasant \\
14. & Upsetting & Neutral & Welcome \\
15. & Unwanted & Neutral & Positive \\
16. & Negative & Neutral & \\
17. What percentage of the interruptions you experienced today were & $\%$ \\
positive? & & \\
18. What percentage of the interruptions you experienced today were \\
negative?
\end{tabular}

Please provide an estimate of...

$20 . .$. the number of interruptions you experienced at work today:

$21 . .$. the average amount of time each interruption took up today:

times

minutes

22. What was the majority of your interruptions about? 


\begin{tabular}{|c|c|c|c|c|c|}
\hline $\begin{array}{l}\text { Instructions: The following questions are designed to measure certain } \\
\text { characteristics of your work. Please indicate the extent to which you } \\
\text { agree with each of the following by using the response scale provided }\end{array}$ &  & $\begin{array}{l}\text { ㅁ. } \\
\text { D. } \\
\stackrel{0}{0} \\
\mathbb{D} \\
\mathbb{D} \\
\mathbb{D}\end{array}$ & 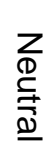 & $\underset{\substack{D \\
\mathbb{D}}}{\stackrel{D}{D}}$ & 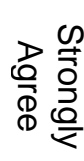 \\
\hline $\begin{array}{l}\text { 23. The job requires me to accomplish my job before other complete } \\
\text { their job. }\end{array}$ & 1 & 2 & 3 & 4 & 5 \\
\hline 24. Other jobs depend directly on my job. & 1 & 2 & 3 & 4 & 5 \\
\hline 25. Unless my job gets done, other jobs cannot be completed. & 1 & 2 & 3 & 4 & 5 \\
\hline 26. My job activities are greatly affected by the work of other people. & 1 & 2 & 3 & 4 & 5 \\
\hline $\begin{array}{l}\text { 27. My job depends on the work of many different people for its } \\
\text { completion. }\end{array}$ & 1 & 2 & 3 & 4 & 5 \\
\hline 28. My job cannot be done unless others do their work. & 1 & 2 & 3 & 4 & 5 \\
\hline 29. The job requires that I only do one task or activity at a time. & 1 & 2 & 3 & 4 & 5 \\
\hline 30. The tasks on the job are simple and uncomplicated. & 1 & 2 & 3 & 4 & 5 \\
\hline 31. The job comprises relatively uncomplicated tasks. & 1 & 2 & 3 & 4 & 5 \\
\hline 32. The job involves performing relatively simple tasks. & 1 & 2 & 3 & 4 & 5 \\
\hline $\begin{array}{l}\text { 33. The job involves solving problems that have no obvious correct } \\
\text { answer. }\end{array}$ & 1 & 2 & 3 & 4 & 5 \\
\hline 34. The job requires me to be creative. & 1 & 2 & 3 & 4 & 5 \\
\hline $\begin{array}{l}\text { 35. The job often involves dealing with problems that I have not met } \\
\text { before. }\end{array}$ & 1 & 2 & 3 & 4 & 5 \\
\hline 36. The job requires unique ideas or solutions to problems. & 1 & 2 & 3 & 4 & 5 \\
\hline
\end{tabular}

Instructions: Please indicate the extent to which you generally feel the following emotions.

\begin{tabular}{|c|c|c|c|c|c|c|c|c|c|c|c|}
\hline & 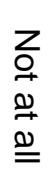 & 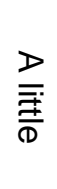 & $\begin{array}{l}\frac{3}{0} \\
\frac{O}{D} \\
\frac{\mathbb{D}}{0} \\
\frac{\mathbb{D}}{\mathbb{D}}\end{array}$ & 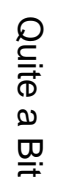 & 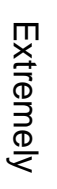 & & 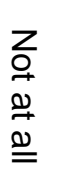 & 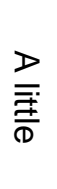 & 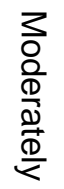 & 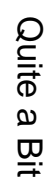 & $\begin{array}{l}\text { W } \\
\underset{\times}{\vec{D}} \\
\stackrel{\text { D }}{3} \\
\stackrel{\mathbb{D}}{<}\end{array}$ \\
\hline 37. Active & 1 & 2 & 3 & 4 & 5 & 47. Afraid & 1 & 2 & 3 & 4 & 5 \\
\hline 38. Alert & 1 & 2 & 3 & 4 & 5 & 48. Scared & 1 & 2 & 3 & 4 & 5 \\
\hline 39. Attentive & 1 & 2 & 3 & 4 & 5 & 49. Nervous & 1 & 2 & 3 & 4 & 5 \\
\hline 40. Determined & 1 & 2 & 3 & 4 & 5 & 50. Jittery & 1 & 2 & 3 & 4 & 5 \\
\hline 41. Enthusiastic & 1 & 2 & 3 & 4 & 5 & 51. Irritable & 1 & 2 & 3 & 4 & 5 \\
\hline 42. Excited & 1 & 2 & 3 & 4 & 5 & 52. Hostile & 1 & 2 & 3 & 4 & 5 \\
\hline 43. Inspired & 1 & 2 & 3 & 4 & 5 & 53. Guilty & 1 & 2 & 3 & 4 & 5 \\
\hline 44. Interested & 1 & 2 & 3 & 4 & 5 & 54. Ashamed & 1 & 2 & 3 & 4 & 5 \\
\hline 45. Proud & 1 & 2 & 3 & 4 & 5 & 55. Upset & 1 & 2 & 3 & 4 & 5 \\
\hline 46. Strong & 1 & 2 & 3 & 4 & 5 & 56. Distressed & 1 & 2 & 3 & 4 & 5 \\
\hline
\end{tabular}


Instructions: The following survey questions are designed to inquire about things your job and work environment require of you. Please indicate, on average, how often you experience these things at work.

\begin{tabular}{|c|c|c|c|c|}
\hline$\underset{\mathbb{\mathbb { \mathbb { D } }}}{Z}$ & \multicolumn{2}{|c|}{ 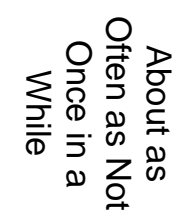 } & 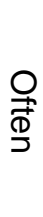 & 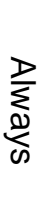 \\
\hline 1 & 2 & 3 & 4 & 5 \\
\hline 1 & 2 & 3 & 4 & 5 \\
\hline 1 & 2 & 3 & 4 & 5 \\
\hline 1 & 2 & 3 & 4 & 5 \\
\hline 1 & 2 & 3 & 4 & 5 \\
\hline 1 & 2 & 3 & 4 & 5 \\
\hline 1 & 2 & 3 & 4 & 5 \\
\hline 1 & 2 & 3 & 4 & 5 \\
\hline
\end{tabular}

Instructions: Please indicate the extent to which you felt the following in the past week.

\begin{tabular}{|c|c|c|c|c|c|c|c|c|c|c|c|}
\hline & $\begin{array}{l}\underset{O}{O} \\
\stackrel{\oplus}{\oplus} \\
\stackrel{Ð}{=}\end{array}$ & $\frac{D}{\stackrel{D}{\bar{\Phi}}}$ & 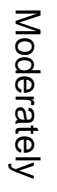 & 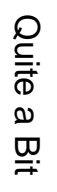 & 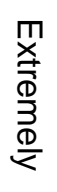 & & $\begin{array}{l}\underset{O}{O} \\
\stackrel{\oplus}{\oplus} \\
\cong\end{array}$ & $\frac{\triangleright}{\frac{\bar{F}}{\bar{D}}}$ & 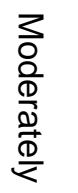 & 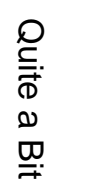 & 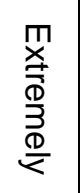 \\
\hline 65. Alert & 1 & 2 & 3 & 4 & 5 & 73. Lively & 1 & 2 & 3 & 4 & 5 \\
\hline 66. Attentive & 1 & 2 & 3 & 4 & 5 & 74. Active & 1 & 2 & 3 & 4 & 5 \\
\hline 67. Concentrating & 1 & 2 & 3 & 4 & 5 & 75. Energetic & 1 & 2 & 3 & 4 & 5 \\
\hline 68. Determined & 1 & 2 & 3 & 4 & 5 & 76. Cheerful & 1 & 2 & 3 & 4 & 5 \\
\hline 69. Sleepy & 1 & 2 & 3 & 4 & 5 & 77. Full of pep & 1 & 2 & 3 & 4 & 5 \\
\hline 70. Tired & 1 & 2 & 3 & 4 & 5 & 78. Carefree & 1 & 2 & 3 & 4 & 5 \\
\hline 71. Sluggish & 1 & 2 & 3 & 4 & 5 & 79. Vigorous & 1 & 2 & 3 & 4 & 5 \\
\hline 72. Drowsy & 1 & 2 & 3 & 4 & 5 & & & & & & \\
\hline \multicolumn{7}{|c|}{$\begin{array}{l}\text { Instructions: The following survey questions are designed to assess } \\
\text { how well you feel you performed on your job. Please think about your } \\
\text { job performance from the past week, respond using the response scale } \\
\text { provided. }\end{array}$} & 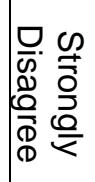 & $\begin{array}{l}\frac{\square}{\infty} \\
\stackrel{\mathscr{Q}}{\bar{D}} \\
\mathbb{\infty}\end{array}$ & 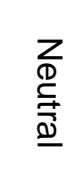 & 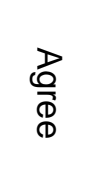 & 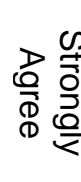 \\
\hline \multirow{2}{*}{\multicolumn{7}{|c|}{$\begin{array}{l}\text { 80. I adequately completed assigned duties relative to my own } \\
\text { expectations. } \\
81 . \text { I fulfilled responsibilities from my job description up to my } \\
\text { expectations. }\end{array}$}} & 1 & 2 & 3 & 4 & 5 \\
\hline & & & & & & & 1 & 2 & 3 & 4 & 5 \\
\hline \multicolumn{7}{|c|}{ 82. I performed the tasks that I expected of myself. } & 1 & 2 & 3 & 4 & 5 \\
\hline
\end{tabular}


83. I met formal performance requirements of the job to my expectations.

84. I neglected aspects of the job that I expected myself to perform.

85. I failed to perform the essential duties I wanted to perform.

\begin{tabular}{|lllll}
1 & 2 & 3 & 4 & 5 \\
1 & 2 & 3 & 4 & 5 \\
1 & 2 & 3 & 4 & 5
\end{tabular} \mid

Instructions: Please indicate how frequent you experienced each of these in the past week using the response scale provided.

86. Cannot remember whether you have or have not turned off work
equipment at work?
87. Fail to recall work procedures at work?
88. Cannot remember work-related contact information at work?
89. Cannot remember what materials are required to complete a
particular task at work?
90. Forget where you have put something you use in your job at work?
91. Fail to notice postings or notices on the facilities bulletin board(s) or
email system at work?
92. Do not fully listen to instructions at work?
93. Day-dream when you ought to be listening to somebody at work?
94. Do not focus your attention on work activities at work?

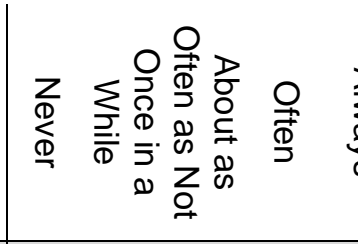

95. Are easily distracted by co-workers at work?

96. Accidentally drop objects or things at work?

97. Throw away something you meant to keep (e.g., memos) at work?

98. Say things to others that you did not mean to say at work?

99. Unintentionally press buttons on machines at work?

100. Accidentally started or stopped the wrong machine at work?

101. I need something pleasant to make me feel better.

102. I feel drained.

103. If I were tempted by something right now, it would be very difficult to resist.

104. I would want to quit any difficult task I was given.

105. I feel calm and rational.

106. I can't absorb any more information.

107. I feel lazy.

108. I feel sharp and focused.

109. I want to give up.

110. I feel like my willpower is gone.

$\begin{array}{lllll}1 & 2 & 3 & 4 & 5\end{array}$

$\begin{array}{lllll}1 & 2 & 3 & 4 & 5\end{array}$

$\begin{array}{lllll}1 & 2 & 3 & 4 & 5\end{array}$

$\begin{array}{lllll}1 & 2 & 3 & 4 & 5\end{array}$

$\begin{array}{lllll}1 & 2 & 3 & 4 & 5\end{array}$

$\begin{array}{lllll}1 & 2 & 3 & 4 & 5\end{array}$

$\begin{array}{lllll}1 & 2 & 3 & 4 & 5\end{array}$

$\begin{array}{lllll}1 & 2 & 3 & 4 & 5\end{array}$

$\begin{array}{lllll}1 & 2 & 3 & 4 & 5\end{array}$

$\begin{array}{lllll}1 & 2 & 3 & 4 & 5\end{array}$

$\begin{array}{lllll}1 & 2 & 3 & 4 & 5\end{array}$

$\begin{array}{lllll}1 & 2 & 3 & 4 & 5\end{array}$

$\begin{array}{lllll}1 & 2 & 3 & 4 & 5\end{array}$

$\begin{array}{lllll}1 & 2 & 3 & 4 & 5\end{array}$

$\begin{array}{lllll}1 & 2 & 3 & 4 & 5\end{array}$

$\begin{array}{lllll}1 & 2 & 3 & 4 & 5\end{array}$

$\begin{array}{lllll}1 & 2 & 3 & 4\end{array}$

$\begin{array}{lllll}1 & 2 & 3 & 4 & 5\end{array}$

$\begin{array}{lllll}1 & 2 & 3 & 4 & 5\end{array}$

$\begin{array}{lllll}1 & 2 & 3 & 4 & 5\end{array}$

$\begin{array}{lllll}1 & 2 & 3 & 4 & 5\end{array}$

$\begin{array}{lllll}1 & 2 & 3 & 4 & 5\end{array}$

$\begin{array}{lllll}1 & 2 & 3 & 4 & 5\end{array}$

12345

$\begin{array}{lllll}1 & 2 & 3 & 4 & 5\end{array}$


111. Most days I was enthusiastic about my work.

112. I felt fairly satisfied with my present job.

113. Each day at work seemed like it would never end for me.

114. I found real enjoyment in my work.

115. I considered my job rather unpleasant.

\begin{tabular}{lllll}
1 & 2 & 3 & 4 & 5 \\
1 & 2 & 3 & 4 & 5 \\
1 & 2 & 3 & 4 & 5 \\
1 & 2 & 3 & 4 & 5 \\
1 & 2 & 3 & 4 & 5 \\
\hline
\end{tabular}

\begin{tabular}{|c|c|c|c|c|c|}
\hline $\begin{array}{l}\text { Instructions: Please indicate how frequent you experienced each of } \\
\text { these in the past week using the response scale provided. }\end{array}$ & $\underset{\mathbb{\mathbb { D }}}{\underset{\mathbb{D}}{\mathbf{Z}}}$ & $\sum$ & 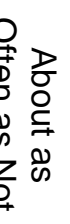 & & $\sum_{\infty}^{\infty}$ \\
\hline 116. That you were unable to control the important things in your life? & 1 & 2 & 3 & 4 & 5 \\
\hline 117. Confident about your ability to handle your personal problems? & 1 & 2 & 3 & 4 & 5 \\
\hline 118. That things were going your way? & 1 & 2 & 3 & 4 & 5 \\
\hline $\begin{array}{l}\text { 119. Difficulties were piling up so high that you could not overcome } \\
\text { them? }\end{array}$ & 1 & 2 & 3 & 4 & 5 \\
\hline 120. Had trouble falling asleep. & 1 & 2 & 3 & 4 & 5 \\
\hline 121. Had trouble staying asleep (including waking up too early). & 1 & 2 & 3 & 4 & 5 \\
\hline 122. Woke up several times during the night. & 1 & 2 & 3 & 4 & 5 \\
\hline $\begin{array}{l}\text { 123. Woke up after your usual amount of sleep feeling tired and worn } \\
\text { out. }\end{array}$ & 1 & 2 & 3 & 4 & 5 \\
\hline
\end{tabular}

Thank you for completing our study

Please detach this page from the remainder of the survey, and turn the survey in to your instructor. You may keep this page for your records.

My colleagues and I are developing a survey measure of intrusions (or interruptions stemming from other coworkers/supervisors/subordinates through any and all mediums such as email, phone, etc.), and your participation will go a long ways in helping us refine this survey instrument. If you are interested in finding out more about this area of research, please consult the following references or contact the principal investigator, Bing Lin (bclin@pdx.edu).

\section{Relevant Interruptions Literature:}

Jett, Q. R., \& George, J. M. (2003). Work interrupted: A closer look at the role of interruptions in organizational life. Academy of Management Review, 28, 494-507.

\section{Other Measure Development Articles:}


Sonnentag, S., \& Fritz, C. (2007). The Recovery Experience Questionnaire: Development and validation of a measure for assessing recuperation and unwinding from work. Journal of Occupational Health Psychology, 12, 204-221.

If you have any questions or concerns regarding your participation in this study, please contact the principal investigator, Bing Lin, by email (bclin@pdx.edu) or phone (503-725-3963). 


\section{Appendix R. Human Subjects Research Review Committee Approval Letter Portland State University HSRRC Memorandum}

To: $\quad$ Bing Lin

From: Todd Bodner, Chair, HSRRC 2012

Date: October 4, 2012

Re: Your HSRRC application titled, “"Do Not Disturb": A Micro-Macro Examination of Intrusions at Work" (HSRRC Proposal \#122321)

In accordance with your request, the Human Subjects Research Review Committee has reviewed your proposal referenced above for compliance with DHHS policies and regulations covering the protection of human subjects. The committee is satisfied that your provisions for protecting the rights and welfare of all subjects participating in the research are adequate, and your project is approved.

Please note the following requirements:

Changes to Protocol: Any changes in the proposed study, whether to procedures, survey instruments, consent forms or cover letters, must be outlined and submitted to the Chair of the HSRRC immediately. The proposed changes cannot be implemented before they have been reviewed and approved by the Committee.

Continuing Review: This approval will expire 9/28/2013, one year from the approval date. It is the investigator's responsibility to ensure that a Continuing Review Report (available in RSP) of the status of the project is submitted to the HSRRC approximately two months before the expiration date, and that approval of the study is kept current.

Adverse Reactions: If any adverse reactions occur as a result of this study, you are required to notify the Chair of the HSRRC immediately. If the problem is serious, approval may be withdrawn pending an investigation by the Committee.

Completion of Study: Please notify the Chair of the Human Subjects Research Review Committee (campus mail code ORSP) as soon as your research has been completed. Study records, including protocols and signed consent forms for each participant, must be kept by the investigator in a secure location for three years following completion of the study.

If you have questions or concerns, please contact the HSRRC in the Office of Research and Strategic Partnerships, Market Center Building, Suite 620, 1600 SW Fourth Ave, Portland OR 97207 (503)725-2243. 